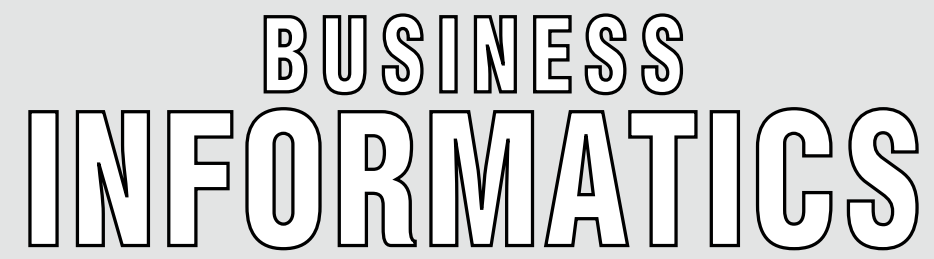

HSE SCIENTIFIC JOURNAL

\section{CONTENTS}

\section{Mathematical methods and algorithms of business informatics}

\section{A.N. Kislyakov}

Structuring advertising campaign costs considering the asymmetry of users' interests

\section{R.S. Rogulin}

A model for optimizing plans for procurement of raw materials from regions of Russia in a timber-processing enterprise.

\section{Business processes modeling and analysis}

\section{A.I. Doljenko, I.Yu. Shpolianskaya, S.A. Glushenko}

Fuzzy production network model for quality assessment of an information system based on microservices.

\section{Modeling of social and economic systems}

\section{D.M. Nazarov}

Classification of models and description of trends in assessing the causality of relationships in socio-economic processes

\section{E.A. Golovanova, A.V. Zubarev}

Building the uncertainty indicator regarding adjustment of the Bank of Russia's monetary policy relying on news sources

\section{A.A. Afanasiev, O.S. Ponomareva}

Wuhan coronavirus spread in Russia: macroeconomic production function in regard to transport and communication infrastructure

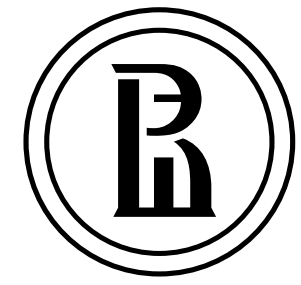

Publisher:

National Research University Higher School of Economics

Subscription index in the Rospechat catalog 80870

The journal is published quarterly

The journal is included into the list of peer reviewed scientific editions established by the Supreme Certification Commission of the Russian Federation

Editor-in-Chief:

Y. Koucheryavy

Deputy Editor-in-Chief E. Zaramenskikh

Computer Making-up: O. Bogdanovich

Website Administration: I. Khrustaleva

Address:

28/11, build. 4, Shablovka Street Moscow 119049, Russia

Tel./fax: +7 (495) 772-9590*26311 http://bijournal.hse.ru E-mail: bijournal@hse.ru

\section{Circulation:}

English version - 200 copies, Russian version -200 copies, online versions in English and Russian open access

Printed in HSE Printing House

3, Kochnovsky Proezd, Moscow, Russia

(C) National Research University Higher School of Economics 


\section{ABOUT \\ THE JOURNAL}

B usiness Informatics is a peer reviewed interdisciplinary academic journal published since 2007 by National Research University Higher School of Economics (HSE), Moscow, Russian Federation. The journal is administered by HSE Graduate School of Business. The journal is published quarterly.

The mission of the journal is to develop business informatics as a new field within both information technologies and management. It provides dissemination of latest technical and methodological developments, promotes new competences and provides a framework for discussion in the field of application of modern IT solutions in business, management and economics.

The journal publishes papers in the areas of, but not limited to:

$\downarrow$ data analysis and intelligence systems

$\downarrow$ information systems and technologies in business

$\downarrow$ mathematical methods and algorithms of business informatics

$\downarrow$ software engineering

$\checkmark$ internet technologies

$\checkmark$ business processes modeling and analysis

$\checkmark$ standardization, certification, quality, innovations

$\uparrow$ legal aspects of business informatics

$\downarrow$ decision making and business intelligence

$\downarrow$ modeling of social and economic systems

$\downarrow$ information security.

The journal is included into the list of peer reviewed scientific editions established by the Supreme Certification Commission of the Russian Federation.

The journal is included into Web of Science Emerging Sources Citation Index (WoS ESCI) and Russian Science Citation Index on the Web of Science platform (RSCI).

International Standard Serial Number (ISSN): 2587-814X (in English), 1998-0663 (in Russian).

Editor-in-Chief: Dr. Yevgeni A. Koucheryavy. 
EDITOR-IN-CHIEF

Yevgeni A. Koucheryavy

Tampere University of Technology, Tampere, Finland

DEPUTY EDITOR-IN-CHIEF

Evgeny P. Zaramenskikh

National Research University Higher School of Economics, Moscow, Russia

\section{EDITORIAL BOARD}

Habib Abdulrab

National Institute of Applied Sciences, Rouen, France

Sergey M. Avdoshin

National Research University Higher School of Economics, Moscow, Russia

\section{Andranik S. Akopov}

National Research University Higher School of Economics, Moscow, Russia

Fuad T. Aleskerov

National Research University Higher School of Economics, Moscow, Russia

\section{Alexander P. Afanasyev}

Institute for Information Transmission Problems (Kharkevich Institute), Russian Academy of Sciences, Moscow, Russia

Anton A. Afanasyev

Central Economics and Mathematics Institute, Russian Academy of Sciences, Moscow, Russia

\section{Eduard A. Babkin}

National Research University Higher School of Economics, Nizhny Novgorod, Russia

Sergey I. Balandin

Finnish-Russian University Cooperation in Telecommunications (FRUCT), Helsinki, Finland

Vladimir B. Barakhnin

Federal Research Center of Information and Computational Technologies, Novosibirsk, Russia

Alexander P. Baranov

Federal Tax Service, Moscow, Russia

Jorg Becker

University of Munster, Munster, Germany

Vladimir V. Belov

Ryazan State Radio Engineering University, Ryazan, Russia

Alexander G. Chkhartishvili

V.A. Trapeznikov Institute of Control Sciences, Russian Academy of Sciences, Moscow, Russia

Vladimir A. Efimushkin

Central Research Institute of Communications, Moscow, Russia

Tatiana A. Gavrilova

Saint-Petersburg University, St. Petersburg, Russia

Hervé Glotin

University of Toulon, La Garde, France

Alexey O. Golosov

FORS Development Center, Moscow, Russia

Andrey Yu. Gribov

CyberPlat Company, Moscow, Russia

Alexander I. Gromoff

National Research University Higher School of Economics, Moscow, Russia

Vladimir A. Gurvich

Rutgers, The State University of New Jersey, Rutgers, USA

Laurence Jacobs

University of Zurich, Zurich, Switzerland

Liliya A. Demidova

Ryazan State Radio Engineering University, Ryazan, Russia

Iosif E. Diskin

Russian Public Opinion Research Center, Moscow, Russia
Nikolay I. Ilyin

Federal Security Guard of the Russian Federation,

Moscow, Russia

Dmitry V. Isaev

National Research University Higher School of Economics, Moscow, Russia

\section{Alexander D. Ivannikov}

Institute for Design Problems in Microelectronics, Russian Academy of Sciences, Moscow, Russia

Valery A. Kalyagin

National Research University Higher School of Economics, Nizhny Novgorod, Russia

\section{Tatiana K. Kravchenko}

National Research University Higher School of Economics, Moscow, Russia

\section{Sergei O. Kuznetsov}

National Research University Higher School of Economics,

Moscow, Russia

\section{Kwei-Jay Lin}

Nagoya Institute of Technology, Nagoya, Japan

Mikhail I. Lugachev

Lomonosov Moscow State University, Moscow, Russia

Svetlana V. Maltseva

National Research University Higher School of Economics,

Moscow, Russia

\section{Peter Major}

UN Commission on Science and Technology for Development, Geneva, Switzerland

\section{Boris G. Mirkin}

National Research University Higher School of Economics,

Moscow, Russia

\section{Vadim V. Mottl}

Tula State University, Tula, Russia

Dmitry M. Nazarov

Ural State University of Economics, Ekaterinburg, Russia

Dmitry E. Palchunov

Novosibirsk State University, Novosibirsk, Russia

Panagote (Panos) M. Pardalos

University of Florida, Gainesville, USA

Óscar Pastor

Polytechnic University of Valencia, Valencia, Spain

Joachim Posegga

University of Passau, Passau, Germany

\section{Konstantin E. Samouylov}

Peoples' Friendship University, Moscow, Russia

Kurt Sandkuhl

University of Rostock, Rostock, Germany

Yuriy D. Shmidt

Far Eastern Federal University, Vladivostok, Russia

Christine Strauss

University of Vienna, Vienna, Austria

\section{Ali R. Sunyaev}

Karlsruhe Institute of Technology, Karlsruhe, Germany

Victor V. Taratukhin

University of Munster, Munster, Germany

José M. Tribolet

Universidade de Lisboa, Lisbon, Portugal

Olga A. Tsukanova

Saint-Petersburg National Research University of Information Technologies, Mechanics and Optics, St. Petersburg, Russia

Mikhail V. Ulyanov

V.A. Trapeznikov Institute of Control Sciences, Russian Academy of Sciences, Moscow, Russia

Raissa K. Uskenbayeva

International Information Technology University, Almaty, Kazakhstan Markus Westner

Regensburg University of Applied Sciences, Regensburg, Germany 


\section{ABOUT THE HIGHER SCHOOL OF ECONOMICS}

$\mathrm{C}$ onsistently ranked as one of Russia's top universities, the Higher School of Economics (HSE) is a leader in Russian education and one of the preeminent economics and social sciences universities in Eastern Europe and Eurasia.

Having rapidly grown into a well-renowned research university over two decades, HSE sets itself apart with its international presence and cooperation.

Our faculty, researchers, and students represent over 50 countries, and are dedicated to maintaining the highest academic standards. Our newly adopted structural reforms support both HSE's drive to internationalize and the groundbreaking research of our faculty, researchers, and students.

Now a dynamic university with four campuses, HSE is a leader in combining Russian educational traditions with the best international teaching and research practices. HSE offers outstanding educational programs from secondary school to doctoral studies, with top departments and research centers in a number of international fields.

Since 2013, HSE has been a member of the 5-100 Russian Academic Excellence Project, a highly selective government program aimed at boosting the international competitiveness of Russian universities. 


\section{ABOUT THE GRADUATE SCHOOL OF BUSINESS}

$\mathrm{H}$ SE Graduate School of Business was created on September 1, 2020. The School will become a priority partner for leading Russian companies in the development of their personnel and management technologies.

The world-leading model of a 'university business school' has been chosen for the Graduate School of Business. This foresees an integrated portfolio of programmes, ranging from Bachelor's to EMBA programmes, communities of experts and a vast network of research centres and laboratories for advanced management studies. Furthermore, HSE University's integrative approach will allow the Graduate School of Business to develop as an interdisciplinary institution. The advancement of the Graduate School of Business through synergies with other faculties and institutes will serve as a key source of its competitive advantage. Moreover, the evolution and development of the Business School's faculty involves the active engagement of three professional tracks at our University: research, practice-oriented and methodological.

What sets the Graduate School of Business apart is its focus on educating and developing globally competitive and socially responsible business leaders for Russia's emerging digital economy.

The School's educational model will focus on a project approach and other dynamic methods for skills training, integration of online and other digital technologies, as well as systematic internationalization of educational processes.
At its start, the Graduate School of Business will offer 22 Bachelor programmes (three of which will be fully taught in English) and over 200 retraining and continuing professional development programmes, serving over 9,000 students. In future, the integrated portfolio of academic and professional programmes will continue to expand with a particular emphasis on graduate programmes, which is in line with the principles guiding top business schools around the world. In addition, the School's top quality and allencompassing Bachelor degrees will continue to make valuable contributions to the achievement of the Business School's goals and the development $t$ of its business model.

The School's plans include the establishment of a National Resource Center, which will offer case studies based on the experience of Russian companies. In addition, the Business School will assist in the provision of up-to-date management training at other Russian universities. Furthermore, the Graduate School of Business will become one of the leaders in promoting Russian education.

The Graduate School of Business's unique ecosystem will be created through partnerships with leading global business schools, as well as in-depth cooperation with firms and companies during the entire life cycle of the school's programmes. The success criteria for the Business School include professional recognition thanks to the stellar careers of its graduates, its international programmes and institutional accreditations, as well as its presence on global business school rankings. 



\title{
Structuring advertising campaign costs considering the asymmetry of users' interests
}

\author{
Alexey N. Kislyakov \\ E-mail: ankislyakov@mail.ru
}

Russian Academy of National Economy and Public Administration under the President of the Russian Federation. Vladimir Branch

Address: 59a, Gorky Street, Vladimir 600017, Russia

\begin{abstract}
This work is devoted to the highly topical problem of structuring costs for contextual and targeted advertising on the Internet. The choice of the ad campaign financing structure is considered from the point of view of violating the principle of symmetry of user interest in ads. The purpose of this work is to develop a methodology for structuring advertising campaign costs based on cluster analysis, taking into account the asymmetry of user interest in advertising. The key feature of the research is the description of the possibility of using the asymmetry of user interest in application solutions, such as online advertising. The Gini coefficient is used as an indicator of the degree of imbalance in the manifestation of a feature in clustering, and the features of using the lift coefficient and the Lorentz curve to evaluate the effectiveness of contextual and targeted advertising for various groups of customers are also considered. Using the Gini index and cluster analysis, you can analyze the possibilities of increasing ad revenue and compare it with the absence of any policy for structuring advertising costs. Identifying such patterns in consumer groups allows you to identify the main directions of product development and customer interest in it. The method described here should be used to improve the effectiveness of banner advertising and clustering algorithms. This approach does not improve banner clickability, but allows you to implement an individual approach to advertising products with the current number of clicks and more effectively structure the cost of various types of advertising.
\end{abstract}

Key words: information asymmetry; Gini index; cluster analysis; banner advertising; hierarchical clustering.

Citation: Kislyakov A.N. (2020) Structuring advertising campaign costs considering the asymmetry of users' interests. Business Informatics, vol. 14, no 4, pp. 7-18.

DOI: 10.17323/2587-814X.2020.4.7.18 


\section{Introduction}

$\mathrm{T}$ Today, one of the most dynamically developing segments of advertising activity is advertising on the Internet.

For example, banner advertising allows you to more accurately and effectively deliver an ad to an interested customer. However, there are quite a few options for monetizing the display of ads depending on the purpose and capabilities.

This type of advertising, of course, requires certain investments, which are not always justified, since the distribution of information and ad delivery technologies, as well as their cost, depend on a large number of factors and are complex and random [1]. It is often difficult to understand which category of users will be interested in an ad, and it is even more difficult to predict sales growth depending on the investment in advertising.

In this regard, there are two fundamentally different types of advertising: contextual and targeted. Contextual advertising allows you to perform automated display of an ad in accordance with the subject area of the customer's search for products. Targeted advertising, on the other hand, searches for the audience for the offer by features, which is a more complex task. Despite the fact that both types of advertising have fine-tuned display settings, the effectiveness of contextual advertising is often higher due to working with an interested audience.

However, companies are also interested in expanding their target audience. Therefore, the task arises of determining the structure of advertising campaign financing by type, depending on the types of business and the behavioral activity of customers, both interested and potential.

It is often advisable to use both types of advertising, instead of giving preference to one type of advertising at the expense of the other. Therefore, the purpose of this study is to develop a methodology for structuring the costs of an advertising campaign that takes into account the violation of the principle of symmetry of user interest in advertising.

The choice of ad campaign financing structure is not as obvious as it might seem at first glance. It is created by the phenomenon of information asymmetry [2, 3] in the market of online sales of goods and services. In this case, sellers conduct business without having full information about the competitive environment, as well as the intentions of buyers $[1,4]$. In turn, customers form their opinion about a product or service based on a different set of factors and sources, constantly listen to the opinion of online communities, reading articles, reviews on the Internet, following opinion leaders, etc. Thus, the interaction between the advertiser and the product user becomes more complicated due to the information asymmetry of the market. The main hypothesis is that the phenomenon of market asymmetry is associated with an imbalance in the behavioral activity of customer groups $[5,6]$.

There are various methods for structuring and planning advertising campaign costs, taking into account the preferences of the target audience [7]. In this case, various offline and online tools are used, such as customer surveys, or selecting one of the types of advertising (contextual or targeted), depending on the organization's goal (launching a new product on the market, increasing the target audience, etc.). On the one hand, these approaches can significantly simplify the planning process, but on the other hand, they do not allow you to flexibly configure and effectively manage your advertising campaign. The approach proposed is one of the modifications of the algorithm for structuring advertising campaign costs based on the assessment of the economic effect of clickability and the use of classification methods [8]. In particular, we propose using cluster analysis methods to create a more suitable model for structuring advertising costs. 


\section{The proposed approach to structuring advertising costs}

The contextual advertising mechanism is an automated transaction for the implementation of advertising, and the usefulness of displaying an advertising banner is measured using the clickability indicator CTR (Click Through Rate) [1,9]:

$$
C T R=\frac{\text { number of clicks }}{\text { number of impressions }} \cdot 100 \% .
$$

When a company knows about the preferences of some of its customers, it can contact one of the ad providers that implements the contextual advertising mechanism for the corresponding users. Such ads are less effective in finding and expanding the target audience, since they are only shown to those customers who are already interested in purchasing this product.

In the case of tagged ads, banner owners are paid based on the number of clicks and impressions when the user sees the banner but doesn't click on it. The way to monetize banners is to sell them at an ad auction, where advertisers bid on these banners with different numbers of auction participants and placement conditions. Targeted advertising allows you to attract more of the target audience, but it is less accurate, although it is a cheaper tool for an Internet marketer.

If the ad campaign budget is limited, these funds can be distributed among ad providers, for example, as follows: $30 \%$ of the funds are allocated to the contextual advertising provider, and $70 \%$ to the targeted advertising providers. As a result, the company needs a model that will allow you to set the proportions of funding for these types of advertising in accordance with the interests of users.

The effectiveness of advertising policy based on the model built can be estimated using the lift coefficient [9]:

$$
\text { lift }=\frac{P(A \cap B)}{P(A) \cdot P(B)},
$$

where $P(A)$ and $P(B)$ - probabilities of interest in contextual and targeted ads, respectively; joint probability $P(A \cap B)-$ probability of interest in both types of ads from users.

The lift coefficient is an indicator of the effectiveness of targeted advertising and is used when predicting or classifying groups of users [10] who show increased interest in advertising. The model works well if the response within the target audience segment is much better than the average for the total number of users who were shown the ad.

Note that if we consider only $30 \%$ of the possible distribution for contextual advertising, this means that we are only interested in customers of deciles 1, 2, and 3. However, there may be a situation where the CTR value is also higher than the average for decile 4 (Figure 1). This approach is based on user classification and is similar to the idea of ABC analysis [11].

One approach to calculating the lift coefficient is to divide users into quantiles and rank the quantiles by the degree of lift. Next, you need to consider each quantile and, after weighing the predicted probability of response

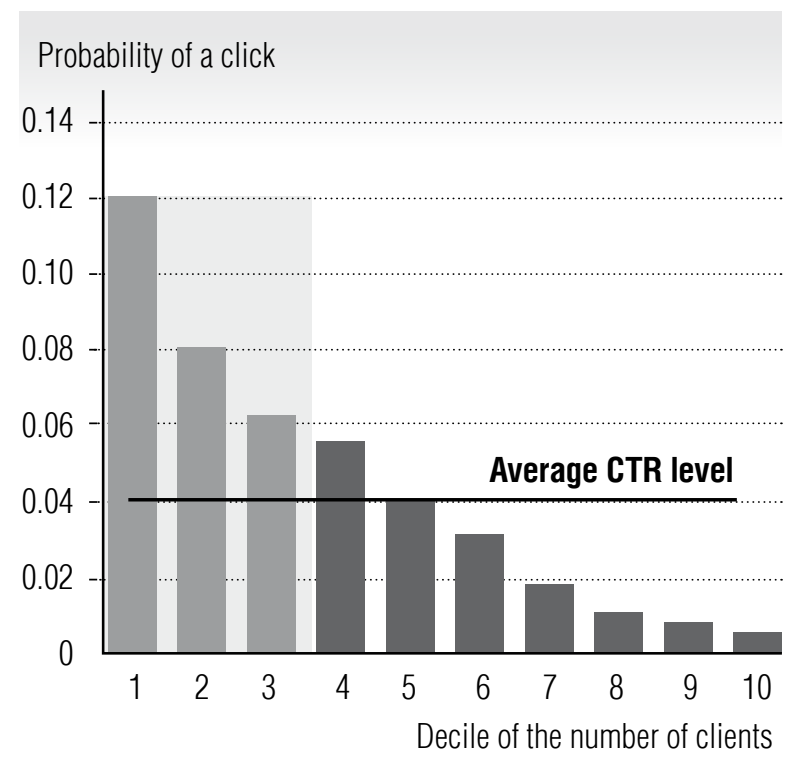

Fig. 1. The probability of a click for each decile of customers 
(and the associated financial benefit) in relation to advertising costs, make a decision on the financing of the advertising campaign. This principle is described in one of the examples shown in Figure 2. The curve, designated as a "random model", characterizes the situation of absolutely uniform distribution of interest in advertising among all users. This curve is called the absolute symmetry curve and means that there is no economic effect from advertising, since users show interest in ads in a random order, regardless of the seller's actions, which is practically unattainable in real conditions $[12,13]$. In this regard, it is possible to evaluate the economic effect that is received from users who have shown interest in advertising. The curves shown in Figure 2 as "ideal model" and "normal model" characterize the effectiveness of advertising for different user segments. This model can be considered as a kind of receiver performance curve (ROC) [14, 15], which is also known as the Lorentz curve [5, 14].

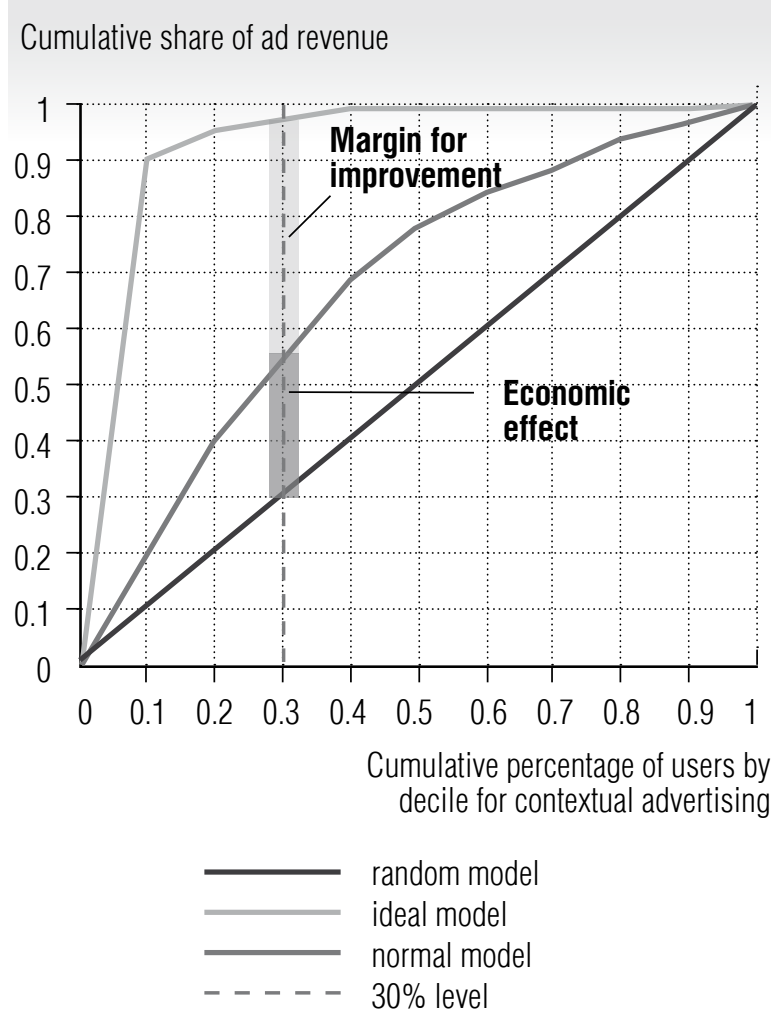

Fig. 2. Optimization of contextual advertising costs
The Lorentz curve for an ideal model describes the case when advertising is effective only for one small segment of users, who account for about $90 \%$ of the profit from ads, and the rest of the users who were shown the ad do not show interest in it. In this case, the cost of contextual advertising can be structured in a smaller proportion in order to find new interested customers using targeted advertising.

If the maximum economic effect compared to the random model is achieved at the fourth decile, then the maximum of interested users is about $40 \%$ of their total number. This case characterizes the normal model, which is most often found in practice. Thus, the search for the maximum economic effect for a different number of interested users allows you to prestructure advertising costs.

\section{Research methods}

It is advisable to divide users into deciles when there is no additional information about users that does not allow us to identify patterns in their behavior. It should be noted that in the case of contextual advertising, marketers have a fairly extensive array of information that characterizes the behavioral activity of product users. Therefore, the second approach to calculating the lift coefficient is to use cluster analysis [16, 17] to construct the Lorentz curve. In order to assess the uniformity of user interest in an ad, as well as to compare ads with their interests, it is necessary to proceed to cluster analysis of user reaction to ads [18].

Existing approaches [19] use the variance of differences between the test and training samples relative to the average level as an indicator of asymmetry. However, cluster analysis methods, being methods of machine learning without a teacher, require the use of other indicators of class symmetry breaking that are used in this paper.

The method developed includes the following steps: 
Step 1. To assess the quality of customer clustering, you need to evaluate the number of clusters (groups of splitting) as well as the uniformity of clusters in terms of the number of customers included in them.

It should be noted that the number of client partitioning groups is unknown in advance, so it is not possible to use clustering based on the $k$-means method. Clustering using algorithms based on decision trees requires a test training sample. However, in the case of an ad campaign, this selection may change dynamically. Therefore, hierarchical clustering methods are used as the most appropriate method [17], which do not require a training sample and allow for dividing clients into groups based on characteristics.

Hierarchical clustering methods allow you to choose one of two options for joining:

1) Agglomerative clustering starts with $n$ clusters, where $n$ is the number of observations (each of them is assumed to be a separate cluster). The algorithm then tries to find and group the most similar data points;

2) Divisional clustering is performed in the opposite way: initially, it is assumed that all $n$ data points are one large cluster, after which the least similar ones are divided into separate groups.

At the same time, agglomerative clustering is better suited for identifying small clusters, while the use of divisional clustering is advisable for identifying large clusters. Since the assumed characteristics of clients are described by categorical variables, the Gower distance is used as the cluster separation metric [18].

Step 2. At this stage, building a Lorentz curve to assess the imbalance of user interest in ads. The Gini coefficient is often used as an indicator of the degree of imbalance in the manifestation of a feature [20, 21]. Figure 3 shows an example showing the dependence of the share of points in the $i$-th cluster (on the total number of points in the sample) on the cumulative share of the number of clusters.

For example, for four clusters, the share of the first cluster will be 0.25 (25\%). This cluster will contain 25 points out of 100 , so the graph will display a point $(0.25 ; 0.25)$. If all clusters have the same number of points, then there is absolute symmetry in the partition groups and the Gini coefficient is zero. Accordingly, the imbalance is described by the area of the bounded Lorentz polyline and the absolute symmetry curve and is calculated by the formula:

$$
G=1-\sum_{k=1}^{n}\left(X_{k}-X_{k-1}\right) \cdot\left(Y_{k}+Y_{k-1}\right), G \in[0 ; 1],
$$

where $n$ - number of clusters;

$X_{k}$ - cumulative percentage of the number of clusters;

$Y_{k}$ - cumulative percentage of the number of points in the cluster.

The greater the value of the Gini coefficient deviates from zero, the greater the asymmetry in the characteristics of clusters [21-23].

\section{Cumulative percentage}

of points in the $i$-th cluster

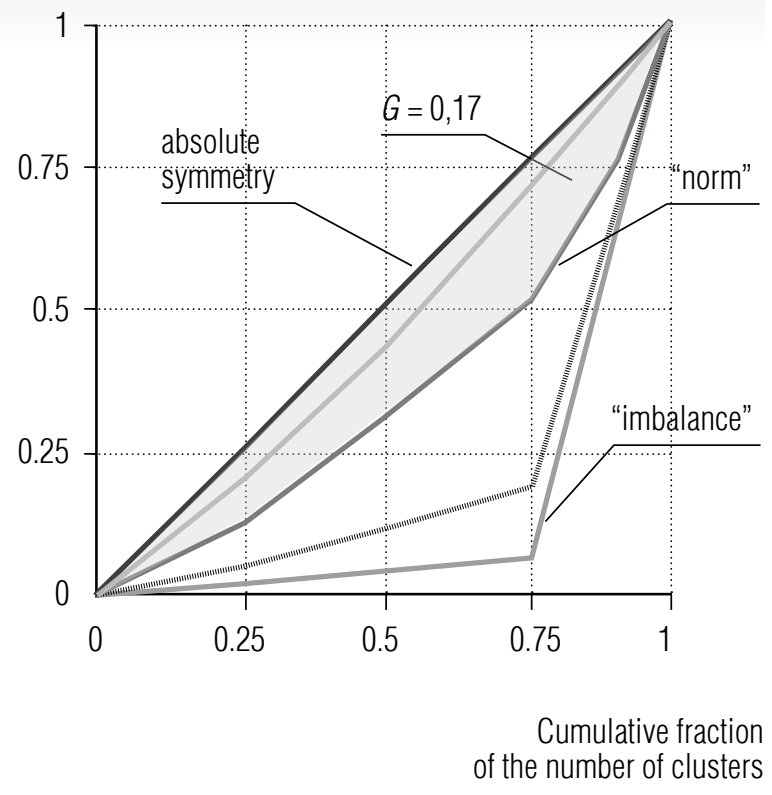

Fig. 3. Interpretation of the Gini coefficient in clustering problems 
Calculating the Gini coefficient makes it possible to find the best match between the clustering options for products and customers, which helps to increase the customer orientation of products and increase the effectiveness of advertising. As a result, switch from user classification methods to clustering, which will simultaneously allow you to make more precise settings for both contextual and targeted advertising. However, to do this, it is necessary to evaluate the quality of grouping into clusters using the Gini coefficient.

Figure 4 shows an example that compares several Lorentz curves for four, five, and ten clusters. It is shown that in this case, with five clusters, not only the best quality of splitting users into groups is observed, but it is also possible to conclude that users of the first cluster provide the maximum increase in advertising revenue.

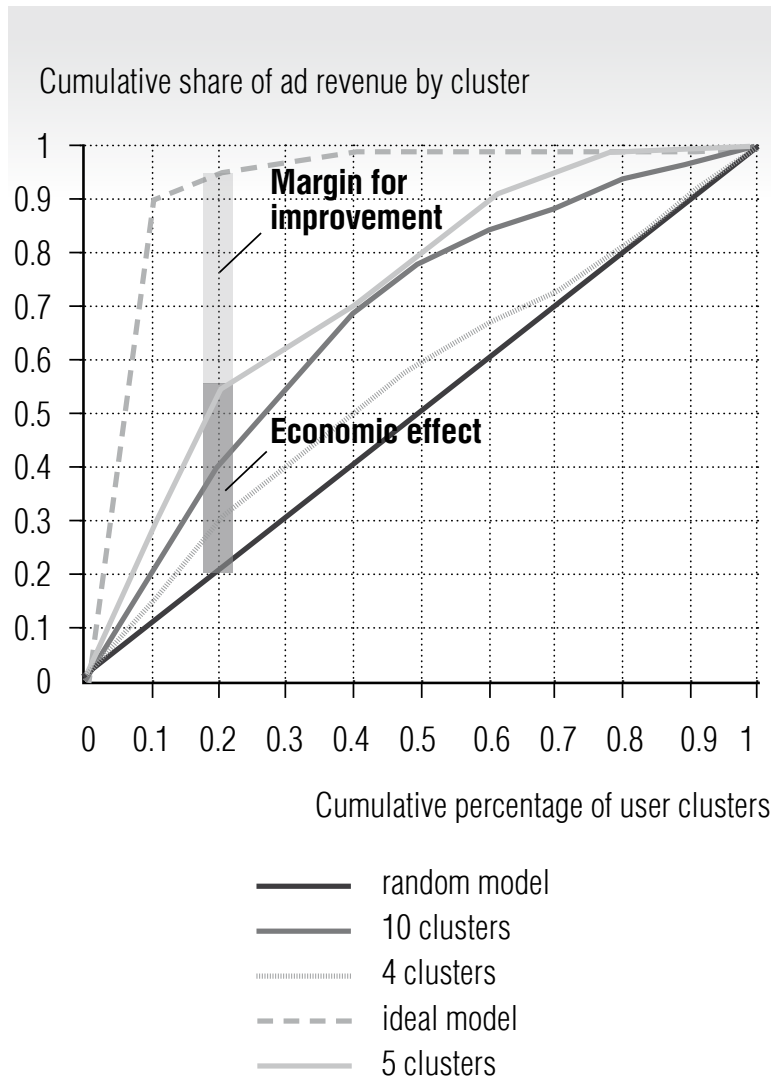

Fig. 4. Example of structuring advertising costs based on cluster analysis
Step 3. At the final stage, it is necessary to determine at what value of the cumulative share of clusters the maximum lift coefficient is observed, which allows us to conclude that the part of users for whom contextual advertising is more effective is allocated, according to which the share of contextual advertising in the total cost is set.

\section{Example of application of the proposed approach}

Using the Gini index and the cluster approach, you can calculate how much it is possible to improve advertising revenue in the same conditions by using the methodology described in this paper and compare it with the results obtained in the absence of any policy for structuring advertising costs. It should be noted that this method does not allow you to improve CTR in general, but it allows you to optimize the cost of advertising a product with the current number of clicks and purchases.

Let's take a concrete example of how this approach to evaluating the effectiveness of advertising works. First of all, the source data was modeled using the $R$ language using the "dunif" and "dbinom" batch functions. Modeling was performed on the basis of various distribution functions that characterize the appearance of a particular trait. The synthesized test sample consisted of 10 thousand points, each of which describes the user's action in accordance with the following criteria:

- unique identifier of the action, type "string" - sequential numbering;

$\checkmark$ date and time, type "object"- discrete uniform distribution within the range from the start date to the end date;

$\checkmark$ user's operating system, type "string"- discrete uniform distribution across four types of operating systems;

$\checkmark$ the user's browser, type "string" - the discrete uniform distribution on the six kinds of browsers;

$\checkmark$ country, type "string" - discrete uniform distribution across nine countries; 
$\downarrow$ referral link type, type "string" - discrete uniform distribution across five types of links corresponding to different parts of the site where banners are placed;

$\downarrow$ banner name, type "string" - discrete uniform distribution;

$\downarrow$ action (interest or lack of interest), type "binary int" - binomial distribution with a purchase probability of 0.05 ;

↔ buy (or no buy), type "binary int" - binomial distribution with a purchase probability of 0.02 .

As one of the simplifications, it is assumed that the cumulative income from the purchase is measured in relative units - the probability of making a purchase of one unit of identical goods.

The next step is to select the users who responded to the ads. In this case, there were 453 people $(C T R=4.53 \%)$, of whom 50 people made purchases. Then you need to evaluate
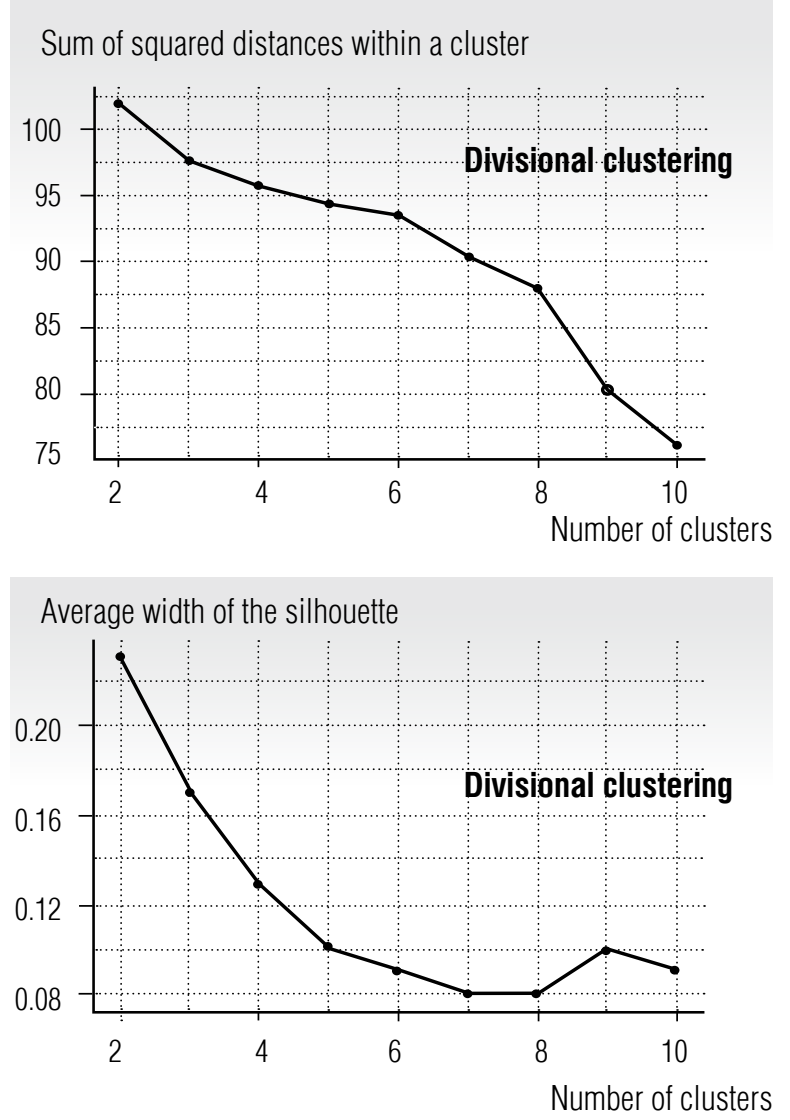

the uniformity across clusters of interested customers who have made purchases.

The next step is to perform client clustering using hierarchical methods [22], using two algorithms: based on divisional and agglomerative clustering.

Indicators of the sum of squares of distances between points within the cluster and the average width of the silhouette [24, 25] allow us to assess the quality of clustering. For the sum of squared distances, the "elbow bend" method is used $[22,26]$ to determine the optimal number of clusters, and the local maximum of the silhouette width value allows you to select the number of clusters with the best separation. Thus, the optimal number of partitioning groups - clusters is five for the agglomerative and eight for the divisional clustering algorithm (Figure 5). In addition, it is possible to evaluate
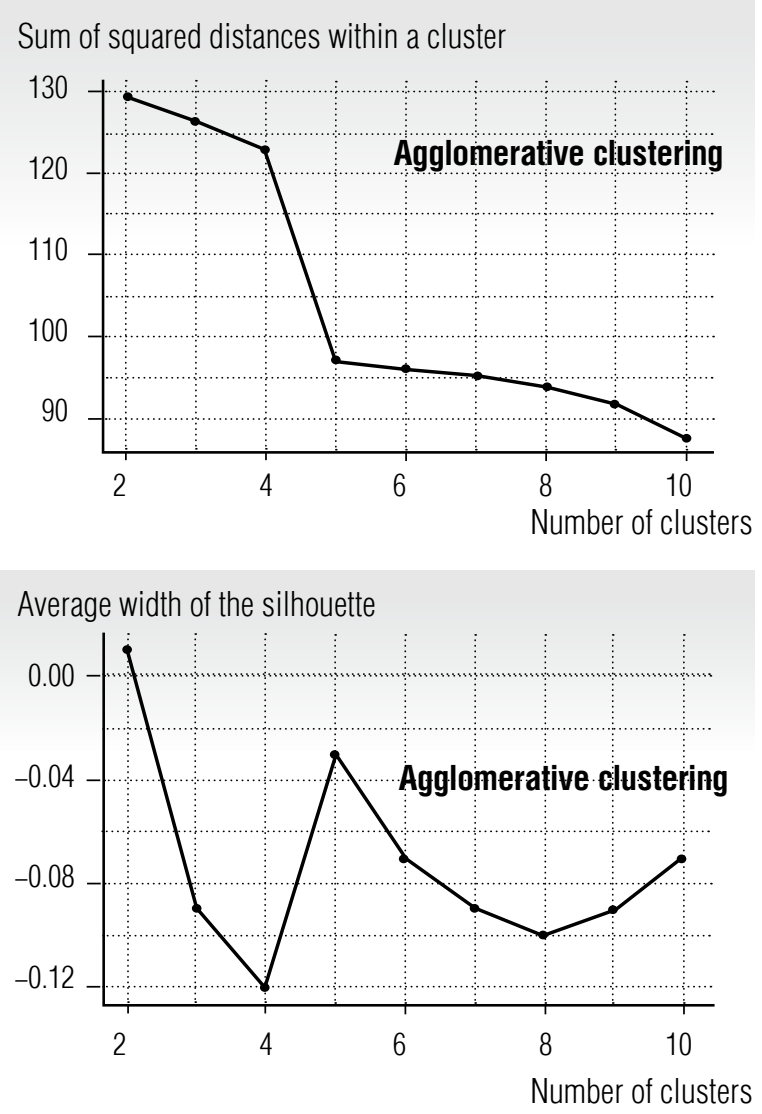

Fig. 5. Indicators for evaluating the quality of clustering 
the intra-cluster variety of user actions regarding purchases. To do this, you need to compare how advertising costs can be structured based on the Gini coefficient. The indicators that characterize cluster diversity for splitting into 5 and 8 clusters are shown in Table 1 .

The threshold value of the buyers share (Figure 6), which characterizes the maximum economic effect (lift coefficient) from advertising, for five clusters varies from 0.66 to 0.71 for agglomerative and divisional clustering algorithms, respectively. This means that for optimal structuring of advertising costs, it should be taken into account that the majority of users (about $80 \%$ ) belonging to cluster 2 (Table 1) do not have clear intentions and signs of actions related to the purchase of a product, i.e. they most likely bought it spontaneously [2, 27], searching by needs. Therefore, in this example, about $70 \%$ of advertising costs should be given to contextual advertising, which will allow you to target only interested users, while the remaining $30 \%$ should be given to targeted advertising to attract new customers.

However, in the case of five clusters, the area under the curve is significantly smaller than in the case of eight clusters, when there is a more detailed partition. It should be noted that the agglomerative clustering algorithm provides a large area, which in this case shows the best results, despite the increase in the number of clusters. The threshold values for the share of buyers for both algorithms have not changed much, which indicates that the results are balanced and reliable. However, the very value of the lift coefficient has grown significantly and

\section{Results of hierarchical clustering of interested users}

Table 1.

\begin{tabular}{|c|c|c|c|c|c|c|c|c|}
\hline Cluster No & 1 & 2 & 3 & 4 & 5 & 6 & 7 & 8 \\
\hline \multicolumn{9}{|c|}{ Divisional clustering } \\
\hline $\begin{array}{l}\text { Percentage of the total number } \\
\text { of interested customers }\end{array}$ & 0.071 & 0.717 & 0.082 & 0.029 & 0.040 & 0.035 & 0.015 & 0.011 \\
\hline Probability of buying & 0.04 & 0.9 & 0.04 & 0 & 0.02 & 0 & 0 & 0 \\
\hline $\begin{array}{l}\text { Percentage of the total number } \\
\text { of interested customers }\end{array}$ & 0.071 & 0.717 & 0.168 & 0.029 & 0.015 & - & - & - \\
\hline Probability of buying & 0.04 & 0.82 & 0.1 & 0 & 0.04 & - & - & - \\
\hline \multicolumn{9}{|c|}{ Agglomerative clustering } \\
\hline $\begin{array}{l}\text { Percentage of the total number } \\
\text { of interested customers }\end{array}$ & 0.2649 & 0.6225 & 0.0442 & 0.0265 & 0.0155 & 0.0110 & 0.0110 & 0.0044 \\
\hline Probability of buying & 0.1 & 0.86 & 0.02 & 0 & 0 & 0.02 & 0 & 0 \\
\hline $\begin{array}{l}\text { Percentage of the total number } \\
\text { of interested customers }\end{array}$ & 0.265 & 0.660 & 0.044 & 0.026 & 0.004 & - & - & - \\
\hline Probability of buying & 0.16 & 0.76 & 0.04 & 0.04 & 0 & - & - & - \\
\hline
\end{tabular}



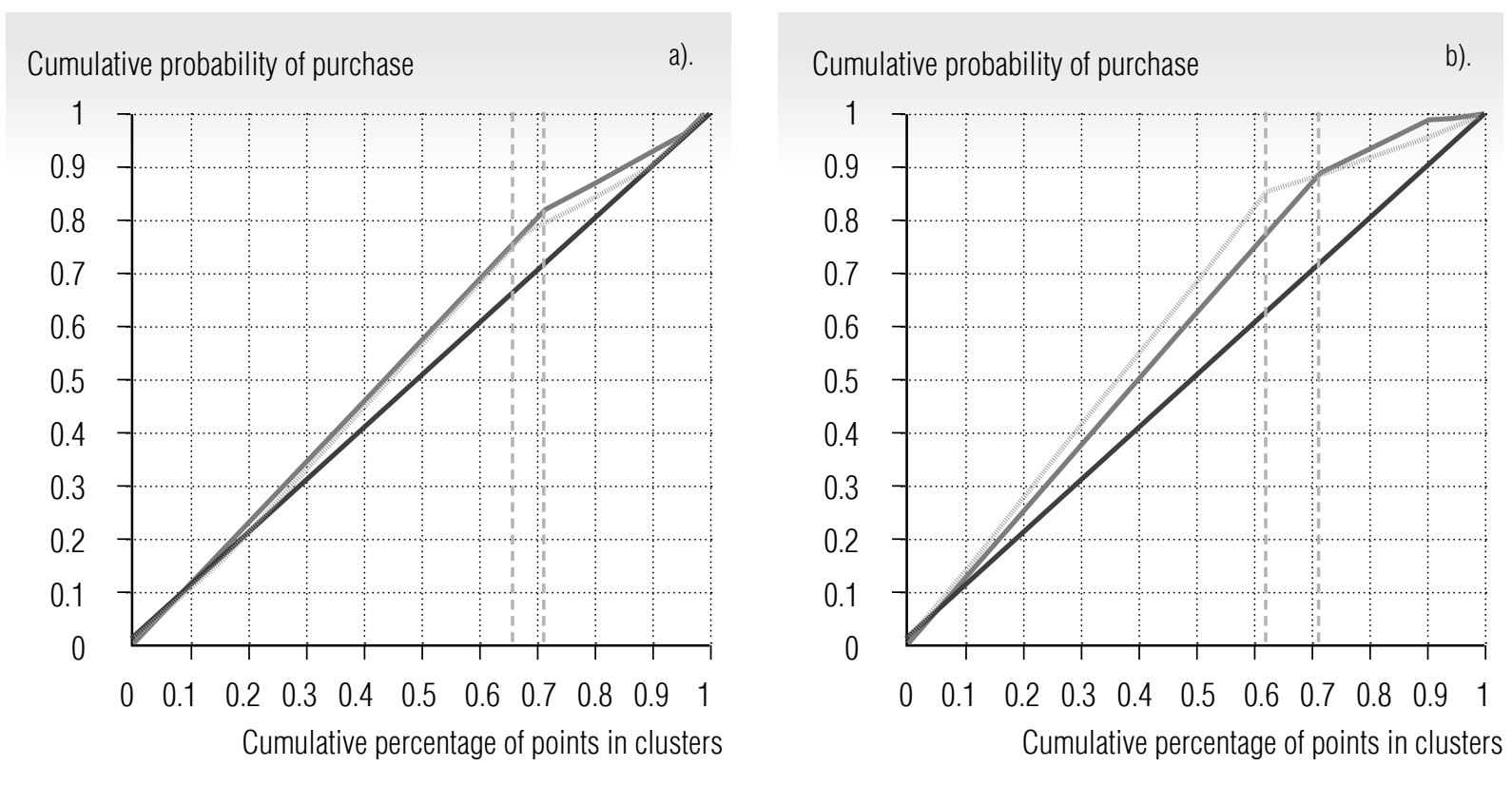

random model _ _ divisional clustering

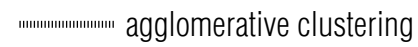

Fig. 6. Example of structuring advertising costs

based on hierarchical clustering for five (a) and eight (b) clusters

it can be judged that the maximum economic effect of advertising is achieved by financing contextual advertising in the amount of $62 \%$ of total costs. This clarifies the characteristics of users who are most likely to buy the product, and the probability of purchase increases from $82 \%$ to $90 \%$.

\section{Discussion of the proposed approach}

In order to evaluate the possibilities of the proposed approach, let's look at the diagram that shows the results of structuring the costs of an advertising campaign based on the ranking of customers by deciles (Figure 7).

Figure 7 shows that the cost structure for contextual and tagged advertising by ranking by decile differs markedly from the cluster approach. In the case of ranking clients by deciles, the maximum lift coefficient was obtained for $20 \%$ of clients, which indicates that contextual advertising is financed in the
Cumulative probability of purchase

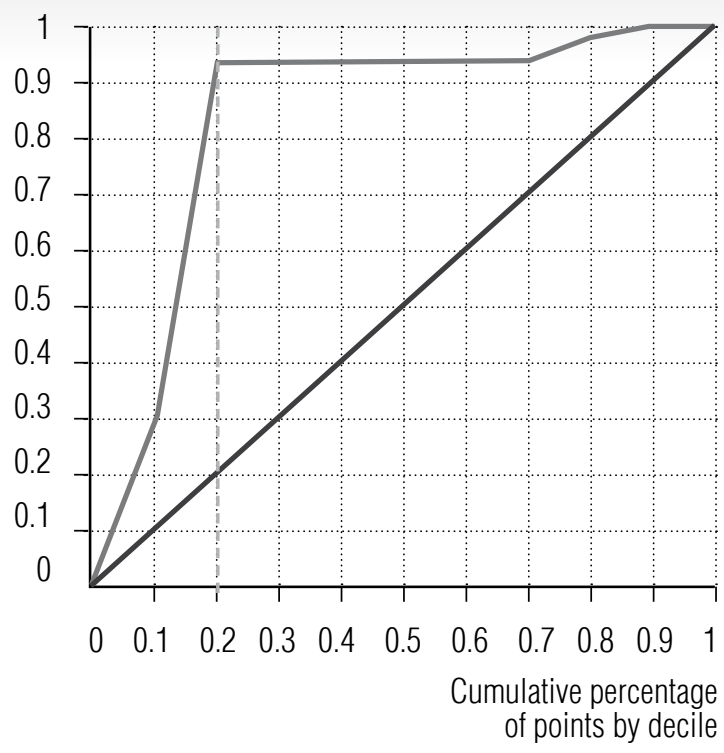

random model
ranking by decile

Fig. 7. Results of structuring advertising campaign costs by ranking by decile 
amount of only $20 \%$ of the total cost. Despite the fact that this graph is closer to the ideal case, this model has a minimal margin for improvement. In addition, it is impossible to correctly compare the obtained Lorentz curves for the cumulative fraction of points by deciles and the cumulative fraction of clusters, since in the first case, ranking was performed, and in the second - feature clustering. For the same reason, the areas under the Lorentz curves obtained in Figures 6 and 7 cannot be compared. However, the lift coefficient in both cases can be used to determine the proportions of advertising costs. The noticeable differences are explained by the fact that in the case of ranking by deciles, only the facts of the transaction are taken into account, but this approach does not take into account the characteristics of customers. The main advantage of the proposed method is the ability to more flexibly configure the structure of advertising costs depending on the signs of customer behavioral activity. The cluster approach allows you to build a more appropriate model and configure contextual advertising more precisely.

\section{Conclusion}

Analysis of the results allows us to draw the following conclusions.

1. To expand the capabilities of approaches to structuring banner advertising costs, it is necessary to use clustering algorithms based on categorical characteristics of user actions.

2. Hierarchical clustering methods are well suited for estimating the required number of clusters, and also make it possible to identify hidden patterns in customer behavioral activity.

3. The Gini coefficient makes it possible to evaluate the quality of clustering and determine the user groups that give the maximum purchase probability.

4. Using the cluster approach allows you not only to structure advertising costs, but also to determine which type of advertising should be applied to which users. This gives more opportunities to optimize costs and increase the effectiveness of your advertising campaign.

Identifying hidden patterns in consumer groups allows you to identify the main directions of product development and customer interest in the product as well as assess the stability of the market for products with similar characteristics and the stability of its development.

The results obtained reveal the applied possibilities of using the principle of symmetry breaking in business tasks, and, in contrast to existing works $[6,27]$, they reflect the possibilities of structuring the costs of an advertising campaign. This approach allows you not only to identify the popularity of products by characteristics, but also to determine the most effective ways to attract customers for a particular type of product. This is achieved by comparing the results of consumers' behavioral activity in relation to their performance of target actions, as well as the characteristics of the products for which they performed these actions. Also, one of the advantages is the ability to use the Gini uncertainty and the lift coefficient as indicators of user groups for which contextual or targeted advertising is more effective.

\section{Acknowledgement}

The study was supported by RFBR grant No 18.07.00170.

\section{References}

1. Kislyakov A.N. (2019) Evaluation of the effectiveness of advertising campaigns in social networks using simulation methods. Economics and Management: Problems, Solutions, vol. 5, no 3, pp. 20-26 (in Russian). 
2. Rau V.G., Kislyakov A.N., Tikhonyuk N.E. Rau T.F. (2018) The problem of asymmetry in the models of economic systems development. Proceedings of the XI International Scientific and Practical Conference "Regional Economy: Experience and Challenges", 15 May 2018. Eds. A.I. Novikov, A.E. Illarionov). Vladimir: RANEPA, Vladimir Branch, pp. 201-211 (in Russian).

3. Rau V.G., Polyakov S.V., Rau T.F., Firsov I.V., Togunov I.A. (2019) Some features of application of broken symmetry groups for "visualization" of processes in natural, "living" and socio-economic systems. Proceedings of the XI International Scientific and Practical Conference "Regional Economy: Experience and Challenges”, 15 May 2018. Eds. A.I. Novikov, A.E. Illarionov). Vladimir: RANEPA, Vladimir Branch, pp. 111-119 (in Russian).

4. Kislyakov A.N., Tikhonyuk N.E. (2019) Model of price formation of a homogeneous market taking into account the asymmetry of information. Innovative Development of Economy, no 1, pp. 93-100 (in Russian).

5. Perskii Yu.K., Dmitriev D.V. (2009) Formation of the information-economic mechanism of information asymmetry level management at the regional branch market. Bulletin of SUSU. Series: Economics and Management, no 29, pp. 66-74 (in Russian).

6. Kislyakov A.N. (2020) Asymmetry of information in the analysis of socio-economic processes. Vestnik NSUEM, no 1. pp. 64-75 (in Russian). DOI: 10.34020/2073-6495-2020-1-064-075.

7. Baranovskaya T.P., Ivanova E.A., Khachak F.R. (2016) The automated subsystem for advertising budget planning. Scientific Journal of KubSAU, no 120, pp. 223-238 (in Russian).

8. Barnés M. (2020) Calculate the economic impact of your click-through prediction. Available at: https://towardsdatascience.com/calculate-the-economic-impact-of-your-click-through-prediction1 fa6eee64494 (accessed 25 April 2020).

9. Galyamov A.F., Tarkhov S.V. (2014) Customer relationship management of a commercial organization based on methods of segmentation and clustering of customer database. Vestnik USATU, vol. 18, no 4, pp. 149-156 (in Russian).

10. Andreeva A.V. (2012) Optimal control of a company's customer base using the customer lifetime value parameter. Business Informatics, no 4, pp. 61-68 (in Russian).

11. Tsoy M.E., Zaleshin P.A. (2017) Consumer segmentation on the basis of the study of consumer behavior styles. Rossiyskoe Predprinimatelstvo, vol. 18, no 21, pp. 3313-3326 (in Russian). DOI: 10.18334/rp.18.21.38543.

12. Mishra B.K., Hazra D., Tarannum K., Kumar M. (2016) Business Intelligence using Data Mining techniques and Business Analytics. Proceedings of the 5th International Conference on System Modeling \& Advancement in Research Trends (SMART 2016), 25-27 November 2016, Moradabad, India, pp. 84-89. DOI: 10.1109/SYSMART.2016.7894496.

13. James G., Witten D., Hastie T., Tibshirani R. (2013) An introduction to statistical learning with applications in $R$. New York: Springer.

14. Nielsen F. (2016) Introduction to HPC with MPIfor data science. Springer.

15. Hastie T., Tibshirani R., Friedman J. (2017) The elements of statistical learning: Data mining, inference, and prediction. Second Edition. Springer.

16. Kassambara A. (2017) Practical guide to cluster analysis in R: Unsupervised machine learning. Multivariate analysis I. STHDA.

17. Tripathi S., Bhardwaj A., E P. (2018) Approaches to clustering in customer segmentation. International Journal of Engineering \& Technology, vol. 7, no 3.12, pp. 802-807. DOI: 10.14419/ijet.v7i3.12.16505.

18. Gower J.C. (1971) A general coefficient of similarity and some of its properties. Biometrics, vol. 27, no 4, pp. 857-871. 
19. Kislyakov A.N. (2020) Indicators of asymmetry in the tasks of studying the behavioral activity of product users. Izvestia Sankt-Peterburgskogo Gosudarstvennogo Ekonomicheskogo Universiteta, no 3, pp. 110-116 (in Russian).

20. Frunza M.-Ch. (2013) Computing a standard error for the Gini coefficient: An application to credit model validation. Journal of Risk Model Validation, vol. 7, no. 1, pp. 61-82. DOI: 10.21314/ JRMV.2013.099.

21. Zorina A.A. (2014) The formation of fluctuating asymmetry during individual development of Beluta pendula. Principles of the Ecology, no 4, pp. 27-46 (in Russian).

22. Murtagh F., Contreras P. (2011) Methods of hierarchical clustering. ArXiv. Available at: https://arxiv.org/ pdf/1105.0121.pdf (accessed 30 March 2020).

23. Korolev O.L., Coussy Yu.M. Segal A.V. (2013) Application of entropy in modeling decision-making processes in the economy. Ed. A.V. Segal. Simferopol: OJAK Publishing House (in Russian).

24. Pechenyi E.A., Nuriev N.K., Starygin S.D. (2019) Dynamic clustering of big data flow. Proceedings of the International Scientific Conference "Mathematical Methods in Technics and Technologies", vol. 3, Ed. A.A. Bolshakov). Saint-Petersburg: Polytechnical Institute Publishing House, pp. 19-21 (in Russian).

25. Prokofyeva E.S., Zaytsev R.D. (2020) Clinical pathways analysis of patients in medical institutions based on hard and fuzzy clustering methods. Business Informatics, vol. 14, no 1, pp. 19-31. DOI: $10.17323 / 2587-814 X .2020 .1 .19 .31$

26. Yakimov V.N., Shurganova G.V., Cherepennikov V.V., Kudrin I.A., Il'in M.Yu. (2016) Methods for comparative assessment of the results of cluster analysis of hydrobiocenoses structure (by the example of zooplankton communities of the Linda River, Nizhny Novgorod Region). Inland Water Biology, vol. 9, no 2, pp. 200-208. DOI: 10.7868/S0320965216020169.

27. Baranov S.G., Burdakova N.E. (2015) Assessment of development stability. Methodological approaches. Vladimir: Vladimir State University Publishing House (in Russian).

\section{About the author}

\section{Alexey N. Kislyakov}

Cand. Sci. (Tech.);

Associate Professor, Department of Information Technologies, Russian Academy of National Economy and Public Administration under the President of the Russian Federation, Vladimir Branch, 59a, Gorky Street, Vladimir 600017, Russia;

E-mail: ankislyakov@mail.ru

ORCID: 0000-0001-8790-6961 


\title{
A model for optimizing plans for procurement of raw materials from regions of Russia in a timber-processing enterprise
}

\author{
Rodion S. Rogulin \\ E-mail: rafassiaofusa@mail.ru \\ Vladivostok State University of Economics and Service \\ Address: 41, Gogolya Street, Vladivostok 690014, Russia \\ Far Eastern Federal University \\ Address: 10, Ajax Bay, Russky Island, Vladivostok 690922, Russia
}

\begin{abstract}
In this paper a model for the formation of sustainable supply chains of raw materials for a timber processing complex is proposed. The model allows one to optimize the plan of purchases from the Russian Commodity Exchange, as well as the plan of manufacturing finished products. The model presents the task of mathematical programming, whereby the company's profit is used as the objective function, and the input data include the forecasted values of structure and volumes of offers available on the Russian Commodity Exchange, as well as demand for finished products. The recurrence dependencies of the model describe the flow of raw materials at the enterprise's warehouse, taking into account revenues from purchased lots, transportation time and consumption of resources that are required for production of simulated volumes of products. Constraints of the model represent formalization of the limited flow of financial resources, taking into account sales and warehouse characteristics. The optimization task deals with variables including volumes of daily output of finished products according to a given nomenclature, as well as variables that specify the inclusion of lots into the portfolio of applications purchased on the exchange. The model solution is found using the branch and bound method with preliminary clipping based on the modified Chvatal-Gomory method. One example considers formation of optimal plans for the purchase and sales in a timber processing complex located in the Primorsky Territory (Russia), which does not have its own forest plots providing production with raw materials. The usefulness of the interaction of the enterprise with the timber department of the commodity and raw materials exchange is assessed.
\end{abstract}


Key words: supply chain; enterprise economics; timber exchange; data analysis; resource consumption rate; warehouse capacity.

Citation: Rogulin R.S. (2020) A model for optimizing plans for procurement of raw materials from regions of Russia in a timber-processing enterprise. Business Informatics, vol. 14, no 4, pp. 19-35.

DOI: 10.17323/2587-814X.2020.4.19.35

\section{Introduction}

I $n$ any industry of the economy, production is a quite complex and time-consuming process. When managing the manufacturing process, there are many tasks that have different levels of complexity. Such tasks require appropriate tools to optimal solutions determining. In its development strategy, an enterprise can focus on goals that are different from the financial point of view. In most cases, this goal is to maximize profit, which amount depends on multiple factors coming from both the external and internal environment of the enterprise.

Typically, the entire manufacturing process can be subdivided into three stages. The first stage is securing the material resources (raw materials). The second stage is production. The third stage is sale of the finished products, including logistics issues.

Each of these processes is quite complex in its own way. A serious problem for any production in the timber industry is to obtain resources [1]. If the necessary raw materials are purchased outside the enterprise, then the enterprise faces the task of selecting the best option for purchasing and delivering raw materials from the production areas to the production site. For a timber industry enterprise that buys raw materials on a commodity exchange, the number of possible options on a planning horizon of several months is quite large. This requires analysis of significant volumes of data and the use of special tools [2, 3].

Another important issue is the problem of selecting the optimal volume of products for each type, taking into account current market demand $[3,4]$. However, it is difficult and even dangerous for the prospect of the enterprise to form a production plan on the middle or longrange planning horizons without understanding the current situation on the raw materials market. It may turn out that the prices for raw materials are too high to purchase in sufficient quantities, while the production plan is drawn up relying on the availability of certain types of raw materials. In this regard, for high-quality planning of production volumes, it is important to take into account the trends on the raw materials market.

To solve the task of arriving at an optimal manufacturing plan, it is necessary to develop the plan on the basis of the available forecasts for raw materials, or relying on the known distribution of orders sold in the market. So, there is a question that is known in the literature as the problem of supply chain management (SCM).

\section{Review of the literature and stating the problem}

The tasks of supply chain management (SCM) are always complex from several points of view. First, there is no exact universal method for finding optimal (or more or less effective) solutions of SCM problems [4]. Secondly, there are a huge number of factors that must be taken into account when looking for solutions $[1,3,5]$.

The timber industry has its own specifics of the raw material delivery process. Raw materials from this industry are very similar to food products, because both have a time factor - the factor of the stock availability. If a commodity is stored for too long, then there is a high probability that it will deteriorate and lose liquidity. Therefore, the speed of delivery of raw materi- 
als to the point of production should be maximized [2, 3].

To achieve the maximum speed of delivery of raw materials, so that raw materials remain liquid for the manufacturer, the following is essential. First, it is necessary to know the distribution of market bids [1]. Second, one should take into account the delivery time of raw materials $[4,6]$. Finally, you must take into account the important factor of the number of consumed types of raw materials per unit of manufactured goods, and also take into account the stock of each raw material and storage capacity.

The authors of [7] developed one of the rare purely linear models for the raw material delivery system. By transforming a linear programming problem into a two-step scenario-based problem, it is possible to eliminate uncertainty in production levels and weather conditions. The scenario based model allowed the authors to minimize overall costs, including transportation, warehouse expansion and throughput penalties.

Authors of [4] solved the problem of forming a supply chain, taking into account the norms of labor costs for the production of each unit of goods. The authors modeled the situation for the delivery of the final product to consumers by forming a matrix of input and output flows. The indicator of the difference between the sales revenue and the costs of transporting goods was used as an objective function. It should be noted that the solution of this problem has a one-time nature for the current situation, and for solving subsequent tasks of the supply of goods it will be necessary to solve this problem again. This is extremely difficult from the point of view of the volume of appropriate computations.

Article [8] discusses a new multi-period, multi-product supply chain project that takes into account economic, environmental and social aspects. The model aims to minimize the total cost of the system, including the fixed costs of installation, transportation, manufacturing, purchasing, distribution and environ- mental protection. The model considers several aspects of supply chain network design, such as capacity of facilities, maximum coverage radius, limited budget and the acceptable level for social assessment of enterprises and distribution centers. The model captures various categories of uncertainty, including on the supplier side and the receiver side. To deal with undefined parameters, a limited fuzzy programming approach is used. Several test tasks are used to analyze the characteristics of the problem proposed. The results of the calculations show that accounting for the different categories of uncertainty is critical to designing an efficient and effective supply chain network. The disadvantages of this model include failure to account for the delivery of raw materials to the point of production, as well as the maximum volume of raw materials and goods that can be simultaneously stored in warehouses.

The authors of [9] argue that a decline in market prices leads to the need to reduce the cost of supplying wood chips to ensure profitability in the supply chain and continued supply of wood chips. Shredding and transporting are two main factors affecting the overall cost of a biofuel supply system. In order to fully utilize the payload of trucks and reduce transport costs, logging residues are usually cleaved at planting so that there is a minimum of empty space between the raw materials. It is important for the contractor to maximize the proportion of effective working time in relation to the planned working time. It is now widely believed that effective working time is less than 50 percent of planned working time due to transporting chips using a crusher, waiting for trucks for chips and other delays. The increased loading of the shredder requires more efficient coordination between the equipment and the chip loaders that deliver the produced chips to the customer. Supply system models were constructed using discrete event simulation to examine how transport distance, number of trucks, shift scheduling and chip buffers affect system costs for a high-performance crusher 
system. System cost and machine utilization vary greatly depending on system configuration.

In [10], the authors proposed a new approach for re-optimization of transportation plans for $\log$ trucks in real time when an unexpected event is detected. This approach uses a spacetime network to represent the evolution of the transport network over time and the changes it undergoes after a failure. Permitted trips and loading / unloading operations are used as input to the mathematical model. The last solution represents the final transportation plan. The simulation procedure was designed to generate unexpected events for real world applications. Compared to the full informational scenario, where it is assumed that the failures are known in advance, the proposed approach yields very good results. In addition, as the authors argue, the mathematical model was solved in a few seconds and thus is well suited for real-time use. However, it should be noted that the authors do not account for various additional factors such as production and warehouse capacity.

The authors of [11] proposed using the genetic algorithm (GA) to find a set of Pareto optimal solutions for a multipurpose supply chain with four echelons, using two different weighting approaches. The authors of [12] developed a model for the supply of raw materials using a two-tier assembly system under conditions of uncertain lead times in order to minimize the expected cost of storage of components and maximize the level of customer service. They used two GA-based multipurpose metaheuristics to solve these problems. In [13], supply networks based on GA (in particular, knowledge-based genetic algorithm, KBGA) for optimization are provided. In [14], a multipurpose model of mixed integer programming for a closed loop network design was formulated. In addition to total costs, the model optimizes total carbon emissions and network responsiveness. An advanced genetic algorithm based on the NSGA II structure was designed to obtain Pareto optimal solutions.
In addition, in [15], the authors considered a two-stage stochastic programming model used for the design and management of biodiesel supply chains in various types of production. The model reflects the impact of uncertainty in the supply of biomass and technology on supply chain decisions. The authors solved this problem using algorithms that combine Lagrange relaxation and L-shaped solution methods.

Based on the review of literature, it can be assumed that the topic of the formation of supply chains for raw materials has been seriously studied in the literature and, due to the lack of common approaches to solving this problem, has a high degree of relevance. In addition, there are no works that would consider the possibility of supplying raw materials from commodity exchanges, taking into account various production restrictions.

Thus, the purpose of this study is to develop a method for the formation of optimal plans for the purchase of raw materials from a commodity exchange and manufacturing of finished products. Such a plan should ensure the maximum profit of the enterprise before tax at a given planning horizon, in order to assess the possibilities of cooperation between the enterprise and the exchange.

To achieve the goal, the following tasks were set:

$\downarrow$ to develop a mathematical model that maximizes the profit of an enterprise based on optimization of procurement planning and production volumes using a forecast of the structure and volume of proposals on the Russian Commodity Exchange, as well as demand for finished products;

$\downarrow$ to test the model in a real enterprise and explore the computational aspects of using the model;

$\downarrow$ to propose an approach to assessing the possibilities of cooperation between the enterprise and the exchange. 


\section{A model for the formation of an optimal plan for the procurement of raw materials and the manufacturing of finished products}

A typical timber processing enterprise may be able to lease a plot (to win a tender), find plots in the nearest district (the legal form of leased forest plots) and to purchase raw materials from this plot, as well as to consider alternative sources of raw materials supply, including external sources $[16,17]$. Next, we will consider enterprises that purchase raw materials from external sources. To test the model, one of the enterprises of the Primorsky Territory of Russia is considered.

Thus, we consider the problem of forming optimal plans for the purchase of raw materials and production of products by a manufacturing company of the timber processing industry at a given planning horizon $M$, taking into account the offers on the market from the timber industry and the demand for finished products.

At the initial moment of time $m=0$, there is planning of raw materials procurement and production for the entire given horizon $m \in\{0,1, \ldots, M\}$. On this horizon, for each $m$-th day, a set of offers on the raw material market (in the form of orders on the commodity exchange) and the demand for manufactured products on the market for the period under consideration are given. The market order is set by the region of the logging company, the volume and the price, including the cost of delivery. The demand in the market for finished goods is determined by the possible selling price for each type of product.

We will consider the accumulated profit as the objective function of the model.

Let's introduce the following parameters and variables:

$l$ - type of raw materials for the production of finished products $l=1, \ldots, L$;

$$
k \text { - type of production } k=1, \ldots, K \text {; }
$$

$c_{i l r m}-$ purchase price of the $i$-th application for raw materials of the $l$-th type in the $r$-th region on the $m$-th day (rubles), including the cost of delivery; $v_{i l r m}$ - volume of raw materials of type $l$ in request $i$ from region $r$ per day $m$ (cubic meters);

$u_{l m}-$ stock of raw materials type $l$ per day $m$ (cubic meters);

$u^{\max }$ - maximum storage capacity (cubic meters);

$\dot{v}_{\text {ilrm }}-$ volumes of type $l$ raw materials purchased in the previous period, for which it is known that they will arrive at the warehouse on a day $m$ (cubic meters);

$A_{l k}$ - the volume of resource $l$ spent on the production of a unit of goods $k$ (cubic meters);

$p_{k m}-$ selling price of product type $k$ in day (rubles);

$z_{k}$ - cost of production minus the cost of the main raw materials used (timber);

$F C$ - fixed costs per day (rubles);

$x_{k m}$ - production volume of goods type $k$ in day $m$ (units);

$l$ - the number of orders that were purchased by the enterprise in the previous period (until the moment $m=0$ ), and for which the dates of arrival at the warehouse are known;

$R$ - the number of regions from which orders are placed (raw materials are mined and put up for auction) on the exchange;

$T_{r}$ - the rate of time spent (in days) for the delivery of any volume of raw materials from region $r$ by rail;

$Q_{\operatorname{lnkm}}-$ demand from consumer on item $n$ in $k$ day $m$;

$M$ - the planning horizon under consideration (days), called the current period;

$\dot{M}$ - the number of days from the current period for which purchased orders will arrive at the warehouse during the next period;

Budget $_{0}$ - the company's budget allocated for the introduction of trading, as of the moment the model starts working;

$\dot{x}_{k m}-$ hypothetical production volume of product type $k$ in day $m=1: \dot{M}$, which can be determined as: 


$$
\begin{aligned}
\dot{x}_{k m} & =\left\lceil\frac { 1 } { 2 } \left(\max _{m^{*} \in[m-t, m]}\left(x_{k m^{*}}, \dot{x}_{k\left(m^{*}-1\right)}\right)+\right.\right. \\
& \left.\left.+\min _{m^{*} \in[m-t, m]}\left(x_{k m^{*}}, \dot{x}_{k\left(m^{*}-1\right)}\right)\right)\right],
\end{aligned}
$$

where $t-$ the number of days for which the maximum and minimum values are selected $x_{k m^{*}}$ in constraints (3) and (4), respectively (mathematical notation of constraints is given below).

Parameters $u_{t 0}$ and Budget $_{0}$ are determined and set and correspond to the last day of the previous period.

As an objective function, we will consider the pre-tax profit of the enterprise on the planning horizon $M$.

As a result, the mathematical formulation of the problem is as follows:

$$
\begin{gathered}
\sum_{k, m}\left(p_{k m}-z_{k}\right) x_{k m}-\sum_{i, l, r, m} c_{i l r m} y_{i l r m} \rightarrow \max \\
u_{l m}=u_{l(m-1)}+\sum_{i, r} v_{i l r\left(m-T_{r}\right)} y_{i l r\left(m-T_{r}\right)}+ \\
+\sum_{i \in I, r \in R} \dot{v i l r m}_{i r}-\sum_{k} A_{l k} x_{k m}, l=1: L, m=1: M \\
\sum_{l} u_{l m} \leq u^{\max }, m=1: M+\dot{M} \\
u_{l m} \geq u^{m i n}, l=1: L, m=1: M+\dot{M} \\
\sum_{k} A_{l k} x_{k m} \leq u_{l m}, l=1: L, m=1: M \\
y_{i l r m}=\left\{\begin{array}{c}
1, \text { if lot } i \text { with resourse type } l \\
\text { in region } r \text { in day } m \text { is bought } \\
0, \text { otherwise } \\
\text { Budget }{ }_{0}+\sum_{m=1}^{m^{*}}\left(\sum_{k}\left(p_{k m}-z_{k}\right) x_{k m}-\right. \\
\left.-\sum_{i, l, r} c_{i l r m} y_{i l r m}-F C\right) \geq 0, m^{*}=1: M \\
x_{k m} \leq \sum_{n} Q_{n k m}, k=1: K, m=1: M
\end{array}\right.
\end{gathered}
$$

$$
\begin{gathered}
\text { Budget }_{0}=\text { const } \\
u_{l 0}=\text { const } \\
u_{l m}, x_{k m} \in Z^{+} \\
u_{l m}=u_{l(m-1)}+\sum_{i, r} v_{i l r\left(m-T_{r}\right)} y_{i l\left(m-T_{r}\right)}+\sum_{i \in I, r \in R} \dot{v}_{i l r m}- \\
-\sum_{k} A_{l k} \dot{x}_{k m}, l=1: L, m=M+1: \dot{M}
\end{gathered}
$$

Expression (1) is an objective function that reflects the total profit of production. Expression (2) reflects the recurrent ratio of the stock of each type of raw material as of every day, depending on the planning period. Expressions (3) and (4) guarantee the availability of raw materials in the warehouse within the range between the minimum stock and the maximum storage capacity. Expression (5) means that the total amount of consumed resource of each type will not exceed the stock of the corresponding type of raw material in the warehouse on day $m$. Expression (6) reflects the decision made. Expression (7) reflects the minimum budget per day $m^{*}$. Expression (8) limits the volume of production by demand in the market. Expressions (9) and (10) are input data. Expression (11) guarantees the integer value of the solution obtained. Note that expression (12) does not participate in the search for the optimal solution, therefore, formula (12) is used after the found optimal solution of model (1-11).

The subtracted part in the objective function (1) deserves special attention. The enterprise is unable to purchase part of the lot due to the specifics of the commodity exchange. Therefore, in the model (1-12), in the subtracted part of the objective function, there is a binary variable $y_{i l r m}$. In other 
words, the company either takes the full ${ }^{1}$ lot (and then pays a fixed cost for the full volume of raw materials in the application, including the delivery cost), or refuses to buy the whole.

The model $(1-11)$ is a linear integer programming problem. Let's note some features of this problem. The first is that the number of variables grows at a polynomial rate $\left(O\left(\alpha^{4}\right)\right)$. The second is that the number of constraints with a high probability imposes serious complexity on the search for the first feasible solution, since the polyhedral admissible set of solutions can sharply decrease $[15,18,19]$.

To solve the problem, we will use the branch and bound method with preliminary cutting by the modified Gomorri method included in the system MathWorks².

\section{Model testing and calibration}

For approbation of the model, the company "DNS Wood" LLC was chosen. The company carries out continuous production of certain types of goods. For certain administrative reasons beyond the control of the company, it cannot lease areas for the extraction of raw materials. Therefore, the company is considering the possibility of purchasing raw materials from the regions of the Russian Federation through the St. Petersburg International Commodity ${ }^{3}$ and Raw Materials Exchange (hereinafter "exchange"). The company uses two main types of raw materials: sawlogs $(l=1)$ and pulpwood $(l=2)$. More detailed sub-types of raw materials do not matter due to manufacturing features. Data on the results of trading on the exchange are posted on the official website, where one can see the transactions for any period.

To test the model, data from the "DNS Wood" enterprise and the exchange for five months (from 01 February 2019 to 31 July 2019) were used. During this period, 752 applications were submitted for all types of raw materials that are of interest to the enterprise. According to the exchange data, during this period logging enterprises from four regions participated in the auctions as sellers of raw materials: Irkutsk Region ( $r=1)$, Republic of Udmurtia $(r=2)$, Moscow Region $(r=3)$ and Perm Territory $(r=4)$. Since the exchange does not disclose the real names and locations of the sellers, there is no more detailed information about them. During the specified period, an array of the following data was collected: prices of orders offered $c_{i r m}$, volumes of orders $v_{i r m}$, sales prices of final goods $p_{k m}$, number of orders for each type of raw material. In addition, relying on the analysis of the company's sales statistics, we assume that the daily demand for each type of product is set on the considered planning horizon $\sum_{n} Q_{n k m}{ }^{4}$.

We assume that the prices $p_{k m}$ at which goods are sold on the market are fixed and do not change within the planning horizon. We also consider three cases of enterprise pricing pol-

\footnotetext{
1 This lot already includes shipping costs, because the enterprise in question does not have the ability to independently deliver the purchased raw materials to its warehouse. It is worth clarifying here that if the buyer is able to independently deliver raw materials, then the value of the $c_{i l r m}$ parameter can have two meanings: including and not including the cost of delivery. If the company chooses between registration of delivery and refusal to receive, then such a decision can be considered as a modification of this model.

2 MathWorks. Documentation. Mixed-Integer Linear Programming Algorithms: https:// it.mathworks.com/help/optim/ug/mixed-integer-linear-programming-algorithms.html

3 Official website of the St. Petersburg International Commodity Exchange (JSC "SPIMEX”): https://spimex.com/markets/wood/trades/results/

4 For further research in the field of process modeling in the field of SCM, it is planned to forecast the demand for the manufacturer's products based on the data available to the enterprise. However, in this work, already recorded volume of demand for 2019 was used. This data was used for the assessment of the possibility of interaction between the enterprise and the exchange
} 
icy. In the first case, the prices of the settlement period coincide with the prices at which the company sold goods during the period from January to July 2019. In the second case, the prices of the previous period increase by $5 \%$, which is approximately the same as the inflation rate. In the third option, the company improves the quality of its products and believes that it can increase prices by an amount exceeding inflation by two times. The daily volume of demand of each type will be set as a uniformly distributed random variable in the interval from 0 to 15 . With an increase in the price for the percentage of inflation, we assume that such a trend is characteristic of the market as a whole, therefore, demand does not change. When price dynamics are higher than changes in the market as a whole, we assume that the price elasticity of demand is approximately equal to one. To consider the change in profit for each pricing policy, we carry out 50 realizations of determining the optimal solutions to the problem and average the profit indicators.
The main source data characterizing the enterprise are presented in tables 1 and 2.

Let's consider the instrumental part of the problem. The calculations were performed on a computer with 16 GB RAM and a 12-thread Ryzon 2600x processor. We used 'intlinprog' as a built-in function, which is an integral part of the Matlab programming language. We used the following data as input arrays for the builtin function:

$\downarrow$ objective function multiplied by $-1^{7}$;

$\checkmark$ integer constraints for all model variables;

$\downarrow$ constraint matrices;

$\downarrow$ vectors of the right sides for constraints, such as equalities and inequalities;

$\downarrow$ lower and upper bounds of variable values;

$\downarrow$ starting point for finding a solution (empty vector);

$\downarrow$ the maximum number of vertices of the polyhedral set of feasible solutions that the algorithm can pass (units).

\section{The main input parameters of the "DNS-Wood" enterprise}

Table 1.

\begin{tabular}{c|c} 
Parameter, units measurements & Parameter value \\
$u^{\text {max }}$, cubic meters & 7500 \\
\hline$u^{\text {min }}$, cubic meters & 100 \\
\hline$u_{l 0}{ }^{5}$, cubic meters & $(1550 ; 1550)$ \\
\hline$p_{k m}, \forall m \geq 0, k=1: 9$, '000 rubles & $(22.1 ; 32.8 ; 40.8 ; 43.7 ; 45.5 ; 48.5 ; 57.5 ; 60.5 ; 66.9)^{6}$ \\
\hline$T_{r}$, days & $(3 ; 5 ; 6 ; 5)$ \\
\hline Budget $_{0}$, rubles & $10,000,000$ \\
\hline$F C$, rubles & $1,000,000$ \\
\hline
\end{tabular}

Source: "DNS Wood" LLC (http://dns-les.ru/)

\footnotetext{
5 Input data, as of initial moment of the algorithm's run $(m=0)$

6 Prices of final goods, with numbers. At these prices, the company sold goods on the market for five months in a row

7 Multiplication by $(-1)$ is explained by the specifics of the "intlinprog" built-in function. By default, it is aimed at finding the minimum value of the objective function. More detailed information about this function is available at: https://www.mathworks.com/help/optim/ug/intlinprog.html
} 
Raw materials costs for production of a unit of each of goods

\begin{tabular}{c|c|c|c|c|c|c|c|c|c|c} 
Recourse type $(l)$ / item number $(k)$ & $\mathbf{1}$ & $\mathbf{2}$ & $\mathbf{3}$ & $\mathbf{4}$ & $\mathbf{5}$ & $\mathbf{6}$ & $\mathbf{7}$ & $\mathbf{8}$ & $\mathbf{9}$ & $\sum_{k} A_{l k}$ \\
\hline 1 & 2 & 5 & 6 & 6 & 6 & 5 & 8 & 8 & 12 & 58 \\
\hline 2 & 3 & 4 & 5 & 6 & 8 & 10 & 9 & 10 & 7 & 62 \\
\hline
\end{tabular}

Source: "DNS Wood" LLC (http://dns-les.ru/)

Since the problem has a large dimension, we cannot guarantee that the optimal solution will be found in suitable time, so it was decided to restrict the number of traversed vertices of the set of feasible solutions to $10^{7}$ units. If a solution has been found, but the algorithm has left the loop due to the above constraint, then we assumed that the solution is not optimal, but "conditionally effective."

\section{Discussion}

During testing, an optimal solution was obtained. The algorithm running time was 124.32 seconds; 87,562 vertices were passed. Let us consider in more detail the results of solving the problem of supplying raw materials to the company's warehouse.

Figures 1 and $2^{8}$ show the visualization of the volumes of stock $u_{l m}$ of raw materials $l$ for each day $m$. The darker color reflects the stock of raw materials in the warehouse, the lighter color - its receipt $v_{l m}$. It can be seen that the stock did not fall below the value $u^{m i n}=100$ cubic meters and did not exceed $u^{\max }=7500$ cubic meters. In addition, it should be noted that the warehousing time of the resource $l=2$, on average, exceeds the same time for $l=1$. This is due to the rate of consumption of raw materials $A_{l k}$ per unit of goods. The main arrival of raw materials $l=1$ falls on March, April and May. The main arrivals of raw materials $l=2$ falls on February and March. The intensity of the supply of raw materials $l=1$ is higher than that of $l=2$, which is related with the rates of production costs $A_{l k}$. Additionally, we note that the stock of raw materials in the warehouse changes significantly, which indicates the complexity of planning the procurement of raw materials.

Figure 3 shows the total stock of raw materials in the warehouse. It can be seen that all five cases, when the stock of raw materials in the warehouse was at its maximum, occurred in February and March. This is due to the fact that stock of raw materials of the second type were at their maximum during these months. Figure 3 shows that the threshold value of the minimum volume of raw materials in the warehouse was reached only once - at the end of the planning period. Except for this moment, the minimum recorded volume of raw materials in the warehouse did not fall (second half of April, 84 day of planning) below 990 cubic meters. Figure 3 also shows that the planning of raw material supply chains is an extremely difficult task, since the fluctuations in the volume of raw materials in the warehouse are very large. Therefore, it makes sense for an enterprise to consider the possibility of expanding the storage capacity.

\footnotetext{
8 All figures, except for $4 \mathrm{a}$ and $4 \mathrm{~b}$, refer to the case when prices are set without inflation adjustments
} 


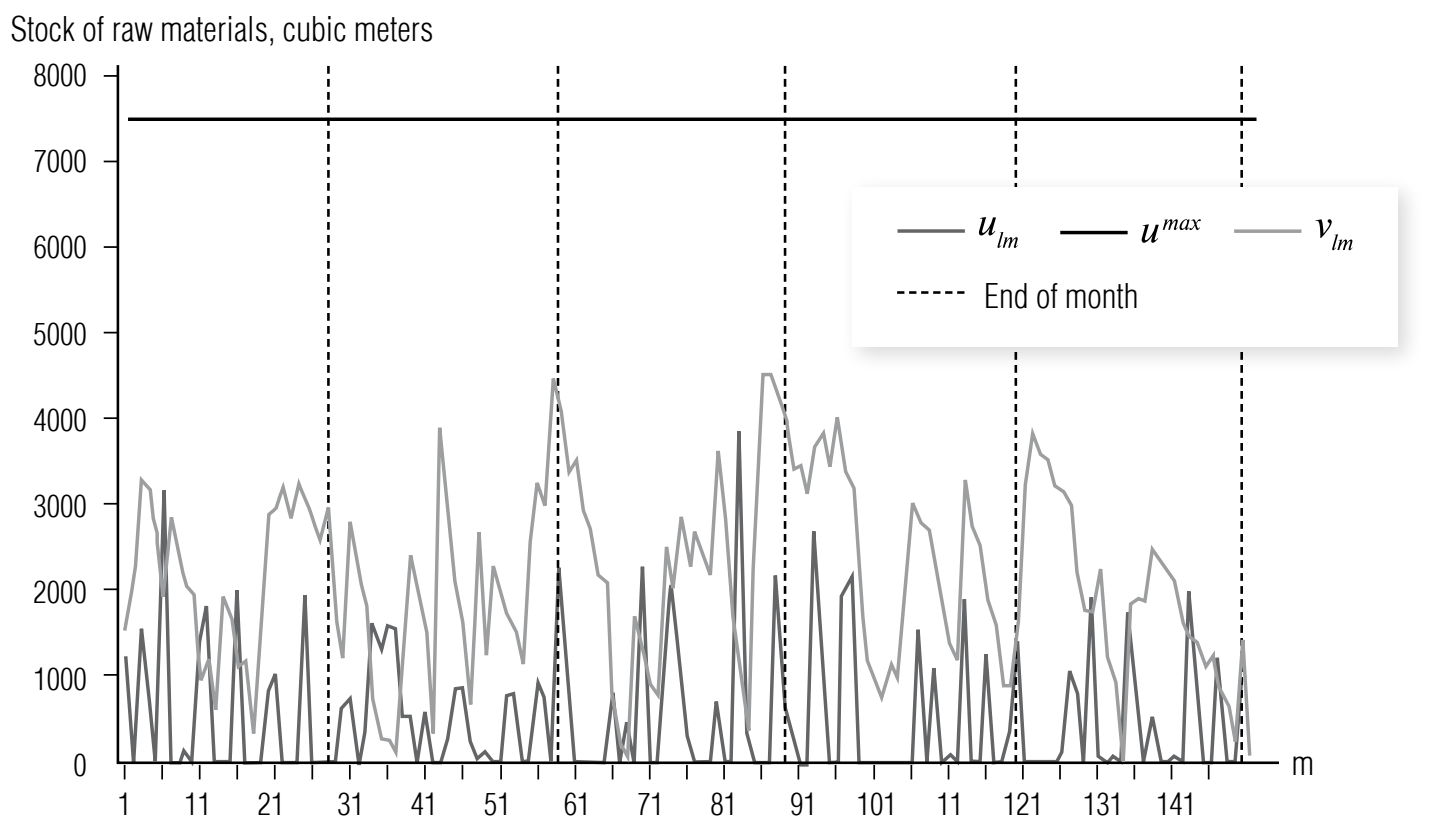

Fig. 1. Visualization of receipt and the current state of stocks of raw materials in the warehouse at a time interval $m=1, \ldots, M$, recourse type $l=1$

Stock of raw materials, cubic meters

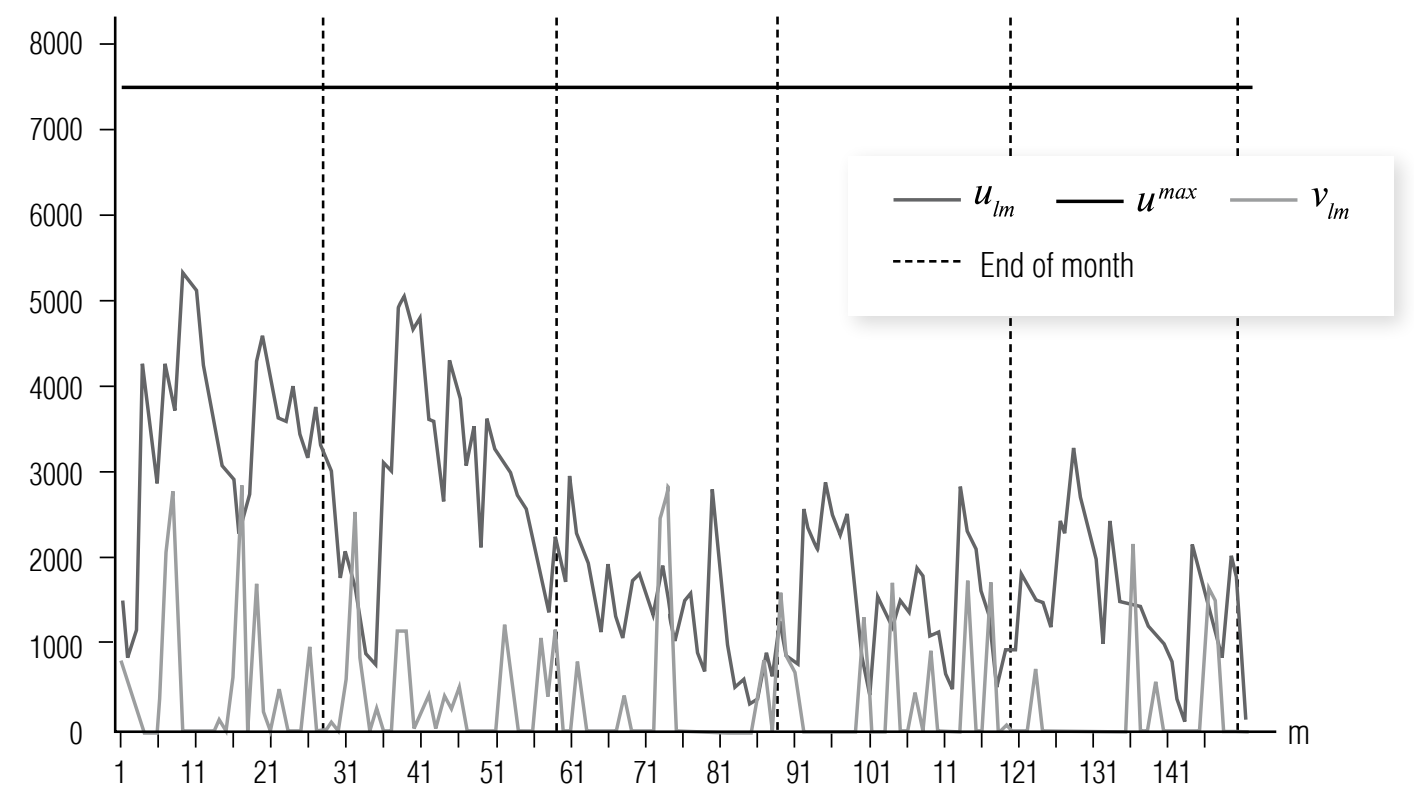

Fig. 2. Visualization of receipt and the current state of stocks of raw materials in the warehouse at a time interval $m=1, \ldots, M$, recourse type $l=2$

Figures $4 a$ and $4 b$ show the visualization of the average values of the company's accumulated and daily profit, respectively. The lines in the figures indicate profit without taking into account price increases during the planning horizon, in the case of five percent price increase 


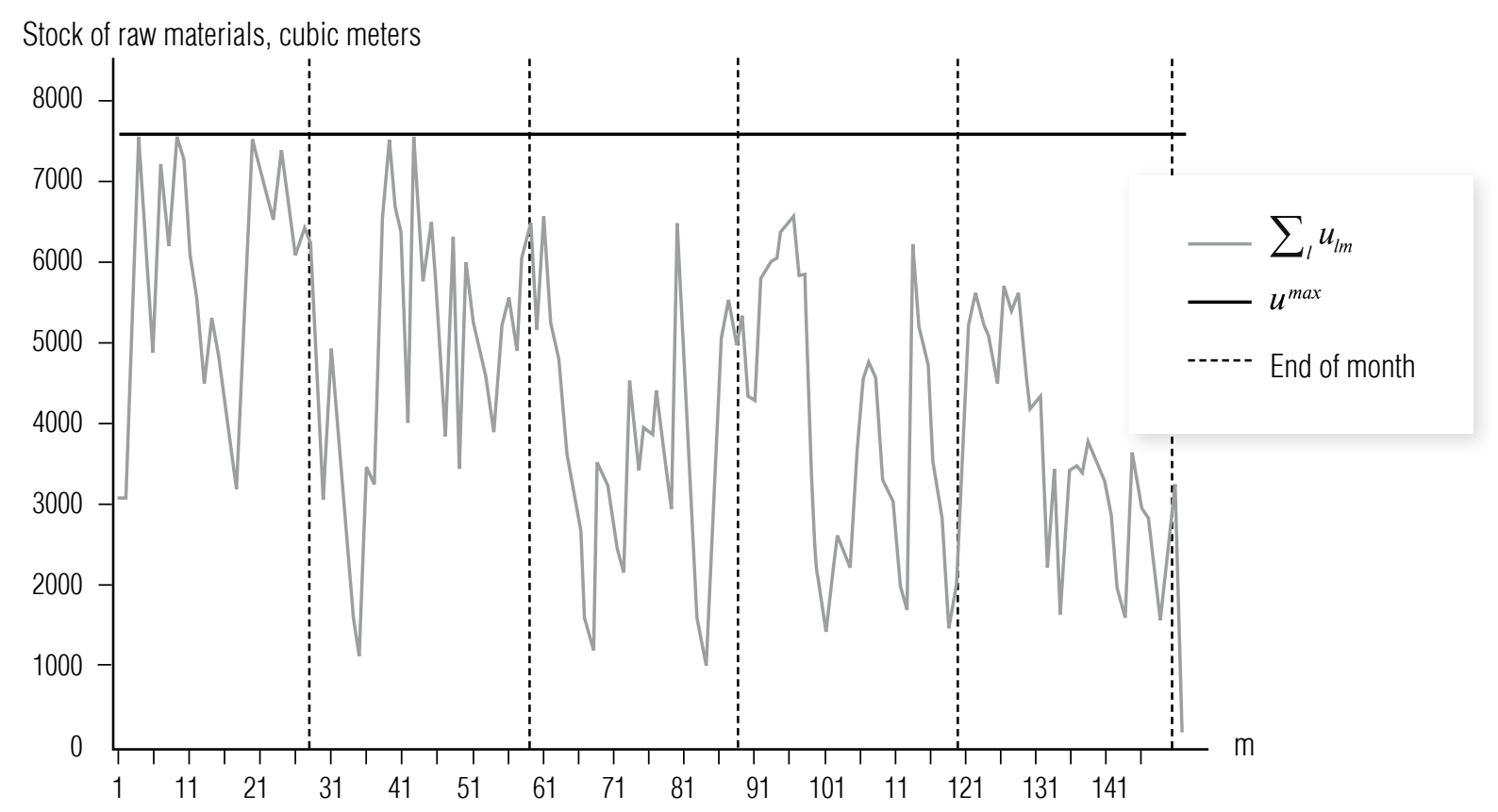

Fig. 3. Visualization of the current state of the total stock of all types of raw materials in the warehouse $\sum_{l} u_{l m}$ every day

$\left(p_{k m}=1.05 p_{k m}\right)^{9}$, and in the case of a ten percent increase in prices $\left(p_{k m}=1.01 p_{k m}\right)$. It can be seen that the total value of profit stabilizes ${ }^{10}$ after April. This is due to demand, which is weakening by the summer, that is to say, there is a seasonality factor.

Let's consider Figures 5 and 6 in details. The figures show the volumes of purchased raw materials $l=1$ and $l=2$ from each region by month. The lower bar indicates the volume of raw materials purchased in the region. The sum of the higher (superstructure) and the lower bars indicates the volume of raw materials put up for auction by the region in the corresponding month. It follows from the figures that most of the raw materials came from the Irkutsk Region. This phenomenon is explained by the fact that the maximum volume of raw materials (relative to all participants in the exchange) is put up for auction in this region. You should also take into account that the delivery time from the Irkutsk
Region is minimal. However, in April it was recorded (Figure 5) that the volume of raw materials received from the Perm Territory is approximately the same as the volume received from the Irkutsk Region. In addition, in February (Figure 6), it was recorded that the volumes of raw materials received from the Perm Territory were not lower than the volumes of raw materials purchased in the Irkutsk Region, despite the fact that every month the volume of raw materials in the Irkutsk Region is traded in large volumes. This is due to raw material prices. Prices for raw materials in the Irkutsk Region are higher than in any other region, which is explained by the proximity of this region to China. In particular, there is a direct railway line to the PRC, where entrepreneurs buy raw materials at high prices. In the Perm Territory, prices are much lower, and it is geographically more remote from China. Hence, we can conclude that in practice the enterprise should monitor the raw materials

\footnotetext{
9 In this paragraph the "_" sign means the operation of re-assignment

${ }^{10}$ According to the data from "DNS Wood" company
} 


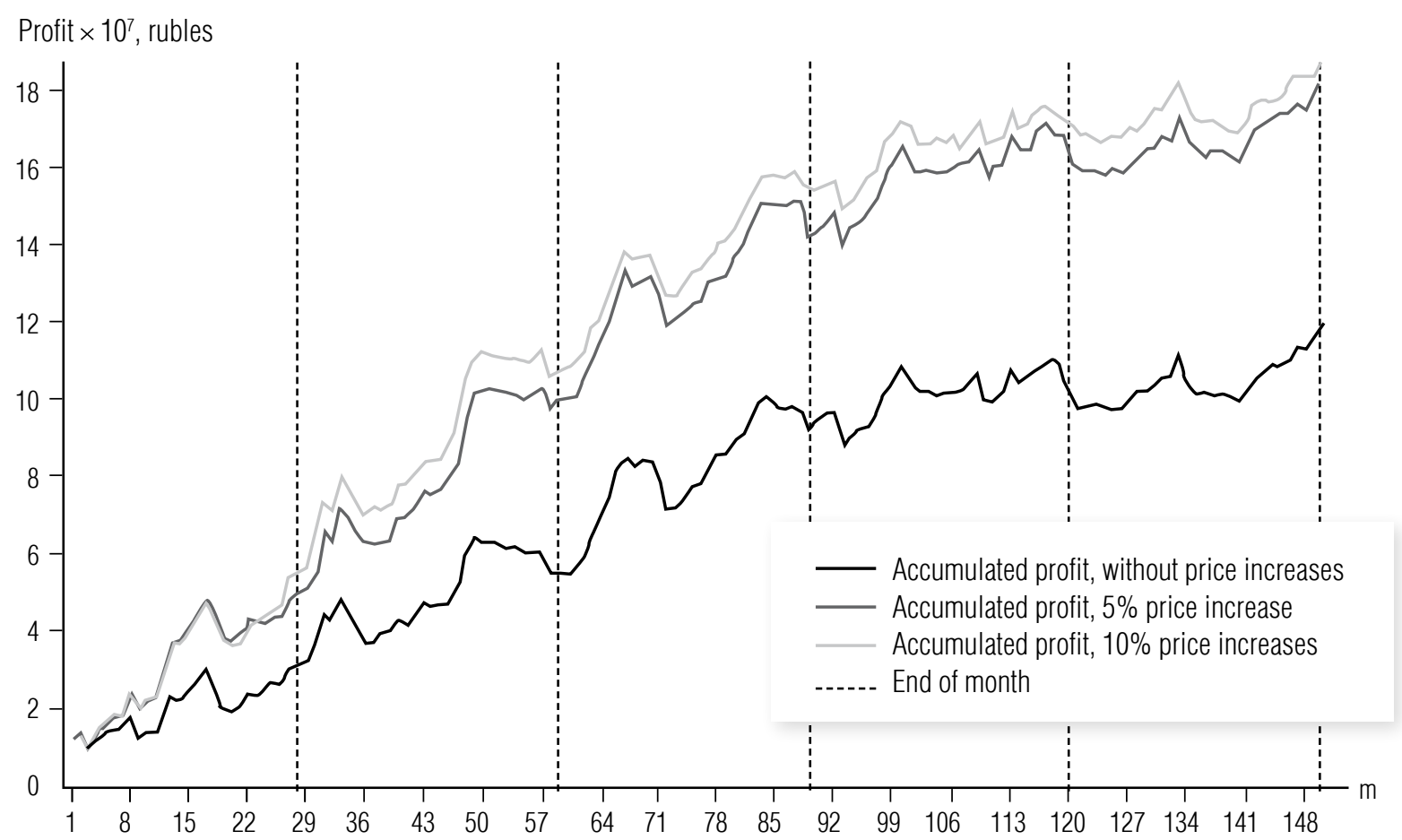

Fig. 4a. Visualization of the average accumulated profit of the enterprise

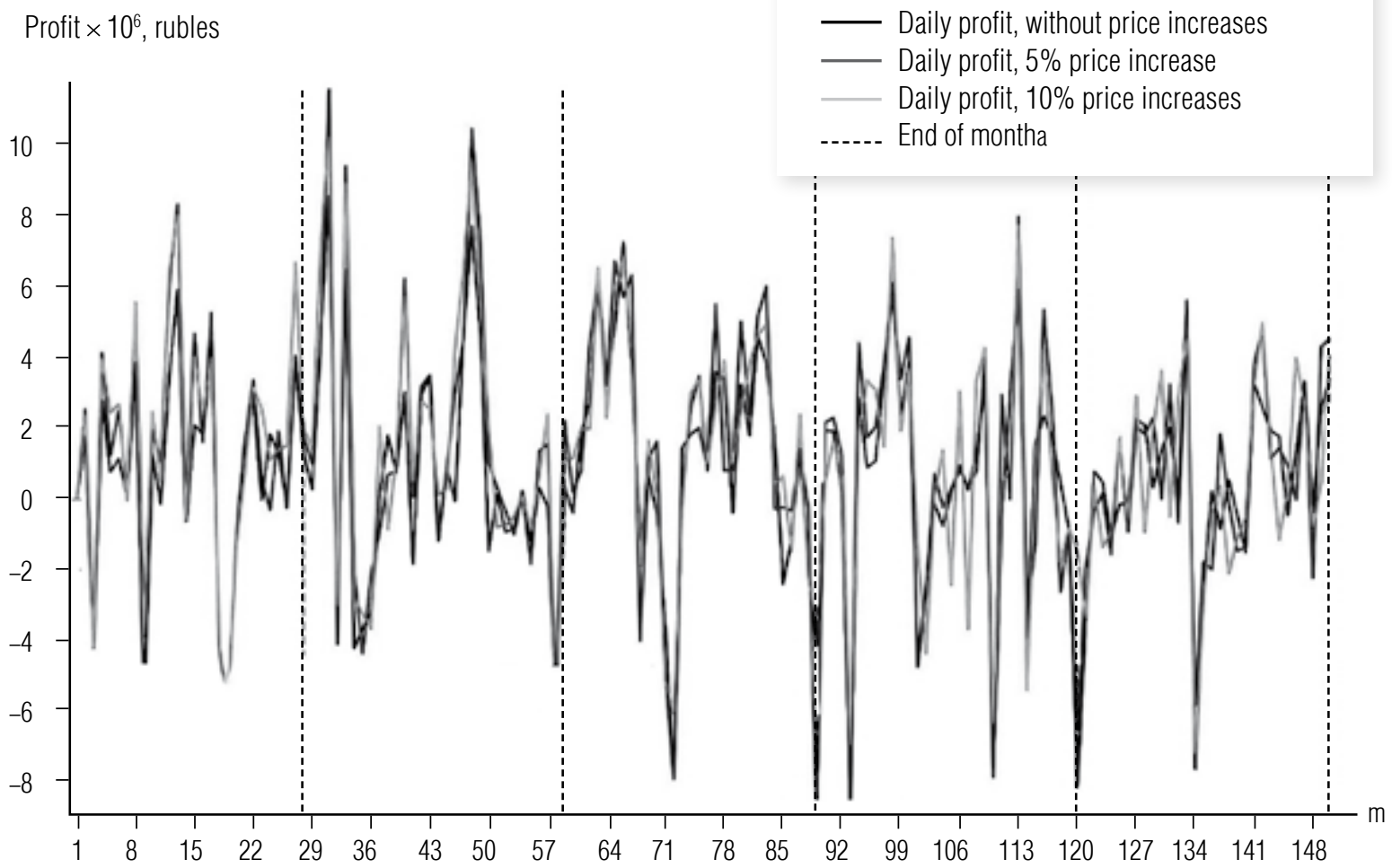

Fig. 4b. Visualization of the average daily profit of the enterprise 
market in the Perm Territory. If a raw material is put up for auction in this region, then it should be closely viewed as a potential purchase.

In addition, we note that in terms of the volume of raw materials produced, the Perm Territory ranks second out of the four considered regions. The volume of export of raw materials from the remaining regions is of no interest, since in aggregate, it does not exceed $30 \%$ of the total volume received from the Irkutsk Region and the Perm Territory.

It also follows from Figures 5 and 6 that the volume of extracted raw materials of any type decreases as the spring and summer approaches. This is due to transportation problems related with the extraction of raw materials. As a rule, production units are carried out with a trick, which, if opened by the supervisory authorities, entails administrative and criminal liability, as well as the revocation of the lease of the site for the extraction of raw materials. The fact is that the Ministry of Natural Resources and Ecology of the Russian Federation approves the norms for deforestation every year by quarters. However, since it is more difficult to extract raw materials during the period of off-season thaw and high summer temperatures, entrepreneurs cut down more in winter than should be in a quarter. Then in the annual reporting they distribute the extracted volume according to the instructions of the Ministry (which undoubtedly leads to improper exploitation of forest resources). This trend can be seen in Figures 5 and $6^{11}$.

The pairs of Figures $(1,5)$ and $(2,6)$ should be considered separately. It can be seen from them that the volume of purchased products is also decreasing, which affects the stabilization of the value of accumulated profit (Figure 4).

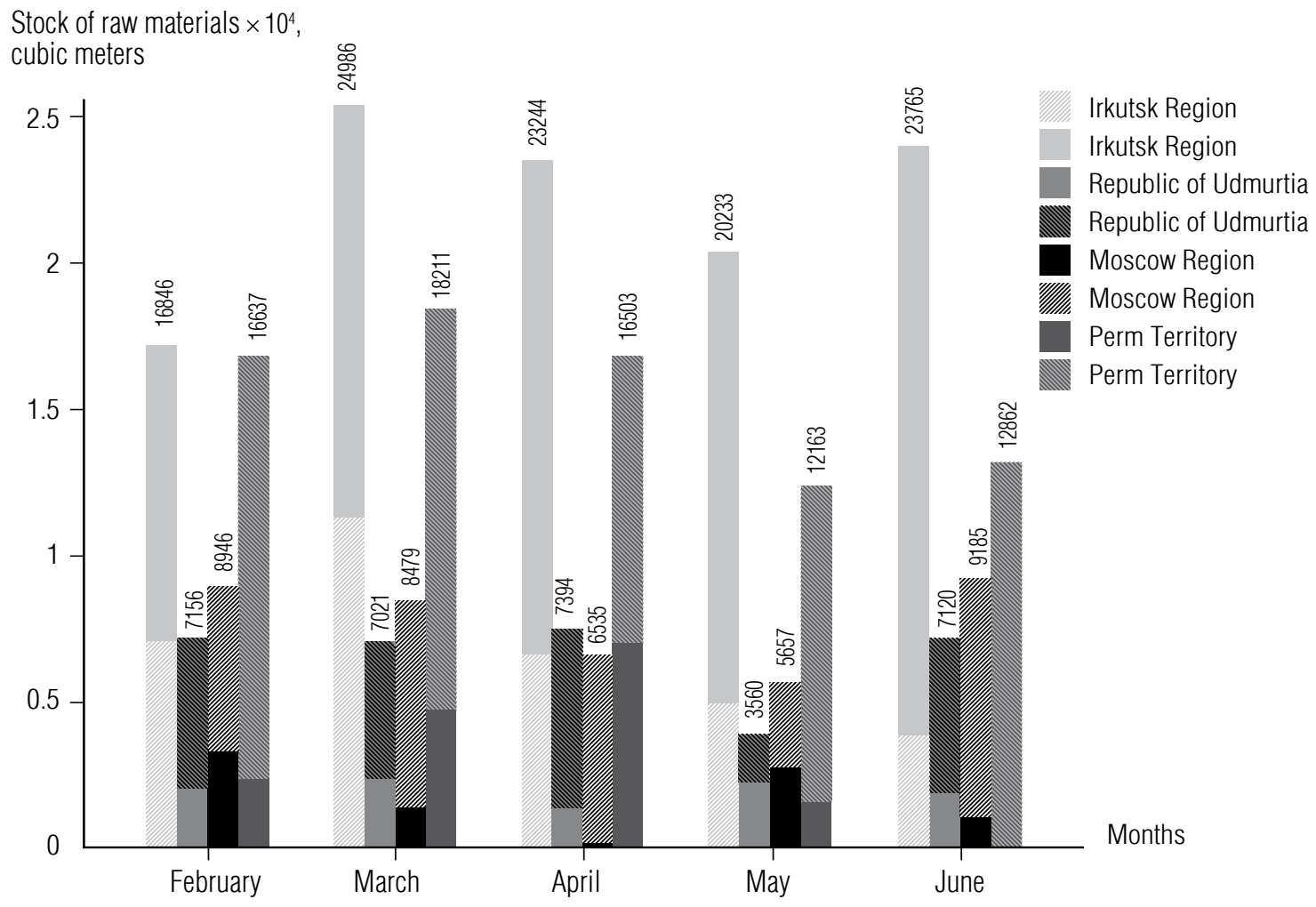

Fig. 5. Visualization of the extracted volumes of raw materials in each region by months

\footnotetext{
${ }^{11}$ Note that these exchanges only show the volume of transactions, but the same conclusions can be drawn from them
} 


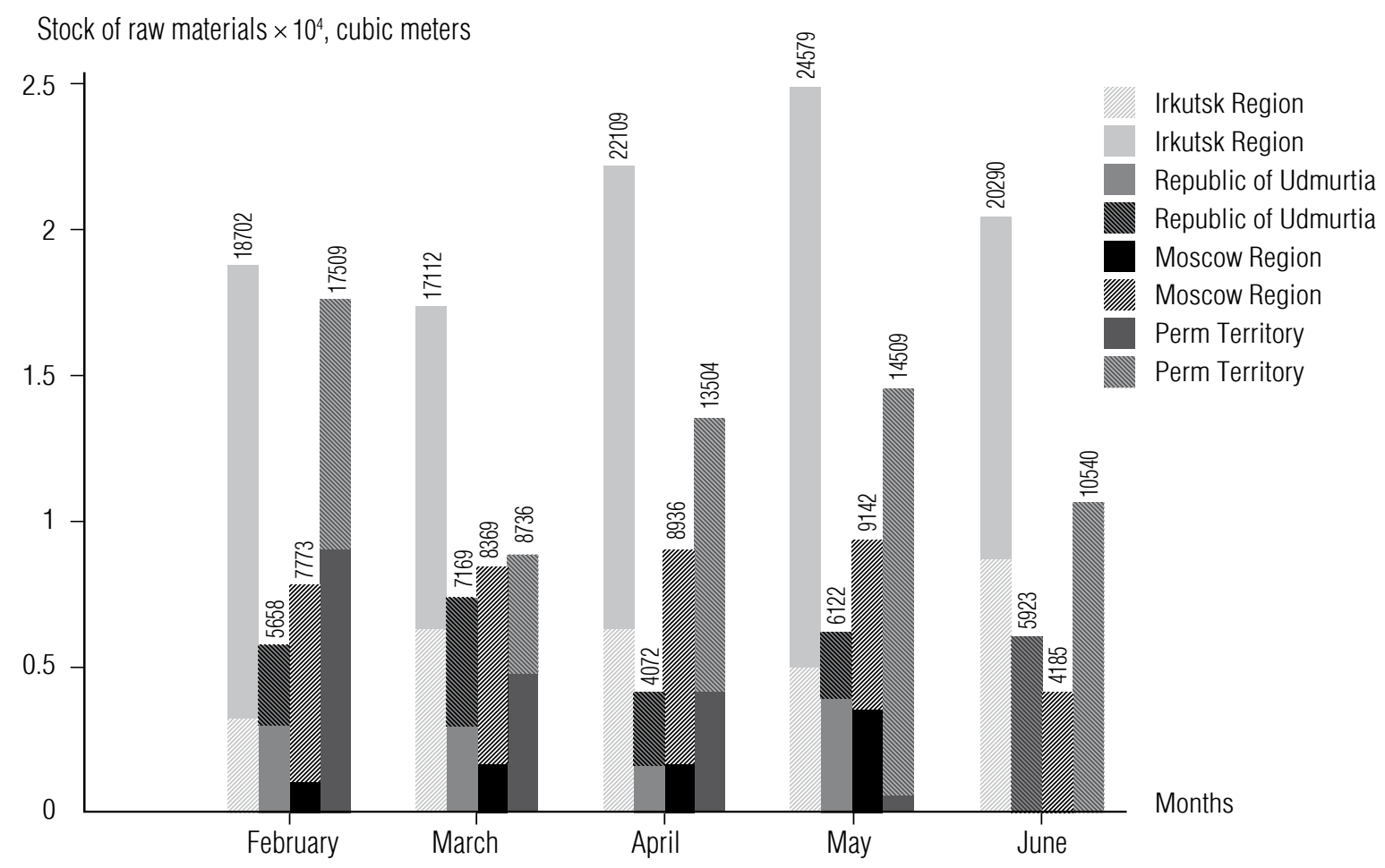

Fig. 6. Visualization of the extracted volumes of raw materials in each region by months

Let's consider Figure 7, which shows a visualization of the production volumes of each product of the enterprise by month. This figure reflects the consequences of a decrease in market demand in the market by summer and, accordingly, the stabilization of the growth of accumulated profit (Figure 4a).

It can be noted that the volumes of production of goods of types 1 and 8 by summer increase (in comparison with May), despite the fact that the statistics of purchases of these types of goods shows a decline in production.

It can also be argued that the volume of production of goods of type 2 should decrease as summer approaches.

Let's consider the behavior of the production volumes of goods 3, 4, 5 and 9 . The volume of products sold by March reaches its peak (3, 4, 9), while after this month the volume of products of these types is constantly falling. The exception is the product of type 5: for it, rise and fall of production are monotonous (the maxi- mum production volume was reached in April, but after that there was a decline).

The exception to the general rule on reducing the volume of sales of each type of product was product 6 . It shows a steady growth in comparison with winter and early spring. Thus, the production should pay attention to its further release in the summer.

Note that the production volume of type 7 is somewhat more complex than the others. Here you can clearly see the "jumping" trend of production. However, we can definitely say that this type of product has always been included in the production plan to a large extent and, accordingly, it makes sense to include it in the summer production plan.

It should be noted that when delivering raw materials to a consumer in the timber industry, there is a peculiarity: enterprises often refuse to accept raw materials if they are on the way for a long time (longer than it is indicated in the sales contract). This is due to the loss of the quality of 
raw materials required for production in accordance with the technology. To take this feature into account, a modification of the model is required, which can be obtained by introducing a probability distribution characterizing the daily distance traveled by railway, taking into account the season. As we know, the closer to winter, the lower the railway throughput is.

In addition, mention should be made regarding changes in production processes, as a result of which production costs are reduced: $A_{l k}^{m+1}=\max \left(0, A_{l k}^{m}-\varepsilon_{l k}\right)$, where $A_{l k}^{m}-$ volume consumption of recourse $l$ to manufacture item type $k$ in day $m ; \varepsilon_{l k}-$ random non-negative value. Taking into account the likelihood of a change in production technology there is a significant modification of the model. In a competitive environment, when modeling production processes and raw material supply chains, this becomes one of the key factors.
This article considers an enterprise that does not have its own plots. However, it should be borne in mind that in the future the enterprise may receive its own plots, which will also have a qualitative impact on its pricing and resource policies.

In addition, it is necessary to test the solution obtained on the basis of the constructed model. Such a solution can be unstable if prices and volume of demand change dynamically. To do this, it is necessary to enter stochastic values (calculate different price vectors for each type of goods on every day) and resume calculations many times (most likely in parallel ${ }^{12}$ ). This will undoubtedly significantly increase the load on the processor and RAM. Also, the question of a method for solving such problems remains open, since nonlinear and/or stochastic problems do not have a unified approach to their solution $[1,4,16]$.

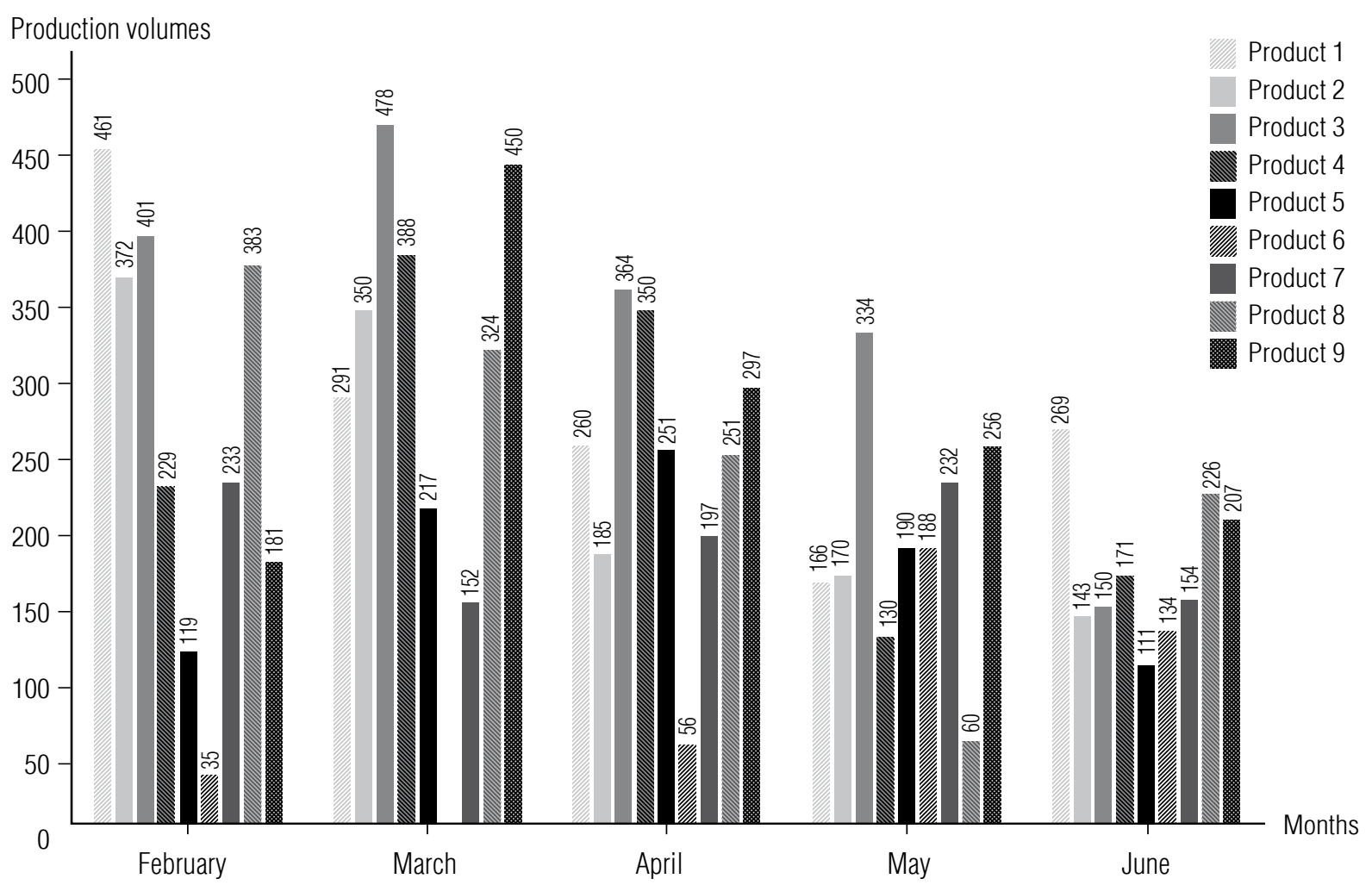

Fig. 7. Visualization of production volumes of each product of the enterprise by month

\footnotetext{
${ }^{12}$ Parallel programming: http://www.ccas.ru/mmes/distcompbook.pdf
} 


\section{Conclusion}

This paper proposes a model for the formation of sustainable supply chains of raw materials for a timber processing enterprise. The model allows us to maximize the value of pre-tax profits and is a mathematical programming problem, characterized by the ability simultaneously to take into account, on the one hand, production rates of consumption of raw materials for the production of final products, and on the other hand, the formation of a vector for purchasing raw materials on a commodity exchange. The solution to the model is the structure of production, the sequence of purchasing raw materials by production on the commodity exchange and the value of profit on each individual day of the enterprise. The process of finding an optimal solution to a problem is complicated by its large dimension, integer constraints, and a rapidly growing load on RAM. To solve such problems, it is worth using combined algorithms. The work implements the two-stage Gomorri method. From a practical point of view, the model is a tool that allows you to form an optimal production plan based on production factors and the volume of raw materials supply on the commodity exchange within the entire planning horizon. In the absence of the possibility of attracting capital from the outside, the model allows you to find the optimal solution that enables the enterprise to avoid a cash gap.

The model was tested on the example of a timber processing complex from Primorsky Territory. On the basis of the calculations performed and the obtained solution, recommendations were formulated for the management of the company on cooperation with the commodity exchange. Analysis of the decision showed that, despite the territorial proximity of the Irkutsk Region to the Primorsky Territory, it makes sense to pay attention to the purchase of raw materials from the Perm Territory, where there is sufficient raw material potential and a more acceptable pricing policy is observed. Analysis has shown that the production of most types of goods should be reduced as summer approaches, due to the seasonality of demand and production of raw materials. In general, the above calculations allow us to draw conclusions about the possibility of rational procurement of raw materials on the commodity exchange.

To analyze qualitatively more complex business processes of an enterprise, it makes sense to modify the model by introducing probabilistic economic and production factors. However, in this case, the question of a method for solving a complicated problem remains open.

\section{Acknowledgments}

The author expresses his gratitude to the company "DNS Wood" LLC for the information provided, as well as to its General Director N. Timokhodtsev and the head of the Timber and Production Department A. Sychikov. The author also expresses gratitude to his scientific advisor - Head of the Department of Mathematics and Modeling of the Vladivostok State University of Economics and Service, Doctor of Economics L.S. Mazelis.

\section{References}

1. Kogler C., Rauch P. (2018) Discrete event simulation of multimodal and unimodal transportation in the wood supply chain: A literature review. Silva Fennica, vol. 52, no 4, article ID 9984. DOI: 10.14214/sf.9984.

2. Haddouch H., Beidouri Z., El Oumami M. (2019) Supply chain management: A review of approaches, practices and impact on performance. International Journal of Supply Chain Management, vol. 8, no 6, pp. 1-13.

3. Escorcia-Caballero J.P., Moreno-Luzon M.D., Chams-Anturi O. (2019) Supply chain integration capability: An organizational routine perspective. International Journal of Supply Chain Management, vol. 8, no 5, pp. 39-47.

4. Rogulin R.S., Nechayev P.V., Pleshanov D.Ye., Yevdakimova N.S., Goncharov Ye.D., Maksimenko V.I. (2018) Complex optimization problem of production-transport processes. Prikladnaya Informatika - Applied Informatics, no 6, pp. 133-141 (in Russian). 
5. Mishra D., Gunasekaran A., Papadopoulos T., Childe S.J. (2018) Big Data and supply chain management: A review and bibliometric analysis. Annals of Operations Research, vol. 270, no 1, pp. 313-336. DOI: $10.1007 / \mathrm{s} 10479-016-2236-\mathrm{y}$.

6. Tuljak-Suban D. (2016) Food supply chain: A review of approaches which enhance sustainability with a focus on social responsibility. Available at: https://www.intechopen.com/books/sustainable-supply-chain-management/ food-supply-chain-a-review-of-approaches-which-enhance-sustainability-with-a-focus-on-social-respons (accessed 01 July 2020). DOI: 10.5772/62536.

7. Cundiff J.S., Dias N., Sherali H.D. (1997) A linear programming approach for designing a herbaceous biomass delivery system. Bioresource Technology, vol. 59, no 1, pp. 47-55. DOI: S0960-8524(96)00129-0.

8. Zarrinpoor N. (2019) A chance-constrained fuzzy programming approach for a sustainable supply chain network design under multiple sources of uncertainty. International Journal of Supply and Operations Management, vol. 6, no 4, pp. 349-359. DOI: 10.22034/2019.4.5.

9. Eliasson L., Eriksson A., Mohtashami S. (2017) Analysis of factors affecting productivity and costs for a high-performance chip supply system. Applied Energy, vol. 185, part 1, pp. 497-505. DOI: $10.1016 / j$.apenergy.2016.10.136.

10. Amrouss A., El Hachemi N., Gendreau M., Gendron B. (2017) Real-time management of transportation disruptions in forestry. Computers \& Operations Research, vol. 83, pp. 95-105. DOI: 10.1016/j. cor.2017.02.008.

11. Altiparmak F., Gen M., Lin L., Paksoy T. (2006) A genetic algorithm approach for multi-objective optimization of supply chain networks. Computers \& Industrial Engineering, vol. 51, no 1, pp. 196-215. DOI: 10.1016/j.cie.2006.07.011.

12. Hnaien F., Delorme X., Dolgui A. (2010) Multiobjective optimization for inventory control in two-level assembly systems under uncertainty of lead times. Computers \& Operations Research, vol. 37, no 11, pp. 1835-1843. DOI: 10.1016/j.cor.2009.06.002.

13. Prakash A., Chan F.T.S., Liao H., Deshmukh S.G. (2012) Network optimization in supply chain: a KBGA approach. Decision Support Systems, vol. 52, no 2, pp. 528-538. DOI: 10.1016/j.dss.2011.10.024.

14. Shi S., Liu Z., Tang L., Xiong J. (2017) Multi-objective optimization for a closed-loop network design problem using an improved genetic algorithm. Applied Mathematical Modelling, vol. 45, pp. 14-30. DOI: j.apm.2016.11.004. DOI: j.apm.2016.11.004.

15. Marufuzzaman M., Eksioglu S.D., Huang Y. (2014) Two-stage stochastic programming supply chain model for biodiesel production via wastewater treatment. Computers \& Operations Research, vol. 49, pp. 1-17. DOI: j.cor.2014.03.010.

16. Rogulin R.S., Maksimenko V.I., Zlobina D.V., Zhandarmov V.O., Pugacheva E.S., Matveev V.V. (2019) The task of combinatorial optimization: The search for an optimal production and transport plan when organizing production in new territories. Bulletin of Ural Federal University. Series Economics and Management, vol. 18, no 3, pp. 364-377 (in Russian). DOI: 10.15826/vestnik.2018.17.3.018.

17. Rabiee M., Zandieh M., Ramezani P. (2012) Bi-objective partial flexible job shop scheduling problem: NSGA-II, NRGA, MOGA and PAES approaches. International Journal of Production Research, vol. 50, no 24, pp. 7327-7342. DOI: 10.1080/00207543.2011.648280.

18. Srinivas N., Deb K. (1994) Multiobjective optimization using nondominated sorting in genetic algorithms. Journal of Evolutionary Computation, vol. 2, no 3, pp. 221-248.

19. Bandyopadhyay S., Bhattacharya R. (2014) Solving a tri-objective supply chain problem with modified NSGA-II algorithm. Journal of Manufacturing Systems, vol. 33, no 1, pp. 41-50. DOI: j.jmsy.2013.12.001.

\section{Rodion S. Rogulin}

\section{About the author}

Doctoral Student, Department of Mathematics and Modeling, Vladivostok State University of Economics and Service, 41, Gogolya Street, Vladivostok 690014, Russia;

Assistant Professor, Department of Applied Mathematics, Mechanics, Control and Software, Far Eastern Federal University, 10, Ajax Bay, Russky Island, Vladivostok 690922, Russia;

E-mail: rafassiaofusa@mail.ru

ORCID: 0000-0002-3235-6429 


\title{
Fuzzy production network model for quality assessment of an information system based on microservices
}

\author{
Alexey I. Doljenko \\ E-mail: doljenkoalex@gmail.com
}

\section{Irina Yu. Shpolianskaya}

E-mail: irinaspol@yandex.ru

\section{Sergey A. Glushenko}

E-mail: gs-gears@yandex.ru

Rostov State University of Economics

Address: 69, Bolshaya Sadovaya Street, Rostov-on-Don 344002, Russia

\begin{abstract}
This article describes the analysis of the quality of microservice architectures, which are one of the main approaches to the creation and maintenance of modern information systems capable of quickly respond to changes in business demands. The implementation of continuous delivery of software components for dynamic business processes of information systems can be carried out by various sets of microservices, the optimal choice of which is a complex multi-alternative task. The paper presents a review of existing approaches to solving the problem, which showed that the development of models for assessing the quality of microservices of information systems requires further elaboration in terms of accounting for uncertainty in the initial data and modes of operation. The authors have proposed an approach to solving the problem of analyzing the quality of a microservice architecture which is implemented on the basis of a fuzzy production network model. The model allows for comprehensive accounting of various parameters (qualitative and quantitative). The article shows the implementation process of the fuzzy production network that was developed to analyze the functional quality of the microservice architecture for processing customer orders using fuzzy modeling software. The results of the analysis will allow managers and system architects to make an informed choice of the microservice architecture of the information system, as well as use it in their reports when arguing the need for scaling the system and increasing the availability of microservices.
\end{abstract}


Key words: microservice architecture; service-oriented architecture; quality of service; business process; information system; fuzzy model.

Citation: Doljenko A.I., Shpolianskaya I.Yu., Glushenko S.A. (2020) Fuzzy production network model for quality assessment of an information system based on microservices. Business Informatics, vol. 14, no 4, pp. 36-46. DOI: 10.17323/2587-814X.2020.4.36.46

\section{Introduction}

$\mathrm{M}$ icroservice architecture is an evolution of the service-oriented architecture (SOA) of information systems (IS). Microservice architecture assumes weak cohesion and strong cohesion of software components, as well as the possibility of their implementation on various technological platforms [1]. At the same time, the issues of choosing a microservice architecture have common principles with the choice of web services for a service-oriented architecture. That demonstrates the similarity of methodological approaches to the procedures for selecting SOA and microservice architectures of information systems.

The technology platforms for implementing microservices can be different, and different vendors can supply microservices. That determines the importance of the problem of quality assessment of a set of microservices for IS developers to implement the information system's business tasks more effectively. A business task is an ordered set of activities that, following some rules, transform resources to achieve the planned result [2]. As an example, we can mention such business tasks of the information system as interaction with customers, order processing, order execution.

API Gateway and Message Bus approaches are used in microservice architecture development in order to organize the interaction of microservices.

The API Gateway sits between clients and microservices (Figure 1). The API Gateway is a single point of interaction with microser- vices for clients, ensuring that client requests are redirected to a specific service - a business task. API Gateway can also act as a load balancer.

Microservices subscribe to specific events that trigger the execution of a given business task when the Message Bus is used (Figure 2).

Within the microservices architecture, microservices do not exchange messages, i.e., they do not interact directly. That eliminates the impact of the service quality of one microservice on another. It should be noted that even

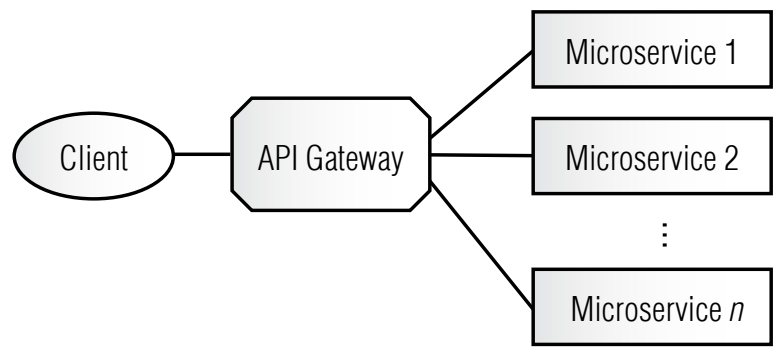

Fig. 1. Microservices architecture with API Gateway

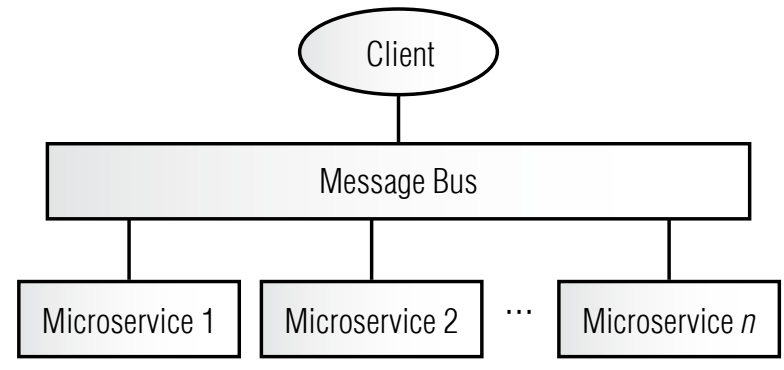

Fig. 2. Microservices architecture with Message Bus 
if one or more microservices may fail, the other microservices will continue to function. That is guaranteed through the weak cohesion of microservices in the microservice architecture. At the same time, the operation quality of the IS may decrease, but the failure of the entire system does not occur.

The choice of the optimal set of microservices that implements the business tasks of the information system with a given level of service quality is an important task for increasing the efficiency of IS [3]. Decision-making processes during the execution of this task proceed under conditions of significant uncertainty, which arises due to a lack of data, the complexity of building functional dependencies that determine the quality of the implementation of business functions, as well as sets of microservices implemented on various technological platforms. In addition, the quality of performance of business functions by microservices depends on functional (qualitative) and non-functional (quantitative) parameters, which increases the complexity of decision making.

\section{Review of the literature}

Further, we consider the existing approaches to solving the problem of selecting the optimal set of microservices and building a model of the microservices architecture of the information system.

In paper [4], the author analyzes the process of modeling microservices in the corporate IS, types of micro-service architectures, ways of interaction between microservices, as well as ways to ensure high application performance. The proposed methodology allows you to create scalable and fault-tolerant applications. However, it does not consider the quality of implementation of business functions with microservices, and that reduces the value of the proposed approach.
The work in [5] considers the problem of selecting IT services for implementation in the organization. The author notes that decision-making when choosing an enterprise's IT services is carried out in conditions of uncertainty and ambiguity. The proposed structural synthesis model is used to develop a serviceoriented enterprise architecture. The model uses an oriented hypergraph that takes into account the constraints of alternative design solutions. The choice of the best option for a set of information services is made according to the specified additive criteria. In general, the proposed approach to solving the problem of selecting IT services for an enterprise can be used in the design of microservices and service-oriented architectures of corporate IS. However, the structural synthesis model does not take into account the uncertainty in the initial data, the quality of IT services that implement business processes, as well as the risks of using microservices on various technological platforms within the information systems.

In [6], the authors proposed using the SOA concept in the Enterprise Architecture framework. They presented an axiomatic method for domain modeling. Domain knowledge is represented as a set of structural elements. The modes match the set of business functions to a set of information services with some restrictions (standards and standardized decisions). Formalization of the rules for constructing the utility function of the IT services elements and decision rules can be used for the integral assessment of design decisions. The authors describe conditions for the formation of a knowledge base based on the structural, mathematical and conceptual foundations of decision-making systems for a given domain when choosing competitive service-oriented architectures of the organization. At the same time, the authors do not analyze the risks of implementing web services, in particular, cloud services, as well as limitations associ- 
ated with uncertainty in assessing the quality of implementation of some business processes of an organization by web services.

The work in [7] considers the problem of assessing the technological level of IT services. The author notes that the task belongs to the class of semi-structured problems. She proposes to use fuzzy sets to assess the technological level of the formed variant of the strategic IT profile - a set of IT services. When forming linguistic variables for unified indicators, the trapezoidal type membership functions on the segment $[0,1]$ are used. The value of aggregated unified indicators is obtained with the double convolution method, and the indicators are ranked based on the Fishburne rule. To assess the parameters of the technological level of the design solution formed in this way, the author proposes to use the ratio of the ranked indicators of the dynamic and static parts of the formed variant of the strategic IT profile. Analysis of the approach proposed in [8] shows that the author has attempted to take into account the uncertainty in setting unified indicators of the quality of IT services in the model for assessing the technological level of IT services. However, the correctness of the fuzzy model is not discussed in the work. Besides, when preparing the initial data for a fuzzy model, it is quite difficult for experts to determine the estimates to form the trapezoidal membership function parameters. The above doubts about the legality of using the fuzzy model can be eliminated by adjusting the parameters of the membership functions of a fuzzy model, but the paper does not address these issues [8].

In [9], the issue of choosing the correct criterion for comparing web services for systems in service-oriented architecture is considered. The author considers the sensitivity of performance to be such a criterion when the load on the web service changes. At the same time, the use of reliability and performance of web services limits the application of this approach to solving the problem of choosing a set of corporate IS web services.

In [10], the use of fuzzy models when choosing a corporate service-oriented architecture is discussed. The model uses functional and non-functional criteria. Non-functional criteria take into account one-time, recurring and indirect costs. Functional requirements are determined by expert judgment. The economic aspect of the web services selection problem predominates in the model and does not consider other significant issues of the problem solving.

The work [11] considers the problem of synthesizing a configuration option for a serviceoriented IS architecture. Structural models were proposed for the synthesis of the information system architecture. The author gives a conceptual scheme for synthesizing a variant of a service-oriented architecture configuration, although it is difficult to understand the mathematical model for solving the problem.

The tasks of choosing web service, as well as the formation of effective criteria and selection methods, are considered in [12]. A typical procedure for selecting appropriate web services from a set of alternatives for subsequent integration into an information system is based on requirements that describe the quality of service [13]. When modeling IS with a service-oriented architecture, the selection of appropriate web services from a set of available services with a given quality of service for non-functional requirements, such as performance, reliability, security, response time, etc., is performed [14-16].

Many of the non-functional properties of web services, such as response time, are stochastic in nature. A dynamic service deployment environment, due to different network conditions, delays, and server overload, can lead to deviations in the values of non-functional indicators of service quality [17]. Some 
web services in a particular set for an information system may require significantly longer execution times, which in turn will increase the total cost of ownership.

Several methods have been developed based on the quality of service characteristics to select appropriate web services from a set of candidates with similar functions. Most of these methods focus on analyzing the non-functional characteristics of web services as the main factors influencing their choice. In [18], the authors proposed a systematic approach to assessing the quality of composite services with complex structures, taking into account the probabilities and conditions of each execution. In [19], evolutionary algorithms for solving the problem of web services selection were discussed.

The above review of literature shows that the existing approaches to solving the problem of choosing the optimal set of microservices for IS do not fully take into account the factors that determine such a choice, which leads to decreased efficiency of information systems in operation. Thus, the issues of developing models for assessing the quality of IS microservices require further development in terms of accounting for uncertainty in the initial data and modes of operation.

\section{Fuzzy methods and models}

The model for analyzing the quality of the microservices architecture should take into account the qualitative and quantitative parameters of the information system performance, as well as uncertainty in the evaluation of the initial data. These requirements can be successfully implemented with fuzzy models, which make it possible to perform an integrated assessment of various parameters (qualitative and quantitative). In addition, the use of fuzzy models makes it possible to build models of subject areas characterized by significant uncertainty, which is relevant to solving the problem.
When constructing a model for analyzing the operational quality of a microservice architecture, it is proposed to use fuzzy production networks [15]. A fuzzy production model is based on fuzzy production:

\section{IF $x$ is $A$, THEN $y$ is $B$,}

where $x-$ an input variable, $x \in X$;

$X$ - the domain of definition of the antecedent of the fuzzy rule;

$A-$ a fuzzy set defined on $X$;

$\mu_{A}(x) \in[0,1]-$ the membership function of a fuzzy set $A$;

$y$ - an output variable, $y \in Y$;

$Y$ - the domain of definition of the consequent of the fuzzy rule;

$B-$ a fuzzy set defined on $Y$;

$\mu_{B}(y) \in[0,1]-$ the membership function of a fuzzy set $B$.

Let us assume that the membership function of a fuzzy set $A-\mu_{A}(x)$ is known, and the fuzzy binary relation $R \subseteq X \times Y$, which reflects the implication $A \rightarrow B$, has a membership function $\mu_{R}(x, y)$. Then, for a fuzzy set $B$, the membership function is determined by the composition rule:

$$
\mu_{B}(y)=\sup _{x \in X}\left\{T\left(\mu_{A}(x), \mu_{R}(x, y)\right)\right\},
$$

where sup - the operation of determining the upper bound of the set of elements;

\section{$T$ - the $T$-norm operation.}

In a fuzzy production model (FPM), input variables are fuzzified to obtain the values of linguistic variables. At the output, we will have a linguistic variable that characterizes the quality of service of a business task by a microservice. We define input and output linguistic variables on the following term sets: Tin/out $=\{$ "low" $(L)$, "middle" $(M)$, "high" $(H)\}$. The $L$ term corresponds to a input low level or low quality of service of the microservice business function, the $M$ term corresponds to the medium level, and the $H$ term - to the high level. 
Input linguistic variables are converted to outputs using a set of production rules.

\section{Method implementation}

Let us consider the problem of analyzing the quality of service of the IS microservice architecture for processing customer orders of the company as an example of the implementation of the proposed approach. The information system includes the following business tasks: interaction with customers, order processing, and order fulfillment. These functions can be realized by microservices implemented on various platforms. When designing a microservice architecture, it is necessary to analyze the quality of microservices performing business tasks and obtain a generalized, integral indicator of the IS service quality.

The developed structure of the fuzzy production network for analyzing the quality of the IS microservice architecture for processing customer orders is shown in Figure 3.

The input parameters for microservices are the intensity of service requests $X n 1$ ( $n$ is the number of the business task/microservice) and the amount of data $X n 2$ requested/transmitted by the microservice. The input data must be pre-normalized and reduced to the interval $[0,10]$. The normalized input data is fed to fuzzification blocks, which form the values of the linguistic variables $\operatorname{Lnm}(m=1,2)$ defined on the term sets Tin/out. Linguistic variables enter the input of the corresponding rule base $(B R n)$, which, based on the generated fuzzy products, determines the output linguistic variables $Y k(k=1,2,3)$, which characterize the quality of microservice while performing the business task. The linguistic variables $Y k$ are the input to the $B R 4$ rule base, which evaluates the quality of the information system microservice architecture. The output linguistic variable $Y$ characterizes the quality of the IS microservice architecture as a whole. Experts set the parameters of fuzzy term sets and the rule base.

The data were obtained by summarizing the opinions of experts with the Delphi method, the essence of which is collective expert search forecasting. This method assumes the anonymous survey of experts by several rounds to identify an agreed assessment of a group of experts. According to the approach in [20], the results of the previous round should be announced for additional adjustment of the expert's assessment in the next round.

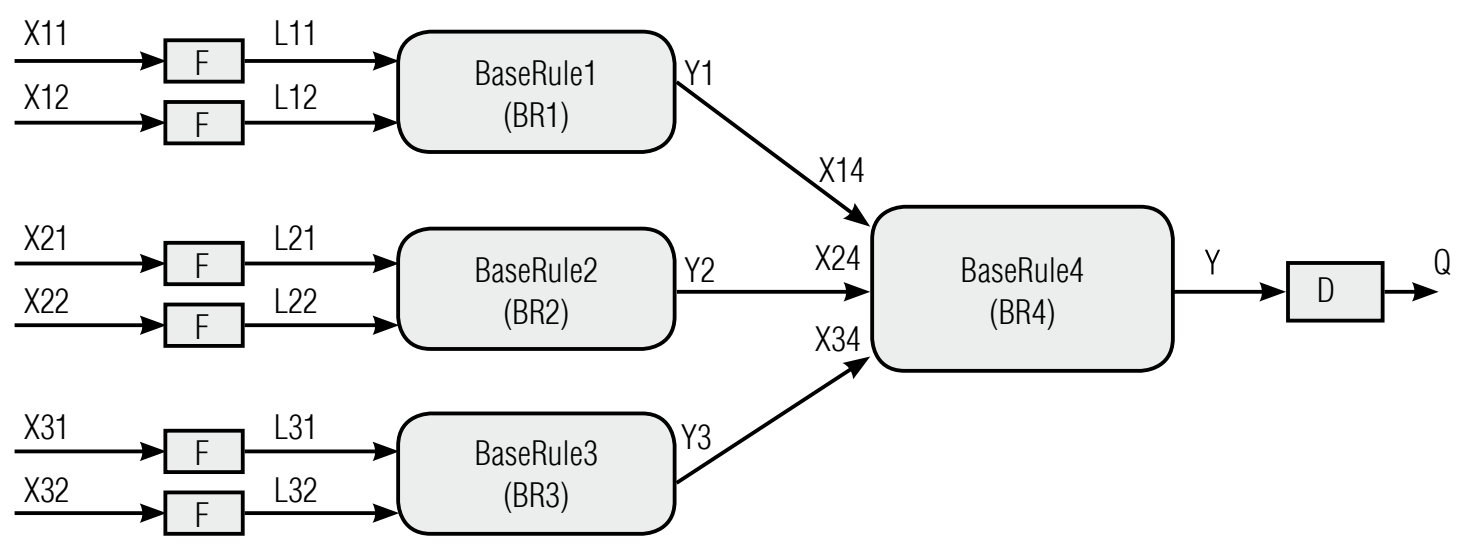

Fig. 3. The structure of a fuzzy production network 
When forming the rule base for the fuzzy inference system for analyzing the quality of the IS microservices architecture, a situation may arise in which a group of experts forms incompatible rules. Some mathematical methods have been used to form rule bases in conditions of the inconsistency of expert opinion $[21,22]$ to eliminate this problem. The essence of the methods is to add incompatible rules to the rule base based on the confidence level of the experts. The confidence level value for the rule is calculated based on the skill level and the number of experts and is determined by the formula [21]:

$$
\bar{y}=\frac{\sum_{i=1}^{n} y_{i} k_{i}}{\sum_{i=1}^{n} k_{i}},
$$

where $\bar{y}-$ the average value of the confidence level;

$y_{i}$ - the estimate provided by the $i$-th expert;

$n$ - the total number of experts in the group;

$k_{i}$ - the coefficient of competence of the $i$-th expert.

The difference between the method used and similar methods used in the formation of rule bases in the presence of conflicting expert assessments consists in taking into account each expert opinion to form a balanced decision, which eliminates the loss of information about the research object. The algorithm of the method and the results of the numerical experiment are presented in [22].

An example of a $B R 1$ rule base for assessing the quality of microservice 1 for a business task of interacting with customers is presented in table 1.

The output linguistic variable $Y$ enters the defuzzification block $D$, which forms a single crisp value of the quality indicator of the IS microservices architecture.

The implementation of the production model was done using a fuzzy modeling software tool (ST) ModelingFuzzySet [23]. It is necessary to carry out some actions that are described in detail in [24] to perform the process of fuzzy modeling.

At the first step, it is necessary to create a multilevel fuzzy production model using the model designer following Figure 3. The second step involves the creation of a membership function for term sets of input and output linguistic variables. Figure 4 shows the membership functions for the term sets of the input lin-

\section{Fuzzy production rules}

Table 1.

\begin{tabular}{|c|c|c|c|}
\hline $\begin{array}{c}\text { Rule } \\
\text { designation }\end{array}$ & Antecedent & Consequen & $\begin{array}{l}\text { Confidence } \\
\text { level }\end{array}$ \\
\hline \multicolumn{3}{|c|}{ Rule Base 1 (BR1) } & \\
\hline $\mathrm{R} 1.1$ & $\begin{array}{l}(X 11=L \wedge X 12=L) \vee(X 11=L \wedge X 12=M) \vee(X 11=M \wedge X 12=L) \vee \\
(X 11=M \wedge X 12=M)\end{array}$ & $Y 1=H$ & 1 \\
\hline $\mathrm{R} 1.2$ & $\begin{array}{l}(X 11=M \wedge X 12=H) \vee(X 11=H \wedge X 12=M) \vee(X 11=L \wedge X 12=H) \vee \\
(X 11=H \wedge X 12=L)\end{array}$ & $Y 1=M$ & 0.9 \\
\hline R1.3 & $X 11=H \wedge X 12=H$ & $Y 1=L$ & 1 \\
\hline
\end{tabular}




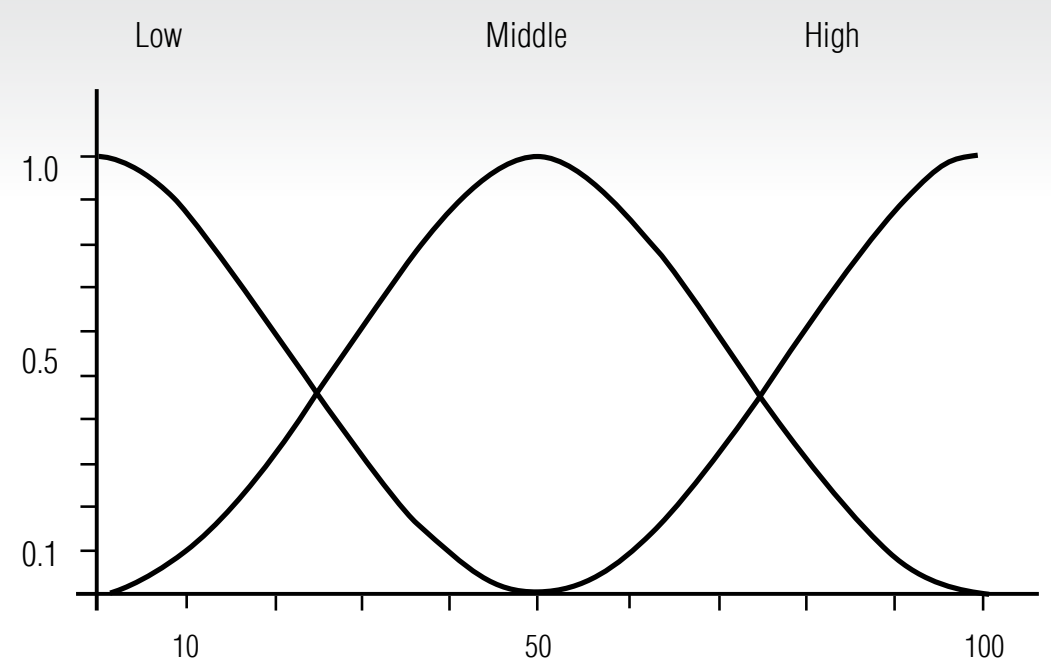

Fig. 4. Terms of the linguistic variable "The intensity of the customer's requests"

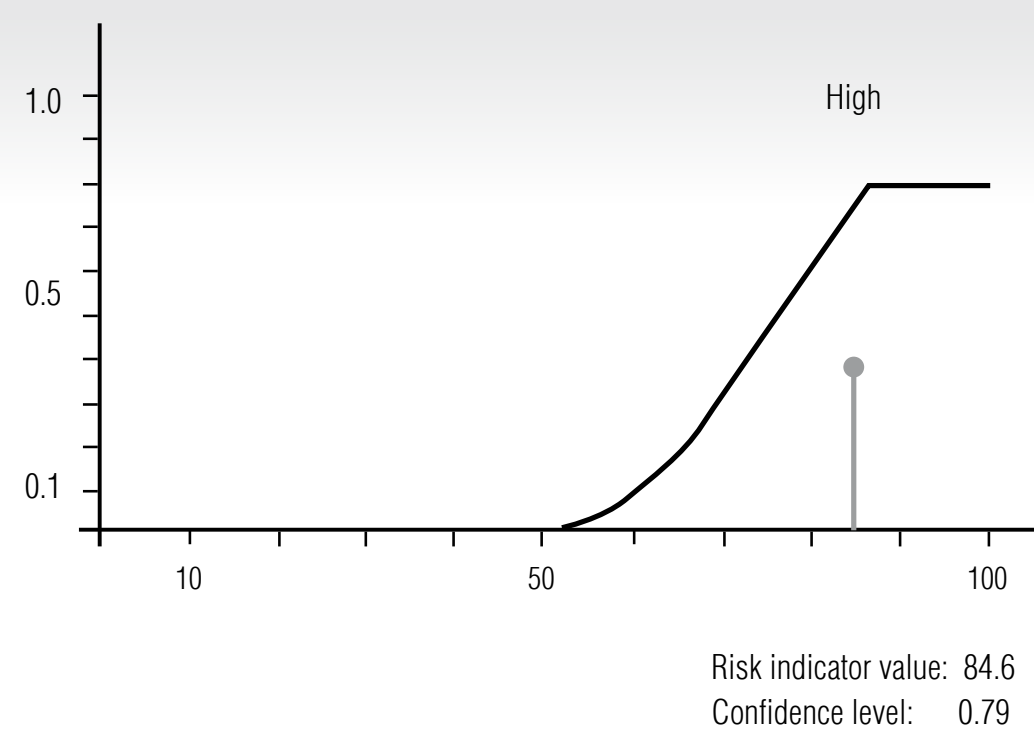

Fig. 5. The terms of the linguistic variable "Quality of microservice 1"

guistic variable (LV) $X 11$ "The intensity of the customer's requests".

When the third step "Setting fuzzy rules" was completed, fuzzy modeling was performed to evaluate the quality of microservice 1 with nor- malized input variables: the low intensity of client requests ("low" $(L)),(X 11=1.5)$ and the average amount of transmitted data ("middle" $(M)),(X 12=5.5)$. As a result, the quality of microservice 1 performing the business task "Interaction with customers" is assessed with 


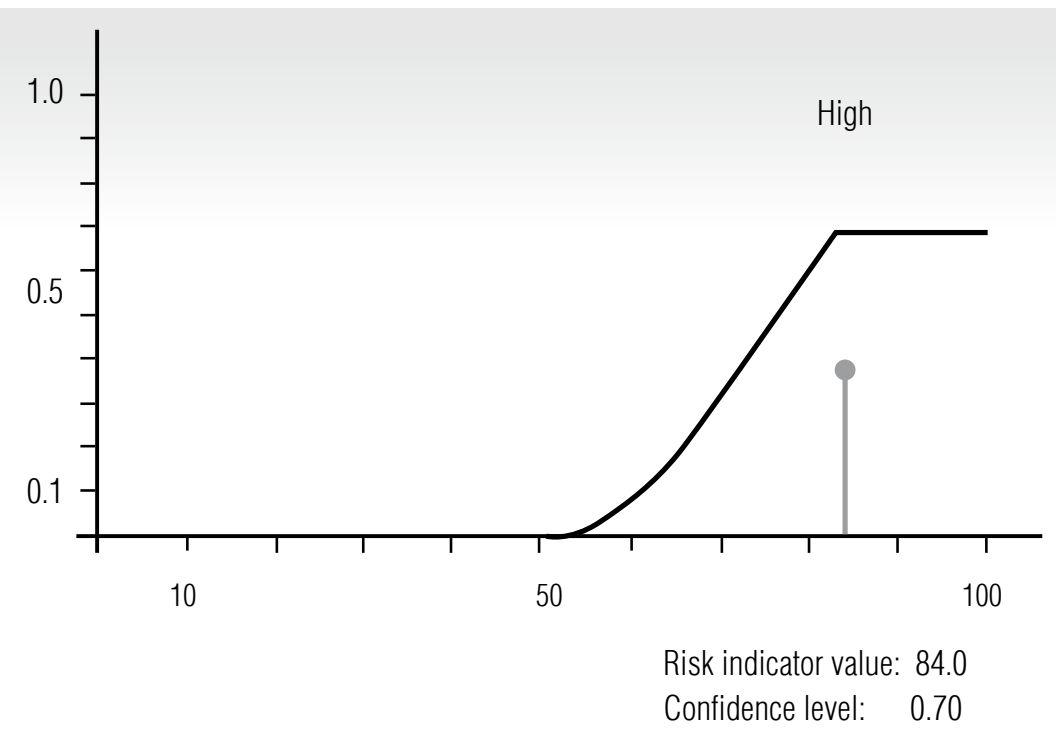

Fig. 6. The results of modeling of the information system microservices architecture quality

the model as high ("high" $(H))$ with a confidence of $79 \%$ (Figure 5).

When modeling IS microservices architecture with a high service quality by microservice 1 and microservice $2(X 14=8.2, X 24=9.5)$ and an average service quality by microservice $3(X 34=7.5)$, the integral assessment of the information system service quality is high with a degree of confidence $70 \%$ (Figure 6).

\section{Conclusion}

Thus, the article proposes a fuzzy production model for analyzing the quality of the microservice architecture of an information system. The results of the analysis can be used when choosing microservices from different vendors, justifying the need to scale the system, and also to increase the availability of microservices. The example shows the possibilities of developing a microservice architecture of an IS using a fuzzy model to analyze the quality of its performance.

In further research in this area, the authors plan to carry out a deep comparative analysis of the results of applying the proposed method and similar approaches.

\section{References}

1. Malikov S.N. (2017) Construction of the concept of service-oriented approach to management of information technologies based on the axiomatic method. Information Technologies, vol. 23, no 3, pp. 212-218 (in Russian).

2. Grubnikov S.Yu. (2019) Definition of the "business process" concept: The ontological level. Herald of Tver State University. Series: Economics and Management, no 2 (46), pp. 241-249 (in Russian).

3. Dolzhenko A.I. (2014) Tasks of selecting cloud technologies for economic information systems. Vestnik of Rostov State University of Economics, no 4 (48), pp. 22-27 (in Russian).

4. Shitko A.M. (2017) The design of the microservice software architecture. Proceedings of BSTU. Series: Physics and Mathematics. Informatics, no 2 (200), pp. 122-125 (in Russian). 
5. Parfenova M.Ya. (2016) Structural synthesis of service-oriented IT architecture profile. Educational Resources and Technologies, no 4 (16), pp. 64-71. DOI: 10.21777/2312-5500-2016-4-64-71 (in Russian).

6. Ouzzani M., Bouguettaya A. (2004) Efficient access to web services. IEEE Internet Computing, vol. 8, no 2, pp. 34-44. DOI: 10.1109/MIC.2004.1273484.

7. Parfenova M.Ya. (2017) Assessment of technological level of formed variants of strategic IT-profile of the organization on the basis of fuzzy model. Proceedings of the 10-th All-Russian Multi-Conference on Management Problems, pp. 90-92 (in Russian).

8. Newman S. (2016) Building microservices. Saint-Petersburg: Piter (in Russian).

9. Evlanov M.V. (2016) Development of a model and method for choosing a description of rational information system architecture. Eastern-European Journal of Enterprise Technologies, vol. 79, no 2, pp. 4-12 (in Russian).

10. Zatesa A.V. (2010) Fuzzy cost model in terms of service-oriented architecture approach. Economics, Statistics and Informatics, no 6, pp. 162-164 (in Russian).

11. Dushkin D.N. (2012) Sensitivity analysis of web services in the problem of choosing the optimal system configuration with a service-oriented architecture. Control in Large Systems: Collection of Works, no 40, pp. 164-182 (in Russian).

12. Zheng Z., Ma H., Lyu M.R., King I. (2011) QoS-aware web service recommendation by collaborative filtering. IEEE Transactions on Services Computing, vol. 4, no 2, pp. 140-152. DOI: $10.1109 /$ TSC.2010.52.

13. Zeng L., Benatallah B., Ngu A., Dumas M., Kalagnanam J., Chang H. (2004) QoS-aware middleware for Web services composition. IEEE Transactions on Software Engineering, vol. 30, no 5, pp. 311-327. DOI: 10.1109/TSE.2004.11.

14. Menasce D. (2002) QoS issues in web services. IEEE Internet Computing, vol. 6, no 6, pp. 72-75. DOI: 10.1109/MIC.2002.1067740.

15. Piegat A. (2001) Fuzzy modeling and control. Heidelberg: Physica-Verlag.

16. Rosario S., Benveniste A., Haar S., Jard C. (2008) Probabilistic QoS and soft contracts for transaction-based web services orchestrations. IEEE Transactions on Services Computing, vol. 1, no 4, pp. 187-200. DOI: 10.1109/TSC.2008.17.

17. Hwang S., Wang H., Tang J., Srivastava J. (2007) A probabilistic approach to modeling and estimating the QoS of web-services-based workflows. Information Sciences, vol. 177, no 23, pp. 5484-5503. DOI: 10.1016/j.ins.2007.07.011.

18. Zheng H., Zhao W., Yang J., Bouguettaya A. (2013) QoS analysis for web service compositions with complex structures. IEEE Transactions on Services Computing, vol. 6, no 3, pp. 373-386. DOI: 10.1109/TSC.2012.7.

19. Klein A., Ishikawa F., Honiden S. (2014) SanGA: A self-adaptive network-aware approach to service composition. IEEE Transactions on Services Computing, vol. 7, no 3, pp. 452-464.

DOI: 10.1109/TSC.2013.2.

20. Khubaev G.N. (2011) Obtaining a group expert evaluation of indicators: step-by-step procedure and software. Software and Systems, no 2, pp. 13-16 (in Russian).

21. Sergeeva Yu.V. (2016) Mathematical methods of group expert estimates. Vestnik of Nizhny Novgorod Institute of Management, no 1 (38), pp. 33-40 (in Russian).

22. Sorokin A.A. (2019) Development of rules base for a fuzzy inference system in the conditions of unharmonious expert's opinion. Control in Large Systems: Collection of Works, no 81, pp. 26-49 (in Russian). DOI: doi.org/10.25728/ubs.2019.81.2.

23. Dolzhenko A.I., Glushenko S.A., Kalugyan K.Kh., Lozina E.N., Cherednichenko A.S. (2010) Production fuzzy network modeling system (PRONES). Certificate of state registration of a computer program, no 2010612952, 25 May 2010 (in Russian).

24. Glushenko S.A., Dolzhenko A.I. (2015) Fuzzy modeling of risks in investment and construction projects. Business Informatics, no 2 (32), pp. 17-27 (in Russian). 


\section{About the authors}

\section{Alexey I. Doljenko}

Dr. Sci. (Econ.), Associate Professor;

Professor, Department of Information Systems and Applied Computer Science, Rostov State University of Economics, 69, Bolshaya Sadovaya Street, Rostov-on-Don 344002, Russia;

E-mail: doljenkoalex@gmail.com

ORCID: 0000-0002-8168-3290

\section{Irina Yu. Shpolianskaya}

Dr. Sci. (Econ.), Associate Professor;

Professor, Department of Information Systems and Applied Computer Science, Rostov State University of Economics, 69, Bolshaya Sadovaya Street, Rostov-on-Don 344002, Russia;

E-mail: irinaspol@yandex.ru

ORCID: 0000-0002-1834-6419

\section{Sergey A. Glushenko}

Cand. Sci. (Econ.);

Assocoate Professor, Department of Information Systems and Applied Computer Science, Rostov State University of Economics, 69, Bolshaya Sadovaya Street, Rostov-on-Don 344002, Russia;

E-mail: gs-gears@yandex.ru

ORCID: 0000-0001-9255-9722 


\title{
Classification of models
} and description of trends in assessing the causality of relationships in socio-economic processes

\author{
Dmitry M. Nazarov \\ E-mail:slup2005@mail.ru \\ Ural State University of Economics \\ Address: 62, 8 Marta Street, Yekaterinburg 620144, Russia
}

\begin{abstract}
Scientific research of any socio-economic and managerial process can be represented as a chain of reflections on the causes and consequences of this or that phenomenon's occurrence. At the same time, the authors can try not only to answer the question "why?" but also to study and understand the nature of cause-and-effect relationships, to find out the mechanisms of their occurrence, and also to get the answer to the question posed as accurately and reasonably as possible. Each author, using the accumulated experience, offers both qualitative and quantitative methods that allow him to obtain one or another assessment of causality. However, there are not enough articles devoted to a comprehensive review of the methods and technologies of cause-and-effect relationships in socio-economic processes. This article discusses three well-known conceptual approaches to the assessment of causation in socioeconomic sciences: successionist causation, configurational causation and generative causation. The author gives his own interpretation of these approaches, builds graphic interpretations, and also offers such concepts as a linear sequence of factors, the causal field, and the causal space of factors in socioeconomic processes. Within the framework of these approaches, a classification of mathematical and instrumental models for assessing the causality of relationships in socio-economic processes is given, and trends in the development of these and new models are formulated, taking into account the global transition to a digital format. All of these trends are based on the use of digital technologies in different formats and include descriptions of such formats. The article contains specific author's examples of causality model implementation in scientific research related to economics and management.
\end{abstract}

Key words: causality; socio-economic process; sequence of reasons; configuration of reasons; generalization of reasons; causal field; causal space.

Citation: Nazarov D.M. (2020) Classification of models and description of trends in assessing the causality of relationships in socio-economic processes. Business Informatics, vol. 14, no 4, pp. 47-61. DOI: 10.17323/2587-814X.2020.4.47.61 


\section{Introduction}

$\mathrm{T}$ The issues of assessing the causality of relationships in socio-economic processes are discussed in many scientific works. At the same time, it is quite obvious that the mechanisms of the occurrence of cause-and-effect relationships are universal about the subject and object of research. Therefore, the study of cause-and-effect relationships ("causality") is given great attention in many sciences: philosophy, psychology, economics, management, physics, chemistry, etc. In socio-economic sciences, the issues of "causality" are identified with the new term "causality," which is gaining popularity. Causality (lat. causalis) - causal interdependence of events in time [1]. The variety of application spheres of the causality concept determines the diversity of approaches to its study [2-17].

Experimental and quasi-experimental methods have become the basis of research practice in the search for the causality of relationships in socio-economic processes, which have made it possible to make a real "revolution of reliability" [2] in the field of empirical socio-economic research. New methods and approaches which have gone far beyond the scope of econometric and correlation-regression analysis have made it possible to ensure high quality of the quantitative estimates obtained and to reliably identify the presence of causality, and not just correlations. This made it possible to measure accurately the strength of the impact of some observed variables on others in the framework of the socioeconomic processes under consideration.

The general meaning of the experimental approach, within which new methods of studying the causality of socio-economic processes were born, is quite simple. It consists of choosing the object of analysis, determining and formalizing the essence of the impact (influence), building a research hypothesis, as well as a comparative analysis of the impact's assessment of the selected impact (or lack of it) on groups. The most important characteristic of dividing objects into two groups (experimental and control) is the randomization of objects falling into these groups, which helps to effectively solve the problem of endogeneity. Assessment of the difference (dissimilarity) of such impacts on randomly selected groups allows us to obtain an unambiguous answer to the question of whether the selected impact is the cause of changes in the characteristics of objects. Thus, a properly constructed experimental research design is the key to a successful study of causality in socioeconomic processes.

The effectiveness of the causality study in socio-economic processes based on a wellbuilt design is confirmed by Christopher Sims and Thomas Sargent - laureates of the Nobel Prize in Economics for 2011, awarded "for empirical research of causal relationships in macroeconomics" [13, 14]. These scholars have developed methods to answer questions about the causal relationship between economic policy and various macroeconomic variables such as GDP, inflation, unemployment and investment.

When assessing causality in socio-economic processes, there are three main approaches to the study of cause-and-effect relationships in modern science.

The successionist causation approach explores and identifies vital elements of causality, such as variables or methods that describe socio-economic processes. At the same time, research is aimed at observing the relationship between such variables using survey methods, tests, and experiments. The explanation of causality is based on the differences in associative links (real or false, direct or indirect), as well as on the assessment of the strength and significance of these links [2, $3,5,12-14,18,19]$. 
The configurational causation approach implies the study of the socio-economic process based on comparison or "comparative" analysis of data. This means that research begins with the study of some cases of a certain set of socio-economic processes or phenomena that have similarities and differences. The purpose of such studies is to find causality based on the selection of two sets of factors or parameters, some of which lead to similarity and others to difference. Thus, causality in this sense is the basis for dividing the studied set of socio-economic processes into two clusters. As a result of the research, the key configurations of attributes are revealed which make it possible to explain the differences in the results for the entire set of socio-economic processes being considered [18-23].

The generative causation approach also begins by looking at measurable patterns that describe socio-economic processes. However, it is assumed that they are caused by the action of some deep mechanism that describes human actions, and, in the general case, is not formalized in the form of a set of variables or attributes. Causality, in this case, is reduced to the creation of theories of such mechanisms explaining the emergence or lack of uniformity (behavior patterns) [23-28].

The three scientific approaches presented are the basis of most scientific research aimed at elucidating causal relationships in socio-economic processes.

We should emphasize that the focus of the approaches just described is an imperative thing - "logic in use," the reason why this or that approach is applied in the first place. Each of the three approaches is based on some of the key organizational research principles that give rise to the corresponding scientific methodology. This methodology is universal and can be applied in various fields of knowledge, including social and historical sciences, pure sciences, as well as applied sciences on a macroand micro-scale.
Using the approaches discussed above, researchers of socio-economic processes are trying to solve some problems in assessing the causality of relationships between factors: the problem of the direct influence of " $\mathrm{X}$ " on "Y," the problem of delayed or retrospective causality, the problem of functionality (deterministic or probabilistic), the problem of causality of relationships and many others [2-17].

The purpose of this article is to consider the classification of causality models within the framework of the three approaches discussed above and to formulate trends in the development of causality theories concerning socioeconomic processes and phenomena, taking into account the development of tools and the transition of a society to a digital development format.

\section{Analysis of approaches to identifying causality in socio-economic processes}

In a broad sense, causality theory answers the question related to determining the truth of the statement " $\mathrm{X}$ begets $\mathrm{Y}$ ". In this case, " $X$ " is called a cause or a causal factor (or a set of factors), and " $Y$ " is called a consequence, response, or an effective factor (or a set of factors). Mathematically speaking, " $\mathrm{X}$ " is a necessary condition for " $Y$ " and " $Y$ " is a sufficient condition for " $\mathrm{X}$ " (Figure 1).

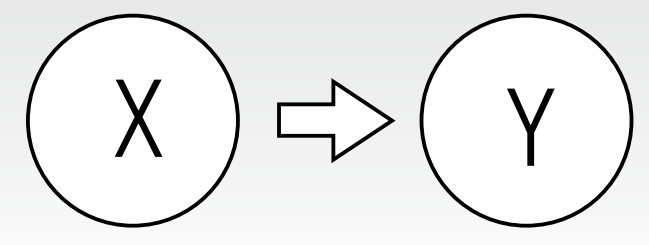

Fig. 1. Graph of factors' causality of the socio-economic process 
In the successionist causation approach, causal links are established between variables that explain the cause within a specific model describing the socio-economic process. In this case, the first step is to identify independent variables that fix the state of the process at a certain moment in time, as well as the result (effect) the dependent variable that needs to be explained. Such patterns, associations, or correlations provide the basic building blocks within the framework of the "cause-effect" dualism. However, it is well known that correlation is not causation. Therefore, within the framework of this approach, it is necessary to do a lot of work to identify the causal relationship by analyzing the data using mathematical methods. Identifying a sequence of causes avoids the fuzzy conclusion that "everything causes everything" and focuses on finding really meaningful influences. This is mainly done in two ways.

The first method is to isolate critical causal relationships by manipulating data that are randomly divided into test and control samples. In this case, all but one of the variables are fixed, and thus the strength of the influence of this variable on the result is determined. Since the samples are identical in composition, only this variable can affect the result. Thus, the direct influence of the highlighted variable on the result can be observed and measured directly.

The second way to identify causality implies a similar logic, but the author achieves control of the result differently. To examine the veracity and strength of any particular causal relationship, a test variable is introduced. The author tests this variable to see if the original influence model has changed. In other words, the strength of this variable's influence on the result and the original variable is checked.

Thus, within the framework of the first approach, the variables describing the socioeconomic process explain the obtained result. Causality is driven by incrementally adding variables, collecting data, creating measurement tools and providing capabilities for processing experimental data. At the same time, the assessment of causality is based on a deep analysis of data associated with the search for effective combinations of variables' arrays that most accurately describe the socio-economic process.

The "configurational causation" approach to identifying the causality of relationships in socio-economic processes is, in fact, based on the ideas of John Stuart Mill outlined in the book "System of Logic" [12], which were developed in [20, 21]. From a technical point of view, this is associated with the transition from a methodology based on variables to a methodology based on specific (particular) cases. From this point of view, the author considers attributes and conditions. Attributes are also identifiable through data collection. The difference is that the author considers attributes as part of the socio-economic process, and not as independent objects, but, nevertheless, they are independent variables. Thus, causality, in this sense, is determined by a special configuration of attributes in the whole system. Variable analysis in the first approach focuses on identifying the contribution of individual causes, while configuration analysis tries to trace the results based on their combination (attributes). This thesis can be schematically depicted in the following form (Figure 2).

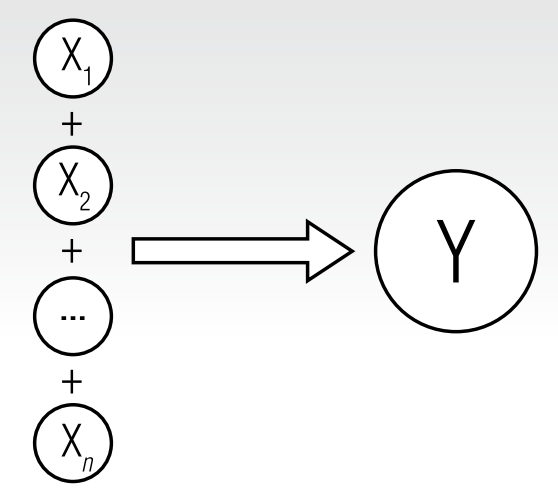

Fig. 2. Graph of factors' configurational causality of the socio-economic process 
To clarify the meaning of this graph, let us give an example of Moore's study [29], in which the early industrialization of Britain was caused by such factors as a weak aristocracy, technological progress, a strong middle class, the movement of cheap labor, the presence of colonies, etc. Any of these factors apart unlikely could cause changes in industrial production. However, taken together, these factors provide a powerful boost. Indeed, technological progress will not scale production without an influx of cheap labor, which is possible through the presence of colonies. Thus, the "+" sign in Figure 2 means the presence of a certain set of attributes. Understanding the attribute as a set of interrelated variables, we get the first fundamental feature of the second approach. Then the limitation of the first approach becomes visible, which we identified when examining a study devoted to modelling the process of Russia's accession to the WTO [30]. The main idea of configurational causality is that the change in the socio-economic process is due to the relationship of variables in the attributes. The absence of any variable in an attribute does not cause changes, consequently, the attribute itself is not the reason for this change. It is the combinatorial nature of the attribute structure that is the key characteristic of causal complexity, which the author considers in the second approach. The second important point in understanding the meaning of configurational causality is that it is comparable phenomena that are compared for the search for causality. Thus, in the example of the early industrialization of Britain, a comparative analysis of attributes' similar structure in the industrialized countries of that period (France and Germany) would give us an answer to the question of why Britain became the leader of the industrialization at that time.

Thus, in the second approach a new causal logic is established which is significantly different from the model of the first approach and has the following characteristics: $\downarrow$ attribute configurations explain the reason;

$\downarrow$ dissimilar configurations of attributes can lead to the same result;

$\downarrow$ similar configurations of attributes can lead to different results;

$\downarrow$ individual sets of attributes can lead to opposite results.

Within the framework of the second approach, a technology for identifying causal relationships was developed, which was called qualitative comparative analysis [21, 22]. This technology consists of four steps:

1. Put forward a hypothesis and select potential attributes that could lead to the investigated result;

2. Collecting data (using primary or secondary means) and placing them in a data matrix;

3. Simplification of the "truth table" to identify the most significant cause-and-effect relationships. Simplification involves deriving basic causal configurations using analytic rules, such as the following: "If two rows of a truth table differ in only one attribute, but still lead to the same result, then the attribute that distinguishes the two rows can be ignored and excluded from consideration: $\mathrm{Y}=\mathrm{X} 1 . \mathrm{X} 2 . \mathrm{X} 3 . \mathrm{X} 4$ (1100), Y = X1.X2.X3.X4 (1101)". Here "X" (uppercase letter) means code 1 (true), while " $x$ " (lowercase letter) means code 0 (false). Such a record means that the presence or absence of attribute number 4 in the truth table $\mathrm{x} 4$ (X4) has no meaning for a certain class of situations $Y=X 1 . X 2 . x 3$, if they are in the same truth table;

4. Choice of attributes' basic configurations and interpretation of results.

The generative causation approach is based on an ordered sequence of applying rules to a set of abstract symbols [1]. Issues related to the emergence and development of this approach have philosophical roots and are associated with the concepts of critical realism [25-28] and 
generative modeling [30-32]. The key difference between generative causality is the study of cause-and-effect relationships at the level of the mechanism of their occurrence and functioning in socio-economic processes (Figure 3).

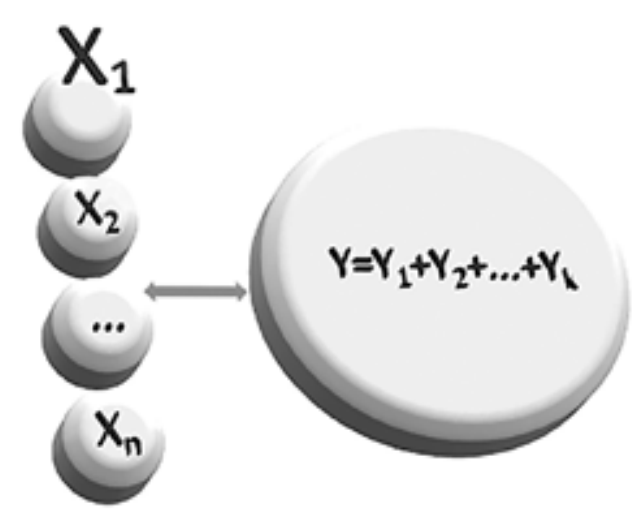

Fig. 3. Graph of factors' generative causality of the socio-economic process

The first fundamental difference of this approach lies in a different presentation of the research result. In generative explanation, the goal is to explain what causes causal relationships, that is, to identify some patterns of relationships between attributes and outcomes in the form of association rules. A set of such patterns can be considered as possible patterns of behavior in the study of socio-economic processes. In essence, the presentation of the result is also understood as a collection of attributes, and the causal arrow is replaced with an "equivalence" sign (double-headed arrow), which shows the relationship of variables' sets. Thus, in the generative approach, the results are the object of explanation, since they describe more complex sequences, comparisons, trends and relationships.

The second difference is "generative mechanisms" or "underlying mechanisms," which reflect the uniqueness of the approach and explain the patterns of results. Causal relationships, in this case, are in the "mechanism of action" of causality and are understood as "potentials" or "processes" inherent in the system under study. Thus, socio-economic research begins with templates of results and with the hypothesis about the choice and argumentation of attributes.

The third difference concerns the contexts that are needed to explain the typology of results. The contexts represent the possible options in the generative explanation of causal links. Contexts are pre-existing institutional, organizational and social conditions that define the framework for the study of causality in the socio-economic process. They allow you to develop an infrastructure for the study of causality in socio-economic processes.

Having described the features of generative causality, one can conceptually describe the search for causality in socio-economic processes. The author explains the causality of connections in socio-economic processes by the fact that the mechanism (M), acting in the context (C), will generate the result, or output $(\mathrm{O})$. This CMO technology offerings are the starting point and end product of research. The research begins with hypotheses aimed at explaining a pattern of outcomes by postulating how they can be explained within a specific context. Then the author is carrying out empirical research to understand better the setting of the action's mechanism as part of an iterative process of correlating input and output.

Thus, comparing the three listed approaches, we can state that all of them are the basis for the construction of stable informative causal links of socio-economic processes and have the property of nesting:

Sequence of causes $\subset$ Configuration of causes $\subset$ Generalization of causes 
All three approaches involve the hypotheses' construction and the interpretation of the causality's model of connections in socio-economic processes.

Within the framework of the first two approaches, researchers focus on finding and applying appropriate methods and tools to perform basic calculations that assess the strength and quality of communication, since these characteristics are fundamental for constructing the causality mechanism, which is described in the third approach. However, in the first two approaches, research has not focused on the question of why the individual partial causalities of variables and attributes make sense. This means that the variables and attributes, as well as their interrelationships, are responsible for establishing the strength of the causal relationship. But they do not take into account the infrastructure and context of the socio-economic process being considered, although these characteristics structure what is happening and affect the quality of the research. In other words, the first approach (sequence of causes), which can be conventionally called linear (one-dimensional model), can be improved by adding variables, but adding such "element-by-element" complexity leads to an increase (exponentially) in computational and descriptive complexity. The second approach (configuration of causes) takes into account the relationships between variables and allows them to be represented as attributes. Applying the provisions of this approach, we can argue that we are dealing with a causal field of factors and attributes (two-dimensional model). To improve research results in this approach, the author used additional comparisons, which also leads to an increase in the complexity of the model for assessing the relationships' causality. Within the framework of these two approaches, it is rather difficult to obtain stable empirical generalizations and explanatory persuasiveness.
The third approach (generalization of causes) has the best technology for assessing the causality of relationships in socio-economic processes since it contains elements that allow strengthening generative reasoning. However, just because "context mechanism - result" configurations provide more explanatory flexibility than variable or attribute-based models does not mean that they are in any way final or complete. Of course, formation the mechanisms of relationships causality requires a more powerful data set and complex assessment methods. At the same time, the presence of context makes it possible to strengthen the explanatory nature of causality in socio-economic processes, and the causal space of factors makes it possible to transfer the constructed mechanism from one area to another with minimal losses.

An example of generative causality can be found in the discoveries of Nobel laureates in the field of economics who build their models proceeding from some causal assumptions, obtaining new and generalizing traditional economic laws. J. Akerloff argues that rational behavior in different market segments should take into account a certain degree of information asymmetry between the seller and the buyer [34]. Thus, to study the effectiveness of market behavior (according to Pareto), it is proposed to add the attribute "information asymmetry." At the same time, the result in such a causal space turns out to be multivalued, since the attribute "asymmetry" for different categories of market agents describes the real market situation in different ways. Generative causation, in this sense, gives rise to a new theory of market behavior. The context, in this case, may be a specific market in which the above causal space of factors is considered: the used car market, insurance, and medical markets and others. 


\section{Examples of applying the approaches to identifying the causality of socio-economic processes}

\section{Example 1. Successionist causation}

In the work by M.S. Yudaeva [30], the author considers the issue of the causal link between the process of Russia's accession to the WTO and the consequences of this accession. Sequential causation here is an acyclic graph. The author proposes using the method of randomized probabilities to evaluate the strength of connections in an acyclic graph using a specific example the electric power sector of the Russian economy.

In his research, the author applied the logic of the first approach. However, the phenomenon of Russia's accession to the WTO goes far beyond the chosen variables, therefore the estimates of the impact obtained can be considered only partial (for example, no effect was found for other industries).

Despite these shortcomings, this study is as accurate as we can get close to manipulating the WTO accession process to observe the effect of one variable (the top of the acyclic graph) on another when all other variables are considered unchanged.

The basic logic of this approach remains unchanged: the author generated hypotheses about causal relationships, collected data on a set of suitable variables to study this pattern, and, in accordance with the results of the analysis, explained the alleged reason with a specific example.

\section{Example 2. Configurational causation}

The studies of the American scientist D. Meister [35] in the field of "corporate culture - profitability of an enterprise" causality reflect the principles of the configurational approach. At the first stage, the author identified several attributes of corporate culture that determine the financial success of a company: self-improvement, leadership, etc. The logic of building causal links is shown in Figure 4 . In this case, the author builds a causal field and assesses the strength of links' causality based on the results' statistical processing of 139 firms employing 5ю.589 people.

Using an econometric apparatus, D. Meister proved that two factors have the greatest influence on financial success: profit growth (0.81) and profit per employee $(0.53)$. The rest of the factors have a significantly lower level of impact ( 0.27 and 0.24 , respectively). The limitation of this study lies in the basic assumption of linearity and independence of the factors' influence.

So, the application of QCA technology in the framework of the configuration approach on specific examples of the study of the corporate culture causality and the main indicators of the enterprise (organization) showed the implementation of all the four stages indicated above. Indeed, the assessment methods developed by the authors begin with defining the structure of attributes that can contribute to the achievement of the result based on common sense, that is, the analysis of management situations in different organizations. Then the author, realizing the complexity of the phenomenon under consideration, made an attempt, each in his own way, to explain the complex interaction of attributes and build various combinations, sorting them according to their importance. Based on the configurations obtained, a method for assessing the causality of corporate culture and the main indicators of the enterprise (organization) was developed.

\section{Example 3. Generative causation}

D. Denison's model [36] of assessing the corporate culture's impact on the activities of an enterprise can be attributed to the generative approach to the generative causality study "corporate culture - the efficiency of the enterprise." 
Each component of a dual-link is a synergistic sum of several attributes. The corporate culture includes engagement, alignment, adaptability and company mission. The efficiency of the enterprise includes assets and investments, sales and product quality, employee satisfaction and the level of innovation, creativity and customer focus, sales growth and an increase in market share [36, 37].

Such decomposition allows us to present the mechanism of the relationship between corporate culture and efficiency better and contains clear signs of generative causality. This decomposition is a more accurate tool for determining the impact of corporate culture on the efficiency of an enterprise. D. Denison offered his original causal space of factors connecting the performance of an organization with corporate culture and described the mechanism of their action in various contexts.

The result of assessing the relationships' causality in D. Denison's model can be considered a set of associative relationships that generate the mechanism of corporate culture's causality and organization's performance indicators, linking attributes (components of corporate culture) and results (enterprise performance) [36, 37].

\section{Mathematical and instrumental models of causality}

The work of a fairly large number of scientists - philosophers and psychologists - was devoted to the conceptualization of causality models at the initial stages of development.

J. Mill [12] substantiated the principles of scientific knowledge and developed several conceptual models for detecting causes and effects in the study of socio-economic and other processes. He identified the understanding of the cause, using the logical interpretation of "cause is a necessary and sufficient condition of the effect," and also proposed to use the model of differences to identify causality. The essence of this model consisted of "sifting" the factors of the studied processes through the "sieve" of the criterion, which was associated with an assessment of the collinearity of the change in the premise and result.

The second most important conceptual model of causality of connections was developed by the psychologist D. Hume [38]. The basic characteristics of this model are associations, which the scientist defined as the ability to establish connections between sensations. Associations structure sensations according to the parameters of similarity and spatio-temporal extent. D. Hume defined the conditions for the emergence of the association of causality this way: cause and effect must be adjacent to each other in time and space, the cause must precede the effect and this connection must be necessary.

Thus, thanks to the conceptual models proposed in philosophy and psychology, the main factors influencing the assessment of the causal structure of processes and phenomena include the following: statistical relationships between events, the temporal order of events following each other, a change in the natural course of events as a result of different events, a-priori representations and installations.

The metric evaluating such combinations of occurrence or absence of events can be determined on the basis of the classical formalization of conceptual models - the equation of conjugation of cause and effect: $\Delta \mathrm{p}=\mathrm{p}(\mathrm{Y} \mid$ $\mathrm{X})-\mathrm{p}(\mathrm{Y} \mid \neg \mathrm{X})$. In this equation, the degree of conjugation $(\Delta p)$ is defined as the difference (according to J. Mill) of the conditional probabilities of the consequence $\mathrm{Y}$ in the presence and absence of factor $X$. Note that such formalization does not reflect the direction of the causal connection (from cause to effect), which plays a key role in assessing causality [7, $10,15,17]$. 
In mathematics, there are three well-known theories associated with modeling socio-economic processes under conditions of uncertainty: the probability theory, the theory of possibilities and the theory of fuzzy sets.

Probabilistic-statistical, fuzzy and expert methods and models are considered as fundamental economic and mathematical models of the causality of relationships between factors, implying, first of all, the study of the occurrence of events within the framework of the experiments, taking into account the design of the experimental research.

The first group of models is associated with correlation and regression analysis. Within the framework of this group of models, the structural equations and diagrams of S. Wright, the Neumann - Rubin causal models, Pearl functional models, David's dynamic models and various graph models should be noted. One way or another, in all these models, different types of correlation analysis are used as a measure of determination, and the correlation coefficient is calculated. More detailed information on such models is contained, for example, in works [5, 9, 39-43].

The second group of models has received the general name "confirmatory analysis" [44, 45]. The essence of confirmatory factor analysis is to assess the strength of relationships for some latent variable that affects the results and attributes. This approach, based on the econometric apparatus of dependence studies, allows one to compare different structures of factors. The methodology of confirmatory analysis is based on deductive logic, therefore this method is popular in assessing the causality of relationships.

The third group of models is based on expert methods for assessing various parameters of socio-economic processes based on the analysis and comparison of multi-criteria alternatives. The essence of matrix expert methods consists of the construction of matrices that reflect the relative importance of the investigated alternatives in different forms for a given pool of features. As for graph methods, they, first of all, involve the construction of some kind of hierarchical (or network) structure that reflects mutual influences and implements routes to achieve various goals. Note that the proposed division is conditional since both graph and matrix methods can use separate elements of each other simultaneously. Speaking about the features of each method, we should pay attention to the algorithms of expert assessments that answer the question: how is the opinion of an expert or a group of experts processed? Among these algorithms, at least two groups can be distinguished - algorithms for quantitative and qualitative assessments. The most common methods of expert relationships' causality assessment are methods that allow one to evaluate various coefficients of causal relationships between factors of socio-economic processes: DEMATEL [45-47], MICMAC [48-51], as well as a method for detecting and assessing the influence of implicit factors [39-41].

The DEMATEL method (Decision Making Trial and Evaluation Laboratory) [45-47] is one of many multicriteria decision-making methods that implies the effective identification of causal relationships of a complex system based on the aggregation of expert assessments. This method aggregates the collective expert opinion to exclude random relationships between indicators and criteria and, based on causal links, identify the most important indicators that determine the integral characteristic. The method allows you to determine the direct, reverse and indirect relationships, as well as the direction of the interdependence between the criteria and indicators.

The MICMAC method [48] stands for "Matrix d'Impacts Croises Multiplication 
Appliqué un Classement" which literally means a composition of the cross matrix and classification. The analysis using this method is a procedure for constructing a classification matrix of the factors' cross-influence and is intended to assess the degree of dependence of the variables' influence (the strength of causal links) based on ranking. Each of the factors studied belongs to one of four clusters: autonomous, dependent, interrelated and independent. These factors (drivers) are grouped based on a specific potential and strength of influence. Autonomous factors (quadrant 1) are factors that have weak potential and strength of influence. As a rule, they are practically insignificant in determining causality. Dependent factors (quadrant 2) are factors that have a low potential but strong influence. Interrelated factors (quadrant 3) are factors that have high potential and power to influence. These factors are causally related, which means that an action on one of them will lead to a change in the other. Independent factors (quadrant 4) are factors that have strong potential but little impact. All factors are plotted on a four-cluster graph, where the potential of the variable is on the $\mathrm{Y}$-axis and the force of influence is on the $\mathrm{X}$-axis.

In the works [39-41, 52], a pool of economic and mathematical models is proposed that allows, on the study's basis of organizational management factors' variety, to single out implicit ones. After this, based on the apparatus of fuzzy logic, using the Gauguin's implication, to assess the influence's degree of these factors on other factors' management. As an example, it is proposed to assess the impact of corporate culture on the main indicators of the organization's performance. At the same time, using fuzzy binary relations, it is possible to obtain a causal field of factors that determine the causal relationship "corporate culture - the main indicators of the organization's activities."

\section{The main trends in causality model development of socio-economic processes}

Modern digital technologies make it possible to receive and process large amounts of data in real-time. This makes it possible to widely use the arsenal of mathematical theories and methods associated with probabilistic, statistical and expert assessment of various determinants of socio-economic processes.

Accordingly, there are at least three main trends that will facilitate a "revolution of reliability" in causal studies of socio-economic processes and improve the quality of their management.

The first trend is associated with the development of existing methods based on the aggregation of estimates obtained using big data processing technologies. This trend implies the development within the framework of all three approaches to assess causality; however, it most clearly codifies the first two approaches - the sequence of causes and the configuration of causes. Indeed, the methods of data mining, firstly, are "not afraid" of a multiple increase in variables in causal models of the study of socio-economic processes. This means that using the available tools (SAP Analytics Cloud, SAP HANA, Power BI, QlikView, Phyton, R, etc.), the researcher, given the data, can perform multiple types of checks on various factors for causality and increase the reliability of the result. Secondly, given the availability of data, it is possible to build algorithms for formalizing quantitative estimates (for example, ranking factors) that will partially or completely replace expert opinion.

The second trend is associated with the use of intelligent data processing algorithms that can be configured to "measure" the causality of fields and factor spaces. This trend will significantly formalize the approach of generalization of causes and make it accessible to most researchers. Note that the generalization of 
causes implies the construction of associations and classifications (according to D. Hume and J. Mill). Within the framework of existing algorithms, The author would like to pay attention to two main methods - the algorithm for constructing Bayesian networks and the Apriori algorithm, which, based on specially prepared data sets, allow us to construct association rules characterizing the behavioral characteristics of people - participants of socio-economic processes.

Over the past twenty years, Bayesian networks have become one of the basic tools for formalizing uncertainties in artificial intelligence. Bayesian networks not only provide a natural and compact way to encode factors of exponential size in causal space but also give efficient probabilistic inference in realtime [53-56]. It is important that Bayesian networks are directed acyclic graphs, where nodes are random variables, and edges are conditional relationships between random variables, distributed either discretely or continuously. Since most of the structural and functional models of socio-economic processes are presented in the form of various hierarchies (acyclic graphs), then Bayesian networks are ideal for identifying the causality of relationships in them.

The Apriori algorithm [56] and its modifications allow one to formalize the so-called recommender systems, within the framework of which associative rules are constructed based on data in the form of "if-then" implications. Different data slices and sets of variables make it possible to establish the causality of relationships in different contexts of socio-economic research. The essence of the algorithm makes it possible to drastically reduce the dimension of data, but its settings and speed of action in realtime - to carry out a large number of experiments.

The third trend is related to machine learning algorithms and methods. Due to the flex- ibility of settings and instrumental support, these algorithms allow, within the framework of any of the above approaches, to develop new methods and technologies for assessing causal links in socio-economic processes that are not known today.

\section{Conclusion}

Within the framework of the theoretical and methodological study of generally accepted approaches, an attempt was made to study the causality of socio-economic processes in world science, to build their models based on a deep analysis of the content on this issue. It should be noted that there are clearly not enough publications in Russian science that use the three main approaches to the study of cause-and-effect relationships, which include successionist causation, configurational causation and generative causation. The digital format of the development of socio-economic processes allows one to go from conceptualizing causality directly to the applied use of the accumulated experience and knowledge in this area, using modern tools for analyzing big data. This approach will make it possible to more accurately identify the cause-and-effect relationships of social processes and get a better effect from research in this direction. The versatility of the methods and models considered guarantees the successful application of software for the development of research in the field of building applied digital models of causality in socio-economic processes.

\section{Acknowledgments}

This article was supported by the Russian Foundation for Basic Research, within the framework of the Russian Foundation for Basic Research competition "Expansion-2019" No 19-110-50281. 


\section{References}

1. Ilyichev L.F., Fedoseev P.N., Kovalev S.M., Panov V.G., eds. (1989) Philosophical encyclopedic dictionary. 2-nd ed. Moscow: Soviet Encyclopedia (in Russian).

2. Angrist J.D., Pischke J.-S. (2010) The credibility revolution in empirical economics: How better research design is taking the con out of econometrics. Journal of Economic Perspectives, vol. 24, no 2, pp. 3-30. DOI: $10.1257 /$ jep.24.2.3.

3. Almond D., Mazumder B. (2011) Health capital and the prenatal environment: The effect of Ramadan observance during pregnancy. American Economic Journal: Applied Economics, vol. 3, no 4, pp. 56-85. DOI: 10.1257/app.3.4.56.

4. Asher H.B. (1983) Voting behavior research in the 1980s: An examination of some old and new problem areas. Political science: The state of the discipline (ed. A.W. Finifter). Washington DC: American Political Science Association, pp. 339-388.

5. Dawid A.P. (2012) The decision-theoretic approach to causal inference. Causality: Statistical perspectives and applications (eds. C.R. Berzuini, A.P. Dawid, L. Bernardinelli), chapter 4. Wiley and Sons, pp. 25-42. DOI: 10.1002/9781119945710.ch4.

6. Glymour C.N. (2001) The mind's arrows: Bayes nets and graphical causal models in psychology. Cambridge, MA: MIT Press.

7. Mackie J.L. (1974) The cement of the universe: A study of causation. Oxford, England: Clarendon Press.

8. Murphy G.L. (2004) The big book of concepts. Cambridge, MA: MIT Press.

9. Pearl J. (2009) Causality models, reasoning, and inference. Cambridge: Cambridge University Press.

10. Rescorla R.A., Wagner A.R. (1972) A theory of Pavlovian conditioning: Variations in the effectiveness of reinforcement and non-reinforcement. Classical conditioning II: Current research and theory (eds. A.H. Black, W.F. Prokasy). New York: Appleton-Century-Crofts, pp. 64-99.

11. Steyer K., Simon O., Kraus R.H.S., Haase P., Nowak C. (2013) Hair trapping with valerian-treated lure sticks as a tool for genetic wildcat monitoring in low-density habitats. European Journal of Wildlife Research, no 59, pp. 39-46. DOI: 10.1007/s10344-012-0644-0.

12. Mill J.S. (2002) A system of logic. Honolulu: University Press of the Pacific.

13. Sargent T.J. (1979) A note on maximum likelihood estimation of the rational expectations model of the term structure. Journal of Monetary Economics, no 5, pp. 133-143.

14. Sims C. (1972) Money, income and causality. American Economic Review, vol. 62, no 4, pp. 540-552.

15. Suppes P. (1973) A probabilistic theory of causality. British Journal for the Philosophy of Science, vol. 24, no 4, pp. 409-410.

16. Salmon W. (1984) Scientific explanation and the causal structure of the world. Princeton, N.J.: Princeton University Press.

17. Woodward J. (2003) Making things happen: A theory of causal explanation. Oxford: Oxford University Press.

18. Campbell D., Stanley J. (1963) Experimental and quasi-experimental designs for research. Chicago: Rand McNally.

19. Moore B. (1966) Social origins of dictatorship and democracy. Boston: Beacon Press.

20. Skocpol T., ed. (1984) Vision and method in historical sociology. Cambridge: Cambridge University Press.

21. Ragin C. (1987) The comparative method. Berkeley: University of California Press.

22. Ragin C. (1994) Constructing social research. Thousand Oaks: Pine Forge Press.

23. Abbott A. (1998) The causal devolution. Sociological Methods and Research, vol. 27, no 2, pp. 148-181.

24. Archer M. (1995) Realist social theory. Cambridge: Cambridge University Press.

25. Bhaskar R. (1978) A realist theory of science. Hassocks: Harvester Press. 
26. Bhaskar R., Archer M., Collier A., Lawson T., Norrie A. (1988) Critical realism: Essential readings. London: Routledge.

27. Blalock H. (1961) Causal inferences in non-experimental research. Chapel Hill: University of North Carolina Press.

28. Pawson R. (1989) A measure for measures: A manifesto for empirical sociology. London: Routledge.

29. Moore B. (1966) Social origins of dictatorship and democracy. Boston: Beacon Press.

30. Gorban M.I., Guriev S.M., Yudaeva K.V. (2002) Russia in the WTO: myths and reality. Voprosy Ekonomiki, no 2, pp. 61-82 (in Russian).

31. Boudon R. (2006) Tocqueville for today. Oxford: Bardwell Press.

32. Elster J. (1989) Nuts and bolts for the social sciences. Cambridge: Cambridge University Press.

33. Fararo T. (1989) The meaning of general theoretical sociology: Tradition and formalization. Cambridge: Cambridge University Press.

34. Akerlof G.A. (1970) The market for "lemons": Quality uncertainty and the market mechanism. Quarterly Journal of Economics, no 84, pp. 488-500.

35. Maister D.H. (2001) Practice what you preach: What managers must do to create a high achievement culture. New York: Free Press.

36. Denison D., Hooijberg R., Lane N., Lief C. (2012) Leading culture change in global organizations: Aligning culture and strategy. San Francisco, CA: Jossey-Bass.

37. Denison Consulting (2009) Culture getting started guide. Available at: http://staff.studentlife.umich.edu/ files/dsa/Getting+Started+Guide.pdf (accessed 24 May 2020).

38. Hume D. (1965) A treatise on human nature. Essays in 2 vols. Vol. 2. Moscow: Myisl (in Russian).

39. Nazarov D.M. (2017) Fuzzy model for assessment of causality of factors in collaborative economy. Proceedings of the 2017 IEEE 19th Conference on Business Informatics (CBI 2017), Thessaloniki, Greece, 24-27 July 2017, vol. 2, pp. 28-31. DOI: 10.1109/CBI.2017.4.

40. Nazarov D.M. (2019) The fuzzy logic methodology for evaluating the causality of factors in organization management. Open access peer-reviewed chapter. Available at: https://www.intechopen.com/books/ fuzzy-logic/the-fuzzy-logic-methodology-for-evaluating-the-causality-of-factors-in-organizationmanagement (accessed 01 July 2020). DOI: 10.5772/intechopen.84814.

41. Nazarov D.M. (2016) Methodology for fuzzy-multiple assessment of implicit factors in the organization's activities. Ekaterinburg: USUE (in Russian).

42. Wright S. (1921) Correlation and causation. Journal of Agricultural Research, no 20, pp. 557-585.

43. Rubin D.B. (1978) Bayesian inference for causal effects: The role of randomization. Annals of Statistics, vol. 6 , no 1 , pp. 34-58.

44. Hair J.F., Hult G.T.M., Ringle C.M., Sarstedt M. (2017) A primer on partial least squares structural equation modeling (PLS-SEM). Thousand Oaks, CA: SAGE Publications.

45. Jassbi J., Mohamadnejad F., Nasrollahzadeh H. (2011) A fuzzy DEMATEL framework for modeling cause and effect relationships of strategy map. Expert Systems with Applications, vol. 38, no 5, pp. 5967-5973. DOI: 10.1016/j.eswa.2010.11.026.

46. Chen F.H., Chi D.-J. (2015) Application of a new DEMATEL to explore key factors of China's corporate social responsibility: Evidence from accounting experts. Quality \& Quantity, vol. 49, no 1, pp. 135-154. DOI: $10.1007 / \mathrm{s} 11135-013-9978-2$.

47. Wu H.-H., Chang S.-Y. (2015) A case study of using DEMATEL method to identify critical factors in green supply chain management. Applied Mathematics and Computation, vol. 256, pp. 394-403. DOI: $10.1016 / \mathrm{j}$.amc.2015.01.041.

48. Khanam S., Siddiqui J., Talib F. (2016) Modeling the TQM enablers and IT resources in the ICT industry: An ISM-MICMAC approach. International Journal of Information Systems and Management, vol. 1, no 3, pp. 195-218. DOI: 10.1504/IJISAM.2015.072290. 
49. Mudgal R., Shankar R., Talib P., Raj T. (2009) Greening the supply chain practices: An Indian perspective of enablers' relationship. International Journal of Advanced Operations Management, vol. 1, no 2-3, pp. 151-176. DOI: 10.1504/IJAOM.2009.030671.

50. Poduval P.S., Pramod V., Raj J. (2015) Interpretive structural modeling (ISM) and its application in analyzing factors inhibiting implementation of total productive maintenance (TPM).

International Journal of Quality \& Reliability Management, vol. 32, no 3, pp. 308-331. DOI: 10.1108/IJQRM-06-2013-0090.

51. Raj T.; Shankar R.; Suhaib M. (2008) An ISM approach for modelling the enablers of flexible manufacturing system: The case for India. International Journal of Production Research, vol. 46, no 24, pp. 6883-6912. DOI: 10.1080/00207540701429926.

52. Nazarov D.M. (2016) Theoretical and methodological foundations of fuzzy-multiple assessment of implicit factors of organization management. Doctoral thesis. Saint-Petersburg (in Russian).

53. Russell S., Norvig P. (1995) Artificial intelligence: A modern approach. Prentice Hall.

54. Suwignjo P., Bititci U.S., Carrie A.S. (2000) Quantitative models for performance measurement system. International Journal of Production Economics, vol. 64, no 1-3, pp. 231-241.

DOI: $10.1016 /$ S0925-5273(99)00061-4.

55. Tian J. (2005) Identifying direct causal effects in linear models. Proceedings of the 20th National Conference on Artificial Intelligence (AAAI-05), Pittsburgh, Pennsylvania, 9-13 July 2005, vol. 1, pp. 346-352.

56. Agrawal R., Srikant R. (1994) Fast algorithms for mining association rules in large databases. Proceedings of the 20th International Conference on Very Large Data Bases, Santiago, Chile, 12-15 September 1994, pp. 487-499.

\section{About the author}

\section{Dmitry M. Nazarov}

Dr. Sci. (Econ.);

Head of the Department of Business Informatics, Institute of Management and Information Technologies, Ural State University of Economics, 62, 8 Marta Street, Yekaterinburg 620144, Russia;

E-mail: slup2005@mail.ru 


\title{
Building the uncertainty indicator regarding adjustment of the Bank of Russia's monetary policy relying on news sources
}

\author{
Elizaveta A. Golovanova
}

E-mail: golovanova-ea@ranepa.ru

\section{Andrei V. Zubarev}

E-mail: zubarev@ranepa.ru

Russian Presidential Academy of National Economy and Public Administration

Address: 82, build. 1, Prospect Vernadskogo, Moscow 119571, Russia

\begin{abstract}
Text analysis with machine learning support can be implemented for studying experts' relations to the Bank of Russia. To reach macroeconomic goals, the communication policy of the bank must be predictable and trustworthy. Surveys addressing this theme are still insufficient compare to the theoretical studies on the subject of other bank tools. The goal of this research is to analyze the perception of uncertainty by economic agents. For that purpose, we built an uncertainty indicator based on news sources from the Internet and on textual analysis. The dynamics of the indicator reflect unexpected statements of the Bank of Russia and events affecting monetary policy. Financial theory links monetary policy and stock prices, so we used this fact to examine the impact of the uncertainty indicator on the MOEX and RTS indices. We tested the hypothesis that our indicator is significant in GARCH models for chosen financial series. We found out several specifications in which our indicator is significant. Among the specifications considered, the uncertainty indicator contributes the most to explaining variances of the RTS index. The obtained uncertainty indicator can be used for forecasting of different macroeconomic variables.
\end{abstract}

Key words: uncertainty; Bank of Russia; news sources; data analysis; machine learning; word cloud; stock index.

Citation: Golovanova E.A., Zubarev A.V. (2020) Building the uncertainty indicator regarding adjustment of the Bank of Russia's monetary policy relying on news sources. Business Informatics, vol. 14, no 4, pp. 62-75. DOI: 10.17323/2587-814X.2020.4.62.75 


\section{Introduction}

$\mathrm{O}$ $\mathrm{n}$ the one hand, expectations of economic agents are one of the policy references for central banks, but on the other hand they also influence the effectiveness of their policy. Such expectations can be traced following the opinions of experts published in the mass media on the issue of central bank policy. That news can reflect the perception by economic agents of certain central bank policy measures, as well as influence this perception [1, 2]. In this study, we are making an attempt to quantify these expectations.

Machine learning methods help to process large amounts of information, significantly simplify textual analysis, and allow us to get transparent results in aggregated form. Nowadays, machine learning methods for news analysis have a wide range of applications and can be found in a variety of areas. Machine learning is used to analyze the texts of news sources to predict an election victory [3] and to detect fake news [4]. Comments analysis from financial microblogs and Twitter is used to predict the volatility of securities [5]. The tourism sector, where continuous improvement of service is required (e.g. the restaurant and hotel business), actively uses the analysis of comments and reviews about their businesses on websites $[6,7]$.

Analysis of news source texts can be useful in the context of reviewing research on the policies of central banks. Blinder et al. [8] have shown that the Central Bank's communication policy is a powerful tool, as it can improve the predictability of monetary policy and has the potential to achieve macroeconomic goals such as low and stable inflation.

By processing information from news sources using machine learning methods, it is possible to estimate the level of uncertainty in the expec- tations of economic agents at each moment. For example, uncertainty in macroeconomic news can have a negative impact on financial markets $[1,2]$. However, there is empirical evidence that in some countries monetary authorities are responding to investor sentiment. For example, the study [9] states that the Reserve Bank of Australia lowers the interest rate in response to a higher level of uncertainty amongst experts from the Shadow Board ${ }^{1}$.

Hansen and McMahon [10] investigated how news released by the Federal Open Market Committee influence market and real economic variables. In this study, 76 macroeconomic variables were examined. Using FAVAR models, the authors found out that shocks to forward guidance are more important than the FOMC communication of current economic conditions in terms of their effects on certain market variables, such as stock indices, and macroeconomic variables, such as unemployment and CPI.

Cieslak and Schrimpf [11] calculated the importance of non-monetary news of Central Banks reports. The authors found a significant difference in the news content depending on the communication channel used by central banks. According to their estimates, non-monetary news prevails in about $40 \%$ of FED and ECB statements, and in the context of press conference news this share is especially high.

Despite central bank communication becoming an integral component of the set of tools for conducting monetary policy, the range of research on this topic is still quite limited compared to other macroeconomic policy tools. The goal of this study is to describe the economic agents' perception of uncertainty in relation to Bank of Russia policy, and analyze its impact on financial market indicators.

\footnotetext{
1 The Shadow Board brings together professional macroeconomists who make recommendations for interest rates changes in the week before each meeting of the actual Reserve Bank Board.
} 
To achieve this goal, we construct an indicator of uncertainty in relation to the policy of the Bank of Russia based on news from the Internet and test the hypothesis of the indicator's significance for explaining the volatility of Moscow Stock Exchange indices returns.

\section{Construction of an uncertainty indicator}

In this study, we considered the news from leading Russian media writing about the economy: RBC, Gazeta.Ru, Finmarket, TASS and Kommersant. The data covers the period from 01.01.2014 to 31.05.2020. The following words and phrases were used as queries for the archival search: "Bank of Russia," "Nabiullina," "CB of RF." These requests were formed based on their popularity and direct relationship to the Bank of Russia. The TASS news could not be searched by archives, so it was searched by headlines. Accordingly, the list of keywords was expanded with the following words: "Central Bank," "rouble exchange rate," "Yudaeva," "Skorobogatova," "Tulin," "Shvetsov," "vice chairman of CB." Headlines were searched only for the "politics" and "economics" categories. After processing all sources, 22,156 articles were received. Figure 1 shows the monthly dynamics of the number of all news items.
Figure 2 shows a diagram of the number of articles in each source. The leading position is occupied by RBC, and the lowest - by TASS. Data are unequally distributed by sources, and this is taken into account when constructing the uncertainty indicator.

To build the uncertainty indicator, it is necessary to find out what topics are contained in the collected corpus of texts in order to select the ones that directly relate to the economic policy of the Bank of Russia. Before this, the data needs to be pre-processed. First, we split each text into a list of words and symbols (tokenization). Then we reduced all words to lowercase so that "CB" and "cb" are not considered as different words. To decrease the variety of words, lemmatization is required: we put all nouns in the nominative case and made them singular, all adjectives in the masculine gender and made them singular as well, put verbs in the infinitive form, and so on. The Python 3 package pymorphy was used for this purpose. Punctuation marks and numbers have been removed from the texts, because they do not contain any useful information without context. Also, conjunctions, prepositions, and particles that are quite common in the text, but useless separately from it, were excluded from the list of words. With such text processing, it is assumed that the word order in the text does not change

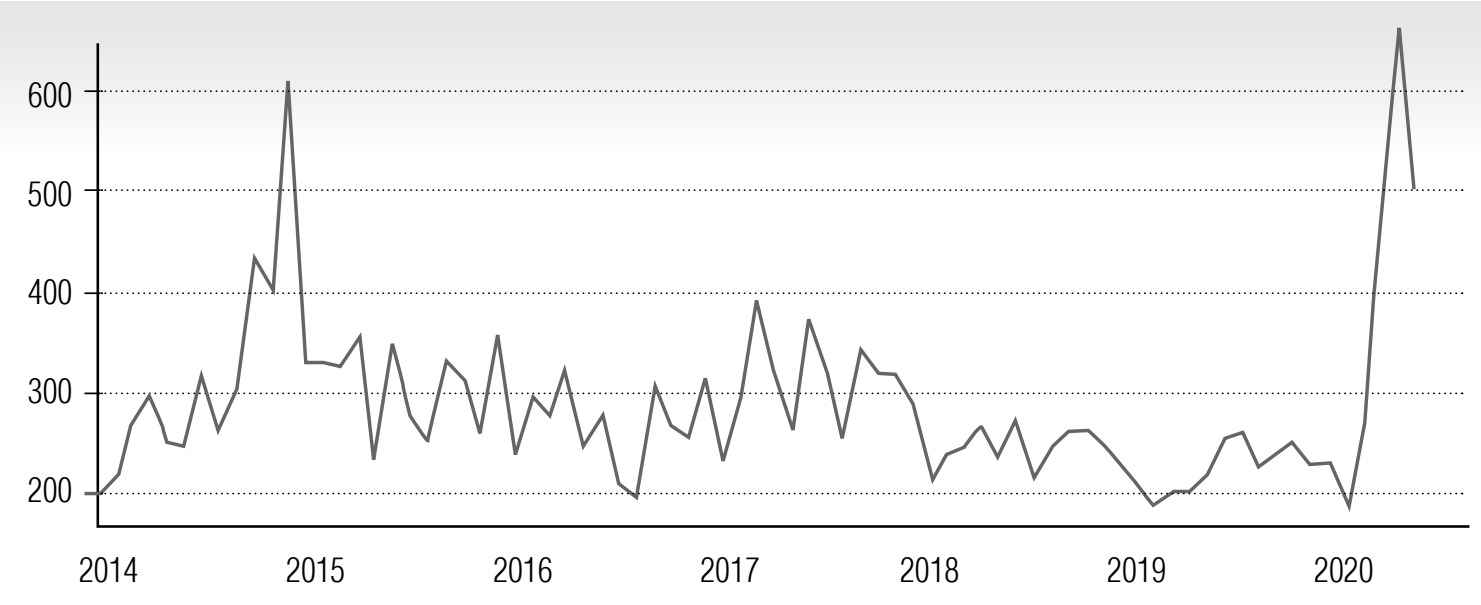

Fig. 1. Monthly dynamics of news by queries 


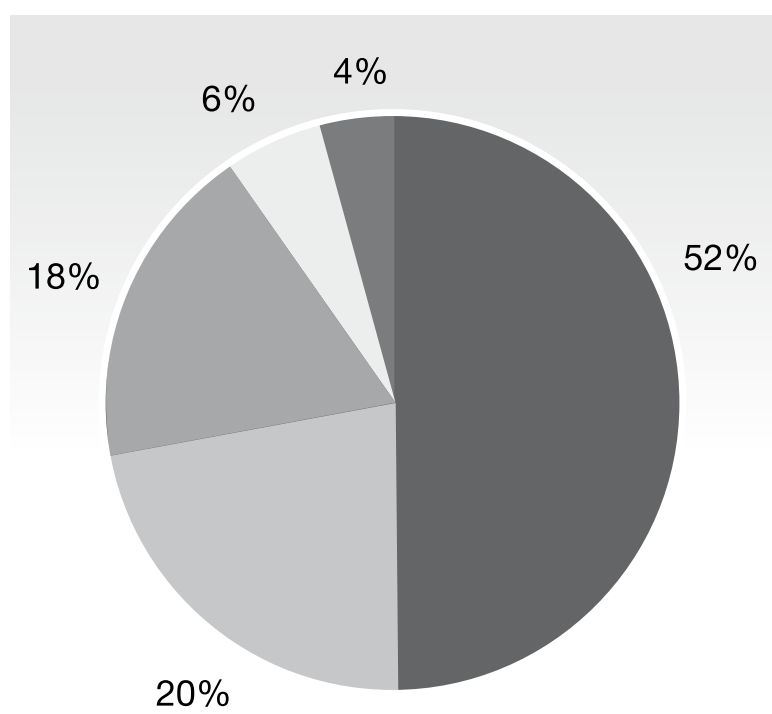

RBC
Kommersant
Gazeta.Ru
Finmarket
TASS

Fig. 2. Number of articles from each source

its sentiment. This method is named a "bag of words." Each text represented a vector showing how many times each word from the dictionary appears in it. The resulting number of unique words was 269.611. However, this list contained words that occur only once in the text, or, conversely, too often. Therefore, we filtered rare and frequently occurring words, assuming that the word should appear in the total array of texts more than three times, but not more often than in $40 \%$ of the texts. The resulting number of unique words after filtering was 52.073.

Afterwards the resulting list of words was divided into thematic lists in order to visualise them using the word cloud and to determine what issues are covered in articles for the queries selected. It is worth noting that each text from the text corpus can have several topics, despite the fact that they were received by queries using the same keywords. Thus, it would be incorrect to assign each text to one specific topic, and it is necessary to use a different approach.

A hierarchical Bayesian model was constructed to identify topics found in texts. On the first level we set a prior parameter that determines the number of the themes splitting $(T)$. On the second level there is a multinomial $^{2}$ variable with a prior Dirichlet distribution which determines the probability of a word's relation to a predetermined theme in the document. This model is also called the latent Dirichlet allocation $(L D A)$. The formal definition is as follows: a dictionary is a list of words that are pre-filtered by the frequency of occurrence in the text $\{1, \ldots, V\}$. Each word is a vector $w, w_{i}\{1, \ldots, V\}$ where exactly one component is equal to 1 . Each text is a sequence of $N$ words $w$. We consider a corpus of $M$ texts $D=\left\{w_{d} \mid=1 . . M\right\}$.

Assume that the number of topics $T$ is set exogenously. Each document has a distribution of topics within it $\theta \sim p(T \mid d)$. Next, the probability that a word appears in the document is calculated. One of the topics is selected randomly. Each word is included in the selected document based on the word distribution $\beta \sim p(w \mid T)$.

Then we form $T$ hypotheses that the word $w$ in document $d$ if it belongs to topic $t_{1}$ or topic $t_{2}$, and so on up to topic $T$. The total probability of the word appearing in the document can be calculated using the formula:

$$
\begin{aligned}
D_{i}(w \mid T)= & \sum_{t \in T} p(w \mid T) \cdot p(T \mid d)= \\
& =\sum_{t \in T} \theta \cdot \beta .
\end{aligned}
$$

Using the latent Dirichlet allocation algorithm, all words were divided into seven top-

\footnotetext{
2 A document is a sequence of events in the multinomial model. Each event is considered as a random selection of one word from the "bag of words"
} 
ics $^{3}$ : money and payment systems, financial regulation, social sphere, international relations, stock market, economic forecasts, and property transactions (Table $\left.1^{4}\right)$. Several iterations were made (different values of $T$ were tried) until clusters of words were formed that could be unambiguously divided into topics. The names of these topics were set post factum based on these lists of words. It is also interesting to look at what percentage of topics each source contains. To do this, we recalculate separately the words within each source that relate to each topic. The results are shown in Figure 3. It can be seen that economic forecasts take up a significant part in each source (13-18\%).
Insofar as the main interest of this study is the economic policy of the Bank of Russia and its perception by economic agents, the topic related to economic forecasts was selected and visualized (Figure 4).

To measure the uncertainty of economic policy, Baker, Bloom, and Davis [12] employed additional criteria to filter out texts from the corpus created by the use of keywords. This approach helped to identify texts that contain words related to the economy and uncertainty, as well as to take into account several terms related to economic policy. Following the experience of the authors and relying on the visualization presented above, the texts that do not contain the words "fore-

\section{List of topic names and keywords}

Table 1.

\begin{tabular}{l|l}
\multicolumn{1}{c|}{ Topic name } & \multicolumn{1}{c}{ Keywords } \\
$\begin{array}{l}\text { Money and payment } \\
\text { systems }\end{array}$ & $\begin{array}{l}\text { stock, asset, investor, bargain, security, bond, million, investment, instrument, sberbank, } \\
\text { large, cryptocurrency, sale, capital, project, shareholder, valuable, gold, exchange, group }\end{array}$ \\
\hline Financial regulation & $\begin{array}{l}\text { system, organization, instrument, banking, customer, million, credit, report, law, information, } \\
\text { license, decision, amount, operation, claim, card, activity, regulator, number, case }\end{array}$ \\
\hline Social sphere & $\begin{array}{l}\text { person, project, thousand, job, region, business, work, nizhegorodsky, most, new, } \\
\text { development, city, region, other, million, center, very, country, money, place }\end{array}$ \\
\hline International relations & $\begin{array}{l}\text { president, country, sanction, government, head, putin, announce, vladimir, power, question, } \\
\text { minister, attitude, against, economic, say, council, state, ukraine, federation, word }\end{array}$ \\
\hline Stock market & $\begin{array}{l}\text { currency, dollar, oil, week, foreign exchange, level, analyst, rate, decline, barrel, index, } \\
\text { investor, fall, petroleum, quote, mark, American, factor, expect, country }\end{array}$ \\
\hline Economic forecasts & $\begin{array}{l}\text { rate, economy, inflation, level, decline, economic, forecast, key, head, nabiullin, policy, } \\
\text { consider, regulator, increase, declare, say, decision, situation, elvira, estimate }\end{array}$ \\
\hline Property transactions & $\begin{array}{l}\text { Ioan, rate, credit, mortgage, thousand, hypothecate, million, borrower, lending, program, } \\
\text { business, region, income, client, make up, housing, amount, condition, real estate, oblast }\end{array}$ \\
\hline
\end{tabular}

\footnotetext{
3 The gensim library is used to implement the latent Dirichlet allocation algorithm in Python 3

4 The table shows the first 20 words generated by the LDA algorithm for each topic

5 As the texts are in Russian, all words on the picture are nothing else but the translation
} 


\begin{tabular}{|c|c|c|c|c|c|c|c|}
\hline 0.36 & 0.20 & 0.18 & 0.17 & 0.09 & 0.08 & 0.07 & A) Distribution of topics within RBC \\
\hline 0.36 & 0.21 & 0.10 & 0.10 & 0.10 & 0.09 & 0.04 & B) Distribution of topics within TASS \\
\hline 0.25 & 0.23 & 0.14 & 0.14 & 0.09 & 0.08 & 0.07 & C) Distribution of topics within Gazeta.Ru \\
\hline 0.24 & 0.22 & 0.15 & 0.15 & 0.09 & 0.08 & 0.07 & D) Distribution of topics within Kommersant \\
\hline 0.38 & 0.22 & 0.13 & 0.13 & 0.07 & 0.06 & 0.03 & E) Distribution of topics within Finmarket \\
\hline 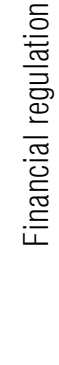 & 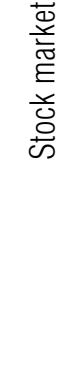 & 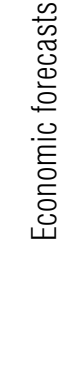 & 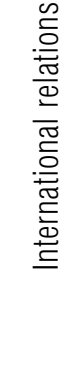 & 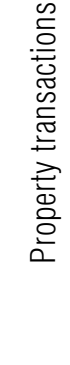 & 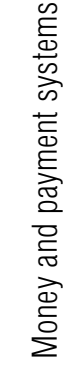 & 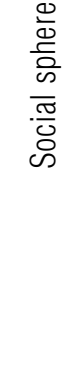 & \\
\hline
\end{tabular}

Fig. 3. Distribution of topics within news sources

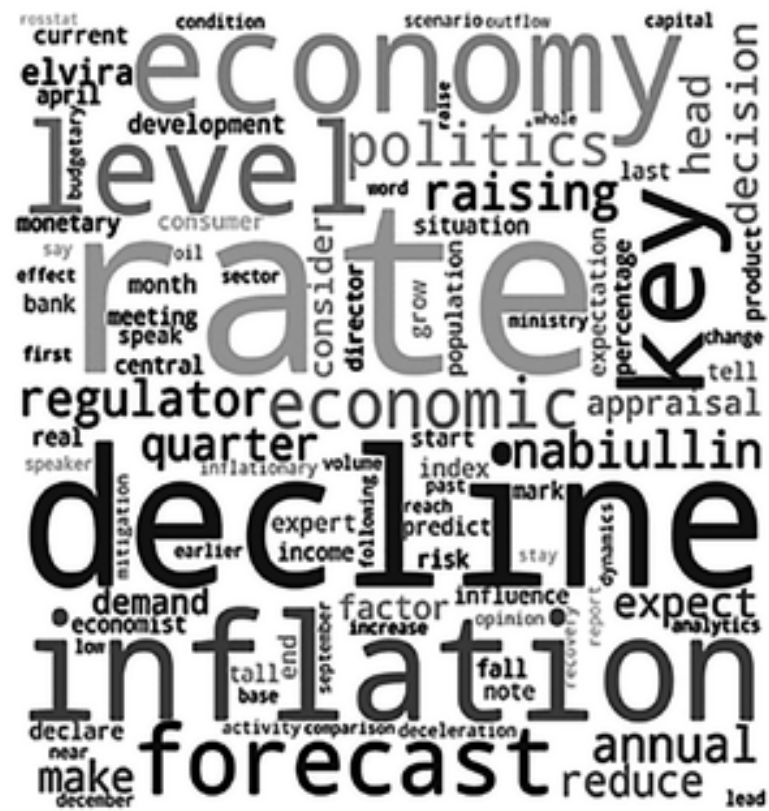

Fig. 4. Visualization of the "economic forecasts" topic (the larger the font size, the more often the word appears in texts) ${ }^{5}$ cast," "risk," "scenario" or "expectation," as well as their derivatives were eliminated. Further, texts that do not contain the word "economy" and its derivatives were excluded from the resulting text array. Finally, texts that are not directly related to the Bank of Russia's policy were eliminated, according to the words "income," "inflation," "rate" and their derivatives. It should be noted that the order of filtering texts by keywords does not matter, but selected texts have to contain at least one word from all three groups of keywords. According to the results of the dropout, 4,691 texts remained, which is about $21 \%$ of the total text corpus.

In addition, in the work of Baker, Bloom, and Davis [12] a certain correction controlling the number of articles in each source was made. Authors divided the number of articles with keywords by the total number of articles for the period and for each source. Then, within 


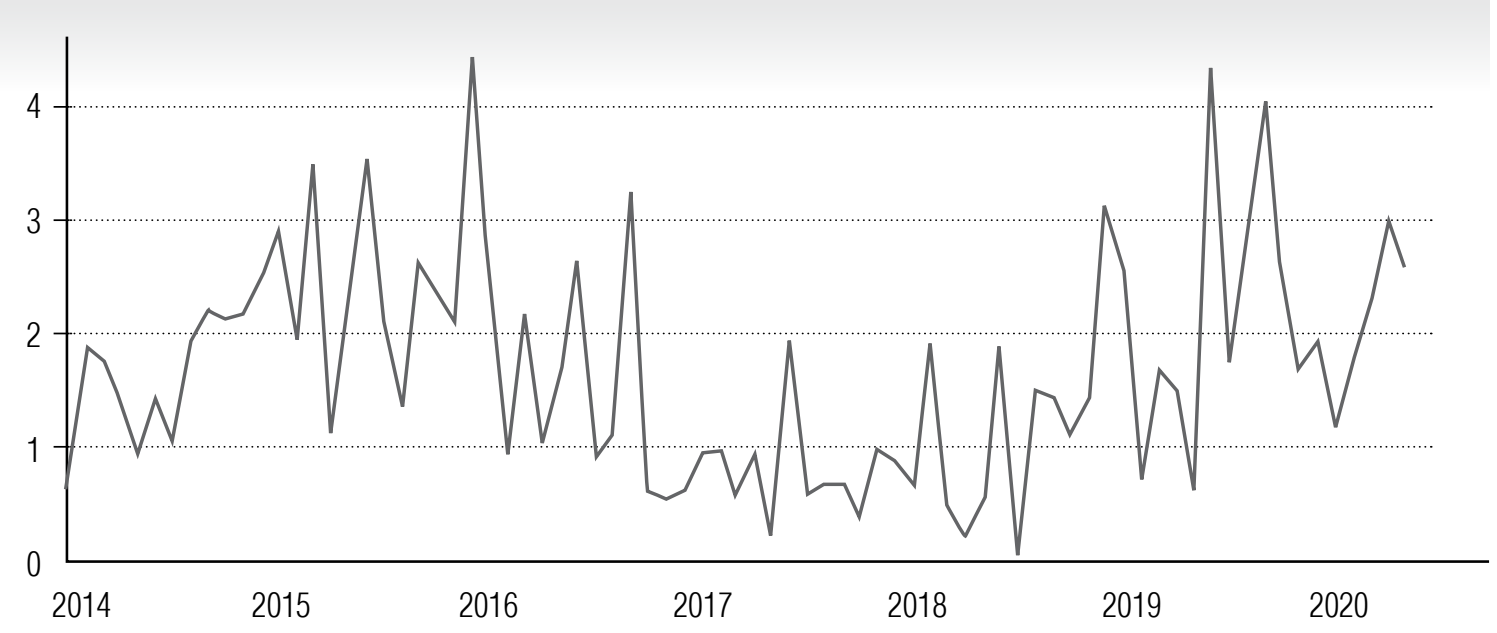

Fig. 5. Dynamics of the uncertainty indicator

each source standardisation was made. In other words, the mean value was subtracted, and the series was divided by the standard deviation. Thereafter, the data was combined into a single array and was summed up over the period. Finally, the array was scaled so that the minimum value is zero.

Since the distribution of articles by source was unequal in the afore-mentioned study, we applied a similar correction. It is important to take this correction into account, because each source reviews the news with different frequency and, furthermore, may have a biased attitude to some issues related to the policy of the Bank of Russia, as well as may cover this topic with different intensity.

The indicator does not reflect the attitude to the Central Bank of Russia in terms of "good" and "bad," but shows an increase of the "discussion" around the Bank of Russia's policy in the context of a certain set of topics related to uncertainty. Thereby it reflects an increase or decrease in the interest in monetary policy. Thus, the constructed indicator reflects the perception of uncertainty in the Bank of Russia's policy by the expert community. It is worth mentioning that this perception is influenced not only by direct actions of the Central Bank, but also by various economic and political shocks, such as sanctions that were imposed on Russia more than once during the period under consideration. The resulting indicator is shown in Figure 5.

In Figure 5 we can observe three periods with an increase in the value of indicator: in 2015, 2016, and 2019. The first increase occurred on January 2015, when the Bank of Russia unexpectedly lowered the key rate [13] after its sharp increase in December 2014 [14], when strict measures were undertaken to stabilise the situation in the foreign exchange market, which arose due to a combination of negative economic factors (oil prices, sanctions, speculative component in the financial market). At the same time, the increase of the uncertainty indicator was observed throughout the second half of 2014. That corresponds to the dynamics of the exchange rate and the overall increase in uncertainty. In March 2015, the Bank of Russia met the market's expectations for monetary policy easing [15], but again we can see the peak of the indicator, which corresponds to the animated debates about the regulator's further actions. At the end of June 2015, inflation decreased dramatically, and the Central Bank lowered the key rate [16]. This was completely at 
odds with the forecasts of experts and the comments of the Bank of Russia. At that moment, we can observe high values of the uncertainty indicator, comparable to the peak in March. In September, October and December 2015, there was much discussion about the destabilization of the situation in the foreign exchange market due to the rise in oil prices and the key rate being unchanged. Further, rate constancy was predictable in September and October, but not in December, when the Bank of Russia promised to reduce the key rate by $0.5 \mathrm{pp}$. [17]. As a result, we can observe a new peak of the indicator in December 2015, which is slightly larger than the values in June and March.

The Central Bank of the Russian Federation also refused to lower the key rate in March 2016, which was in line with the forecasts of many analysts [18]. In June [19] and September [20] 2016, economic sanctions were strengthened, and the key rate was lowered, which led to another increase in uncertainty about the policy of the Bank of Russia.

Since September 2018, the Central Bank had started raising the key rate [21]. By the end of that year, the Bank of Russia announced the resumption of currency purchases from January 2019 and a new increase in the key rate [22], which also came as a surprise to many experts and reflected the growth of the uncertainty indicator. In June 2019, an economic forum took place in St. Petersburg (accompanied by a number of negative political news, such as the ongoing imprisonment of Michael Calvey). The Bank of Russia also lowered the key rate for the first time after its gradual increase since September 2018 [23]. At that moment, there was a sharp increase in the dynamics of the indicator, which corresponds to a higher degree of uncertainty in the economy, that is also transferred to uncertainty in economic policy. The Bank of Russia also commented that the key rate was likely to be lowered during the next meeting, which happened in July and did not cause a surge of uncertainty. In September, the rate was lowered for the third time during the year [24], but this was associated with a new round of economic sanctions, which eventually led to another peak of the indicator.

The current situation differs significantly from the considered peaks of the uncertainty indicator. The coronavirus pandemic has led to a global economic crisis. The decline in economic activity and the downward shift in the aggregate demand curve also affected oil prices, which led to a decrease in the rouble exchange rate. However, maintaining the exchange rate in this case does not make sense precisely because of the nature of the global shock, against which economic policy should be addressed. In this regard, many experts expected softening (or at least not tightening) of monetary policy in order to stimulate aggregate demand. Thus, on April 24, 2020, the Bank of Russia decided to reduce the key rate by 0.5 pp. It is clear that although this decision slightly increased the level of uncertainty, the indicator stayed at a moderate level. In early May, uncertainty began to subside due to the strengthening of the rouble and rising oil prices. However, by the end of May, it was actively discussed that the Central Bank was going to significantly reduce the key rate in June [25]. As a result, dynamics of the constructed indicator reflect the events that took place in the economy; its high values correspond to the increase of uncertainty in terms of perception of the Bank of Russia's policy and falls within the economic logic.

\section{The models with the indicator of uncertainty}

Uncertainty in monetary policy can affect the volatility of the exchange rate, which is one of the factors of stock price movement in the framework of financial theory as extended model of the CAPM. In this regard, it is interesting to analyze the impact of the constructed indicator on the dynamics of market indices.

We considered models with MOEX and RTS stock indices for the period from 01.01.2014 to 31.05.2020. The hypothesis of significance of the 
constructed indicator in terms of the impact on the variance of the financial market was tested using GARCH models. To take into account more information, we used the two-week frequency indicator (instead of the monthly version). Figure 6 shows that the two-week uncertainty indicator generally has dynamics similar to its monthly counterpart. However, the considered peaks are sometimes higher, since they contain information on the events described above and are not smoothed out by other observations within a month.

Firstly, models without the indicator were selected to describe the volatility of each index, then the indicator was added to the indices' variance equations. The $\operatorname{GARCH}(\alpha, \beta)$ process with the mean $\operatorname{ARMA}(p, q)$ equation is generally represented as follows:

$$
\begin{gathered}
y_{t}=c+\sum_{s=1}^{k} p_{s} y_{t-s}+\sum_{s=1}^{l} q_{s} \varepsilon_{t-s}, \\
\varepsilon_{t}=\sqrt{h_{t}} \cdot v_{t}, v_{t} \sim \text { i.i.d. } N(0,1), \\
h_{t}=\omega+\sum_{j=1}^{m} \alpha_{j} \varepsilon_{t-j}^{2}+\sum_{j=1}^{r} \beta_{j} h_{t-j},
\end{gathered}
$$

where $h_{t}$ - conditional variance;

$c-$ constant in the mean equation;

$\omega-$ constant in the variance equation; $p_{s}$ - lags coefficients in the mean equation;

$q_{s}-$ residuals lags coefficients in the mean equation;

$\alpha_{j}$ - lags coefficients in the variance equation;

$\beta_{j}-$ residuals lags coefficients in the variance equation;

$y_{t}-$ current value of the series.

Pearson's chi-squared test was used to analyze whether the selected distributions fit the innovations in models with the uncertainty indicator. To test this hypothesis, the sample is divided into several intervals. Let $n_{i}$ be the number of elements that fall into the $i$-th interval, and the probability of a random variable falling into the $i$-th interval is $p_{i}$. The deviation of the sample distribution from the theoretical one is determined by the formula:

$$
\sum_{i=1}^{k} \frac{\left(n_{i}-n p_{i}\right)^{2}}{n p_{i}} .
$$

The sum has an asymptotic $\chi^{2}$ distribution with degree of freedom $f=k-c-1$, where $c$ is the number of model parameters determined from the sample. If $\chi^{2}$ is less than the $\chi_{1-p}^{2}(f)$ from the table of critical distribution values of $\chi^{2}$ distribution, then the null hypothesis is not rejected.

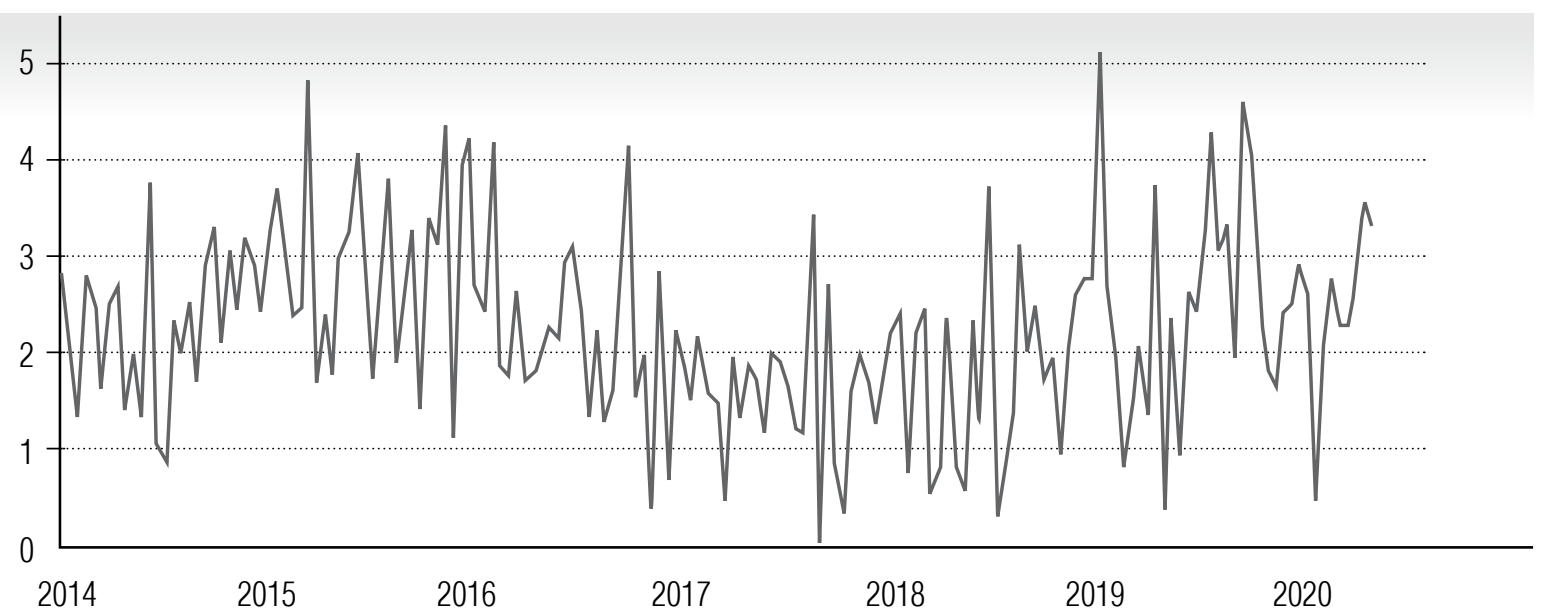

Fig. 6. Dynamics of the two-week uncertainty indicator 


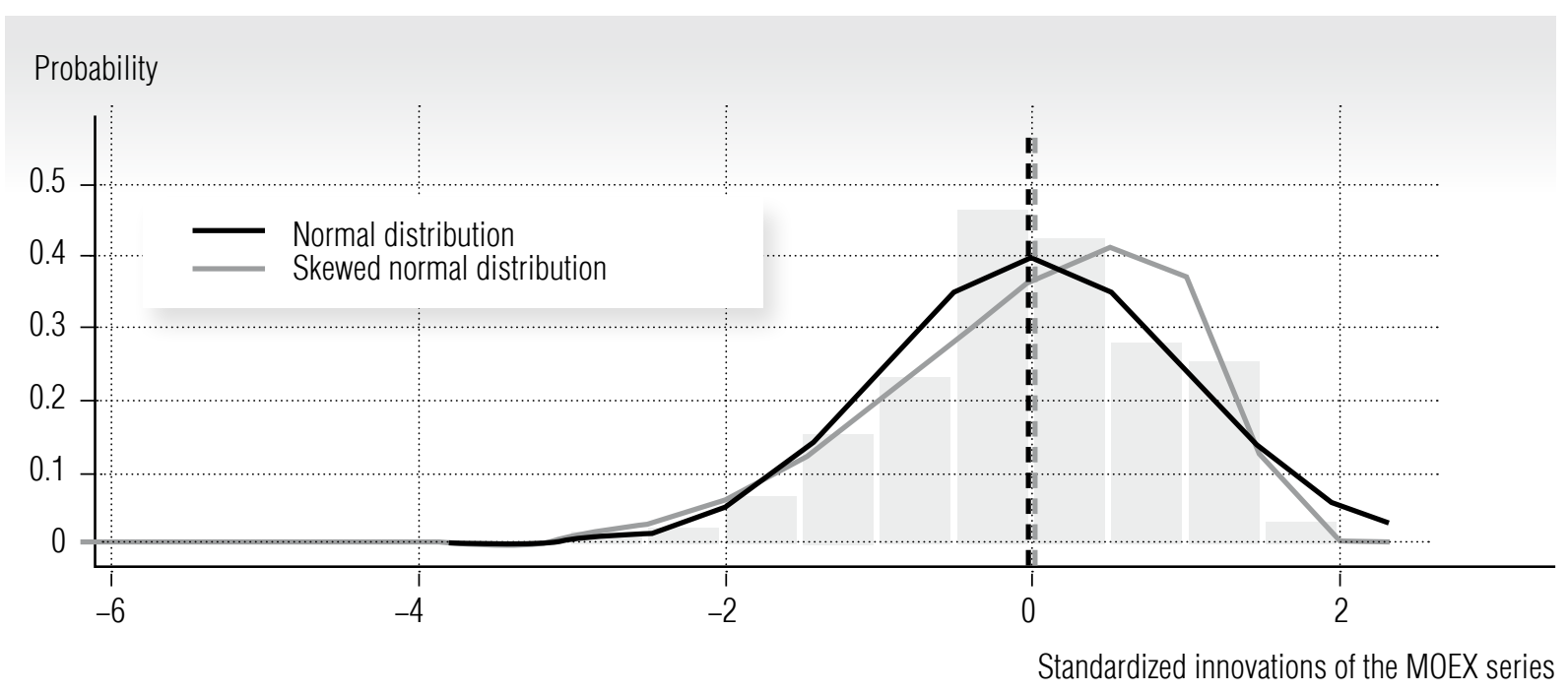

Fig. 7. Comparison of standardized innovations of the MOEX series with normal distribution and skewed normal distribution

Empirically, the $\operatorname{GARCH}(1,1)$ model was selected for the MOEX stock index with the $\operatorname{ARMA}(1,1)$ mean equation and the skewed normal distribution of innovations, i.e. $v_{t} \sim$ i.i.d. $S N(0,1)$. A comparison of the normal distribution and the skewed normal distribution of standardized innovations is illustrated in Figure 7. It is noticeable that the distribution of innovations is asymmetric, that should be taken into account when estimating the model.

To confirm the selected distribution of innovations, the Pearson's test was used (Table 2).

\section{Results of the Pearson's test for the MOEX model with adding the uncertainty indicator}

\begin{tabular}{c|c|c|c} 
& Groups & Statistics & $p$-value \\
\hline 1 & 20 & 21.95 & 0.2867 \\
\hline 2 & 30 & 28.00 & 0.5179 \\
\hline 3 & 40 & 34.54 & 0.6733 \\
\hline 4 & 50 & 38.00 & 0.8725 \\
\hline
\end{tabular}

Table 2.
The $p$-values are always higher than the significance level $\alpha=0.05$, so we can conclude that the distribution of innovations for this model with addition of the uncertainty indicator is selected adequately. The results of GARCH models for the MOEX stock index are presented in Table 3.

GARCH(1,1) models with ARMA $(1,1)$ and skewed normal distribution of innovations were also chosen to describe the volatility of the RTS stock index on two-week data. Figure 8 shows that the distribution of innovation is also skewed to the left.

The selected model with the indicator was also tested to confirm the selected distribution of innovations according to the Pearson's test. The results are presented in Table 4.

The $p$-value is always higher than the significance level $\alpha=0.05$, so the distribution of innovations in the model for RTS with the addition of the uncertainty indicator is selected adequately, according to the Pearson test. The results of GARCH models for the RTS stock index are shown in Table 5. 
Comparison of GARCH models for the MOEX index with and without the uncertainty indicator on two-week data

\begin{tabular}{|c|c|c|}
\hline Coefficients & Model with uncertainty indicator & Model without uncertainty indicator \\
\hline$c$ & $\begin{array}{l}0.0046^{\star \star \star} \\
(-0.0002)\end{array}$ & $\begin{array}{l}0.0046^{\star \star *} \\
(-0.0001)\end{array}$ \\
\hline$p$ & $\begin{array}{c}0.8545^{\star \star \star} \\
(-0.039)\end{array}$ & $\begin{array}{l}0.8232^{\star \star \star} \\
(-0.0528)\end{array}$ \\
\hline$q$ & $\begin{array}{c}-0.9999^{\star * \star} \\
(-0.0024)\end{array}$ & $\begin{array}{c}-1^{\star \star \star} \\
(-0.0023)\end{array}$ \\
\hline$\omega$ & $\begin{array}{c}0 \\
(-0.0000)\end{array}$ & $\begin{array}{c}0.0003 \\
(-0.0002)\end{array}$ \\
\hline$\alpha$ & $\begin{array}{c}0.1275 \\
(-0.0828)\end{array}$ & $\begin{array}{l}0.1016^{\star *} \\
(-0.0414)\end{array}$ \\
\hline$\beta$ & $\begin{array}{c}0.3643 \\
(-0.2804)\end{array}$ & $\begin{array}{l}0.7009^{\star \star \star} \\
(-0.1639)\end{array}$ \\
\hline Uncertainty indicator & $\begin{array}{l}0.0003^{\star \star} \\
(-0.0001)\end{array}$ & \\
\hline $\begin{array}{l}\text { Coefficient of skewness } \\
\text { of the error distribution }\end{array}$ & $\begin{array}{l}0.5681^{\star * \star} \\
(-0.1129)\end{array}$ & $\begin{array}{l}0.6124^{\star * *} \\
(-0.1255)\end{array}$ \\
\hline Schwartz information criterion & -3.7484 & -3.7417 \\
\hline
\end{tabular}

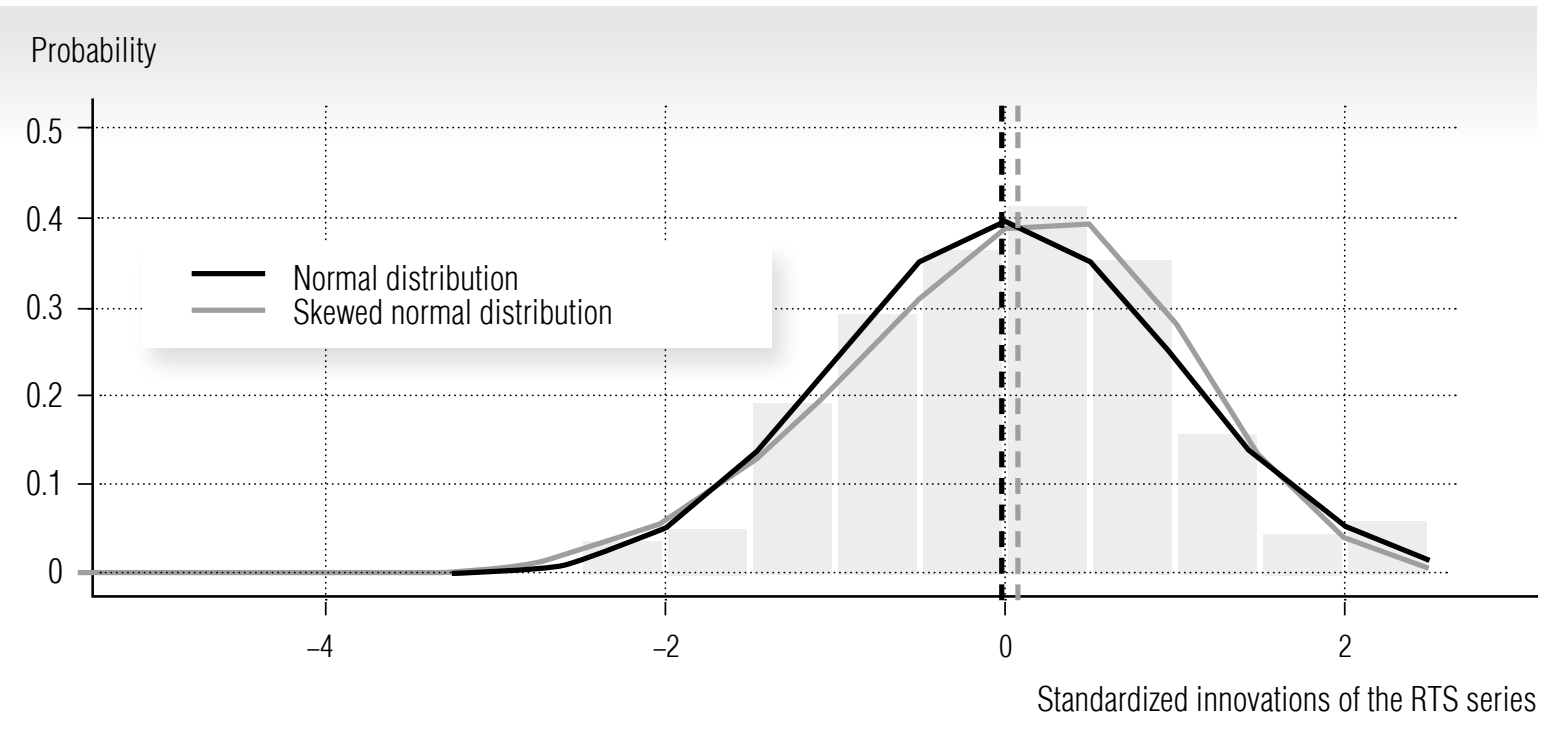

Fig. 8. Comparison of standardised innovations of the RTS series with normal distribution and skewed normal distribution 
Table 4. tor is added. The coefficient of the uncer-

Results of the Pearson's test for the RTS model

with the uncertainty indicator

\begin{tabular}{c|c|c|c} 
& Groups & Statistics & $p$-value \\
\hline 1 & 20 & 24.42 & 0.1805 \\
\hline 2 & 30 & 33.56 & 0.2559 \\
\hline 3 & 40 & 43.43 & 0.2881 \\
\hline 4 & 50 & 53.43 & 0.3079 \\
\hline
\end{tabular}

\section{Analysis of models}

with the uncertainty indicator

Tables 3 and 5 show that the Schwartz information criterion decreases when the indica- tainty indicator in Table 3 has a positive sign, which indicates that the MOEX variance goes up by about 0.0003 as the uncertainty indicator increases by one. Although the uncertainty indicator is significant at $5 \%$ in this specification, its impact on the stock market is limited.

In Table 5, the information criterion also decreased when the indicator was added. The coefficient of the uncertainty indicator is significant at the level of $5 \%$ and has a positive sign. This indicates that RTS variance increases by about 0.0011 as the uncertainty indicator increases by one. This result is significantly higher than for the MOEX, which may suggest that the uncertainty indicator has a greater impact on the RTS's currency component than on shares.

Comparison of GARCH models for the RTS index with and without the uncertainty indicator on two-week data

\begin{tabular}{|c|c|c|}
\hline Coefficients & Model with uncertainty indicator & Model without uncertainty indicator \\
\hline$c$ & $\begin{array}{c}0.0010 \\
(-0.0044)\end{array}$ & $\begin{array}{c}0.0004 \\
(-0.0053)\end{array}$ \\
\hline$p$ & $\begin{array}{c}-0.7837^{\star \star \star} \\
(-0.1154)\end{array}$ & $\begin{array}{c}-0.8065^{\star \star \star} \\
(-0.1104)\end{array}$ \\
\hline$q$ & $\begin{array}{l}0.8163^{\star * \star} \\
(-0.0882)\end{array}$ & $\begin{array}{l}0.8356^{\star \star \star} \\
(-0.0899)\end{array}$ \\
\hline$\omega$ & $\begin{array}{c}0 \\
(-0.0000)\end{array}$ & $\begin{array}{c}0.0003 \\
(-0.0002)\end{array}$ \\
\hline$\alpha$ & $\begin{array}{c}0.0369 \\
(-0.0784)\end{array}$ & $\begin{array}{l}0.0748^{\star *} \\
(-0.0375)\end{array}$ \\
\hline$\beta$ & $\begin{array}{c}0.2438 \\
(-0.2455)\end{array}$ & $\begin{array}{l}0.8529^{\star \star \star} \\
(-0.0667)\end{array}$ \\
\hline Uncertainty indicator & $\begin{array}{l}0.0011^{\star *} \\
(-0.0005)\end{array}$ & \\
\hline $\begin{array}{l}\text { Coefficient of skewness } \\
\text { of the error distribution }\end{array}$ & $\begin{array}{l}0.7971^{\star * *} \\
(-0.1051)\end{array}$ & $\begin{array}{l}0.7329^{\star * *} \\
(-0.0869)\end{array}$ \\
\hline Schwartz information criterion & -2.7201 & -2.7038 \\
\hline
\end{tabular}




\section{Conclusion}

In this study we constructed the uncertainty indicator that reflects the experts' perception of the Bank of Russia's policy. To build the indicator, more than 22,000 articles from five news sources were used. Those texts were preprocessed, and all words collected from them were divided into topics using the latent Dirichlet allocation algorithm. The words from the key topic were visualized using Word Cloud. In addition, normalization on the number of articles in the sources was made. The dynamics of the uncertainty indicator were juxtaposed with the key events and statements of the Bank of Russia.

To check the validity of the constructed indicator, we employed GARCH models that explain the volatility of the MOEX and RTS stock indi- ces based on two-week data. The coefficients of the uncertainty indicator obtained were significant in the $\operatorname{GARCH}(1,1)$ models with the $\operatorname{ARMA}(1,1)$ mean equation and a skewed error distribution for describing both MOEX and RTS volatility.

The indicator we constructed can be used for forecasting individual macroeconomic variables and conducting monetary policy by the Bank of Russia, since it reflects the expectations of economic agents. A possible direction for future research is the construction of indicators of exchange rate and inflation expectations.

\section{Acknowledgement}

The article was written on the basis of the RANEPA state assignment research programme.

\section{References}

1. Kurov A., Stan R. (2018) Monetary policy uncertainty and the market reaction to macroeconomic news. Journal of Banking \& Finance, vol. 86, pp. 127-142. DOI: 10.1016/j.jbankfin.2017.09.005.

2. Husted L., Rogers J., Sun B. (2017) Monetary policy uncertainty. International Finance Discussion Papers, no 1215. DOI: 10.17016/IFDP.2017.1215.

3. Sharma N., Pabreja R., Yaqub U., Atluri V., Chun S.A., Vaidya J. (2018) Web-based application for sentiment analysis of live tweets. Proceedings of the 19th Annual International Conference on Digital Government Research: Governance in the Data Age, Delft, the Netherlands, 30 May - 1 June 2018, pp. 1-2.

4. Reis J.C.S., Correia A., Murai F., Veloso A., Benevenuto F. (2019) Supervised learning for fake news detection. IEEE Intelligent Systems, vol. 34, no 2, pp. 76-81. DOI: 10.1109/MIS.2019.2899143.

5. Ranco G., Aleksovski D., Caldarelli G., Grčar M., Mozetič I. (2015) The effects of Twitter sentiment on stock price returns. PLoS One, vol. 10, no 9, article no e0138441. DOI: 10.1371/journal.pone.0138441.

6. Fu Y., Hao J.-X., Li X., Hsu C.H.C. (2019) Predictive accuracy of sentiment analytics for tourism: A metalearning perspective on Chinese travel news. Journal of Travel Research, vol. 58, no 4, pp. 666-679. DOI: $10.1177 / 0047287518772361$.

7. Park E., Kang J., Choi D., Han J. (2020) Understanding customers' hotel revisiting behaviour: A sentiment analysis of online feedback reviews. Current Issues in Tourism, vol. 23, no 5, pp. 605-611. DOI: 10.1080/13683 500.2018.1549025.

8. Blinder A.S., Ehrmann M., Fratzscher M., Haan J. D., Jansen D.-J. (2008) Central Bank communication and monetary policy: A survey of theory and evidence. Journal of Economic Literature, vol. 46, no 4. pp. 910-945. DOI: 10.1257/jel.46.4.910.

9. Ponomareva N., Sheen J., Wang B.Z. (2019) Does monetary policy respond to uncertainty? Evidence from Australia. The Australian Economic Review, vol. 52, no 3, pp. 336-343. DOI: 10.1111/1467-8462.12338.

10. Hansen S., McMahon M. (2016) Shocking language: Understanding the macroeconomic effects of central bank communication. Journal of International Economics, vol 99, suppl. 1, pp. S114-S133. DOI: $10.1016 /$ j.jinteco.2015.12.008.

11. Cieslak A., Schrimpf A. (2019) Non-monetary news in central bank communication. Journal of International Economics, vol. 118, pp. 293-315. DOI: 10.1016/j.jinteco.2019.01.012.

12. Baker S.R., Bloom N., Davis S.J. (2016) Measuring economic policy uncertainty. The Quarterly Journal of Economics, vol. 131, no 4, pp. 1593-1636. DOI: 10.1093/qje/qjw024. 
13. Bank of Russia (2015) About the key rate of the Bank of Russia. Press release, 30 January 2015. Available at: http://www.cbr.ru/press/PR/?file=30012015_133122dkp2015-01-30t13_15_49.htm (accessed 1 September 2020).

14. Bank of Russia (2014) About the key rate of the Bank of Russia and other measures of the Bank of Russia. Press release, 16 December 2014. Available at: http://www.cbr.ru/press/PR/?file=16122014_004533dkp201412-16t00_39_23.htm (accessed 1 September 2020).

15. Bank of Russia (2015) About the key rate of the Bank of Russia. Press release, 13 March 2015. Available at: https://www.cbr.ru/press/PR/?file=13032015_133031dkp2015-03-13T13_20_49.htm (accessed 1 September 2020).

16. Bank of Russia (2015) Monetary policy report, no 2. Available at: https://www.cbr.ru/Collection/Collection/ File/7846/2015_02_ddcp.pdf (accessed 1 September 2020).

17. TASS (2015) The Bank of Russia kept the key rate at the level of $11 \%$, but promised to reduce it soon. TASS, 30 October 2015. Available at: https://tass.ru/ekonomika/2393054 (accessed 1 September 2020).

18. Kommersant (2016) The Bank of Russia kept the key rate on the level of 11\%. Kommersant, 18 March 2016. Available at: https://www.kommersant.ru/doc/2942422 (accessed 1 September 2020).

19. Kommersant (2015) EU extends sanctions against Russia for half a year. Kommersant, 22 June 2015. Available at: https://www.kommersant.ru/doc/2752381 (accessed 1 September 2020).

20. Vedomosti (2016) USA extended sanctions against Russia. Vedomosti, 1 September 2016. Available at: https://www. vedomosti.ru/politics/articles/2016/09/01/655346-ssha-rasshirili-sanktsii-otnoshenii (accessed 1 September 2020).

21. Bank of Russia (2018) Monetary policy report, no 3. Available at: https://www.cbr.ru/Collection/Collection/ File/7822/2018_03_ddcp.pdf (accessed 1 September 2020).

22. Bank of Russia (2018) Monetary policy report, no 4. Available at: https://www.cbr.ru/Collection/Collection/ File/14169/2018_04_ddcp.pdf (accessed 1 September 2020).

23. Bank of Russia (2019) The Bank of Russia has decided to reduce its key rate by 25 bp to $7.50 \%$ per annum. Press release, 14 June 2019. Available at: https://www.cbr.ru/press/pr/?file=14062019_133000Key.htm (accessed 1 September 2020).

24. RBC (2019) The Central Bank lowered the key rate to a minimum since 2014. $R B C$, 6 September 2019. Available at: https://www.rbc.ru/finances/06/09/2019/5d7216039a794762b661a2e4 (accessed 1 September 2020).

25. RBC (2020) Nabiullina did not see a reason for an unplanned reduction in the key rate. RBC, 22 May 2020. Available at: https:/www.rbc.ru/finances/22/05/2020/5ec78c839a79472a021822be (accessed 1 September 2020).

26. RBC (2020) The Central Bank may lower the rate in a week. What does this mean for an investor. RBC, 17 April 2020. Available at: https://quote.rbc.ru/news/article/5e9986ea9a794764e362322e (accessed 1 September 2020).

\section{About the authors}

\section{Elizaveta A. Golovanova}

Junior Researcher, Institute of Applied Economic Research, Russian Presidential Academy of National Economy and Public Administration, 82, build. 1, Prospect Vernadskogo, Moscow 119571, Russia;

MSc Student, Department of Economics, Mathematics and Informational Technology, Russian Presidential Academy of National Economy and Public Administration, 82, build. 1, Prospect Vernadskogo, Moscow 119571, Russia;

E-mail: golovanova-ea@ranepa.ru

ORCID: 0000-0002-9073-7553

\section{Andrei V. Zubarev}

Cand. Sci. (Econ.);

Senior Researcher, Institute of Applied Economic Research, Russian Presidential Academy of National Economy and Public Administration, 82, build. 1, Prospect Vernadskogo, Moscow 119571, Russia; Lecturer, Department of Economics, Mathematics and Informational Technology, Russian Presidential Academy of National Economy and Public Administration, 82, build. 1, Prospect Vernadskogo, Moscow 119571, Russia;

E-mail: zubarev@ranepa.ru

ORCID: 0000-0003-2945-5271 


\title{
Wuhan coronavirus spread in Russia: macroeconomic production function in regard to transport and communication infrastructure
}

\author{
Anton A. Afanasiev \\ E-mail: aanton@cemi.rssi.ru

\section{Olga S. Ponomareva} \\ E-mail: fondf@cemi.rssi.ru
}

Central Economics and Mathematics Institute, Russian Academy of Sciences

Address: 47, Nakhimovsky Prospect, Moscow 117418, Russia

\begin{abstract}
Transport and communication infrastructure plays an important role in ensuring economic growth, also in the context of the Wuhan coronavirus (SARS-CoV-2) spread worldwide. The role of the communication component increases with the epidemic and the associated restrictive measures, which replace, to a certain extent, the transport component. We offer an econometric study of the macroeconomic production function in the Russian Federation with transport and communication infrastructure (the fixed assets average annual value of the Russian transport and communications sectors) for 1990-2018. The arguments for this function are the average annual value of fixed assets in constant 1990 prices, the average annual rate of the use of production capacities in Russian industry, the average annual number of people employed in the national economy, the average annual value of fixed assets of transport and communications in constant 1990 prices. Our research demonstrates that in 2010-2018 the GDP elasticity to production infrastructure was decreasing. We explain this by the reduction in the volume of capital investments in the infrastructure sector's fixed assets. In addition, we offer an analytical modification of the macroeconomic production function for 2020 in the context of the spread of the Wuhan coronavirus among the Russian population by introducing into this function the average annual rates of labor and infrastructure capacity use, which, along with the average annual rate of fixed assets capacity use are functions of the predicted values of the daily number of the infected Russian citizens. These predicted values are calculated by the time dependent Gaussian quadratic exponent estimated by the least squares. We present the accuracy of the forecast
\end{abstract}


results for the 2020 spring trends of the daily number of Russian and Moscow population infected with the Wuhan coronavirus. The average APE forecast error for 30 days ahead for Russia is $10.4 \%$ and the same for five weeks for Moscow is $10 \%$. Moreover, we make forecasts of the officially published daily number of infected Russian population for fall 2020 - spring 2021.

Key words: econometric study; Russian economy; macroeconomic production function; transport and communication infrastructure; econometric forecasting; Wuhan coronavirus; SARS-CoV-2; COVID-19; rate of use of production factors.

Citation: Afanasiev A.A., Ponomareva O.S. (2020) Wuhan coronavirus spread in Russia: macroeconomic production function in regard to transport and communication infrastructure. Business Informatics, vol. 14, no 4, pp. 76-95. DOI: 10.17323/2587-814X.2020.4.76.95

\section{Introduction}

$\mathrm{T}$ The production infrastructure is of great importance to the national economy. In his Message to the Federal Assembly, the President of Russian Federation declares that its modernization and development play an important role in strengthening the country's framework, that they give impetus to the development of regions (including Crimea and Sevastopol) and contribute to economic growth [1]. In particular, the Crimean railway bridge, put into operation in 2019 , gave a powerful impetus to the development of the Republic of Crimea and the city of Sevastopol. Thus, the development of effective public policy measures for sustainable development, modernization and efficient use of production infrastructure, including its transport and communication component, using modern economic and mathematical tools is a priority.

A large amount of research has been devoted to the development and modernization of the Russian transport and communication infrastructure [2]. One of the pioneers in the study of Russian domestic infrastructure was Grigory D. Dubelir (1874-1942) whose works are devoted to the optimization of the road network [3-7].

In the expertise by N.P. Laverov et al. [8] conducted for the project of the construction of the international sea channel "Eurasia," it is stressed that a preliminary assessment finds possible rather high risks (including transport, economic, environmental, political and legal). The authors investigate the current state of near aquatic and aquatic ecosystems on the territory of the planned construction of the "Eurasia" channel and highlight the importance of additional engineering and environmental studies to clarify the territory's water resources, the necessity for a deeper study of the options for the consequences of the construction of this large water management facility. They also pay special attention to measures aimed at reducing the negative consequences of the project.

M.G. Zavelsky [9] introduces an econometric model for forecasting the main macroeconomic indicators for the regions of the Russian Federation taking into account the influence of the infrastructural factor and, in particular the gross regional product (GRP). This model takes into account the specifics of the Russian administrative-territorial units and allows us to predict with more accuracy the trends in changes in these indicators.

V.N. Livshits, I.A. Mironova and A.N. Shevtsov [10] substantiate the necessity of making State strategic decisions for the development of transport infrastructure based on assessing the socio-economic efficiency of investment projects. They also offer applications of their 
approach taking the example of investment projects for new railway construction in Russia.

E.I. Pozamantir [11] offers a computable general equilibrium model of the economy, where he examines the most important components of the transport infrastructure development strategy - the choice of sources and volumes of capital investment financing infrastructure development, including the impact of this choice on the development of the national economy and on final consumption. E.I. Pozamantir also simulates the formation of internal sources for financing an investment fund from the added value created in the previous period and presents the results of his experimental calculations.

Using methods of mathematical modeling and forecasting, V.A. Sadovnichy et al. [12] provide a quantitative assessment of the long-term effects (macroeconomic, social and geopolitical) of a project for the development of railways in the Far East and Siberia, including the construction of a high-speed passenger-and-freight highway. Their calculations show that the implementation of this project will play an important role in the socio-economic development of the Russian Federation as well as in strengthening the geopolitical and geo-economic positions of Russia in the Asia-Pacific region and globally.

At the same time, the problem of assessing the macroeconomic effect for the development and modernization of transport and communication infrastructure has not been fully resolved. It is primarily due to the concentration of researchers on one of its components: more often the transport component and less often the communication component. The latter, according to V.L. Makarov, plays an important role at the present stage of society's movement towards the knowledge economy [13]. The econometric model of the Russian economy's production function proposed by the authors [14] solves this problem by separating the average annual value of fixed assets of the pure transport and communications sectors ${ }^{1}$ into a separate function argument which makes it possible to assess the influence of infrastructure on such an important macroeconomic indicator of the Russian economy as gross domestic product (GDP) for the previous years 1990-2012. At this stage, it seems relevant to study the production function in the extended time interval 1990-2018 to further analyze the impact of infrastructure on Russian GDP.

\section{Production function model and statistics}

In order to assess the impact of the transport and communication infrastructure on Russia's GDP, we carried out an econometric study of the following macroeconomic production function, which was proposed earlier [14], for the time periods from 1990 up to 2013-2018:

$$
Y_{t}=\mathrm{e}^{\alpha}\left(z_{t} K_{t}\right)^{\beta} L_{t}^{1-\beta} I_{t}^{\gamma},
$$

where $Y_{t}$ is Russian GDP in constant 1990 prices for year $t$;

$K_{t}$ is average annual value of Russian economy fixed assets in constant 1990 prices for year $t$;

$z_{t}$ is the average annual rate of use of production capacities in Russian industry for year $t$;

$L_{t}$ is the average annual number of people employed in the national economy for year $t$;

$I_{t}$ is the average annual value of fixed assets of transport and communications in constant 1990 prices for year $t$.

The econometric study of function (1) was carried out by the least squares method based on statistical data from Rosstat and the Russian Economic Barometer (Table 1). The conver-

\footnotetext{
1 The fixed assets of the pure sectors of transport and communications are the fixed assets of transport and communications of all economic units regardless of their industry affiliation; i.e. the assets of the pure industries or sectors that are reflected in the balance of fixed assets compiled by Rosstat (Russian Federal State Statistics Service)
} 
Statistical data for the econometric study in 1990-2018

Table 1.

\begin{tabular}{|c|c|c|c|c|c|}
\hline Year & $Y_{t}$, billion rubles & $K_{t}$, million rubles & $z_{t}$ & $L_{t}$, thousands of people & $I_{t}$, million rubles \\
\hline 1990 & 644 & 1871649 & 100 & 75325 & 251548 \\
\hline 1991 & 612 & 1957288 & 100 & 73848 & 265806 \\
\hline 1992 & 523 & 2009054 & 73 & 72071 & 277320 \\
\hline 1993 & 478 & 2030396 & 74 & 70852 & 283913 \\
\hline 1994 & 417 & 2014984 & 61 & 68484 & 288435 \\
\hline 1995 & 400 & 1995229 & 60 & 66441 & 289518 \\
\hline 1996 & 386 & 1983823 & 54 & 65950 & 289351 \\
\hline 1997 & 391 & 1967098 & 54 & 64639 & 289427 \\
\hline 1998 & 371 & 1953216 & 55 & 63642 & 289773 \\
\hline 1999 & 394 & 1953747 & 62 & 63963 & 290439 \\
\hline 2000 & 434 & 1962932 & 66 & 64517 & 291581 \\
\hline 2001 & 456 & 1976006 & 69 & 64980 & 295215 \\
\hline 2002 & 477 & 1993845 & 70 & 65574 & 301557 \\
\hline 2003 & 512 & 2015564 & 73 & 65979 & 309364 \\
\hline 2004 & 549 & 2040209 & 74 & 66407 & 318011 \\
\hline 2005 & 584 & 2074736 & 76 & 66792 & 327755 \\
\hline 2006 & 632 & 2119496 & 78 & 67174 & 340138 \\
\hline 2007 & 686 & 2169707 & 80 & 68019 & 353854 \\
\hline 2008 & 722 & 2229842 & 77 & 68474 & 367701 \\
\hline 2009 & 665 & 2292706 & 65 & 67463 & 383787 \\
\hline 2010 & 695 & 2350079 & 72 & 67577 & 402597 \\
\hline 2011 & 725 & 2416816 & 78 & 67727 & 419318 \\
\hline 2012 & 750 & 2499424 & 79 & 67968 & 439598 \\
\hline 2013 & 760 & 2581327 & 78 & 67901 & 468506 \\
\hline 2014 & 765 & 2644159 & 77 & 67813 & 496133 \\
\hline 2015 & 744 & 2673133 & 75 & 68389 & 520271 \\
\hline 2016 & 742 & 2696319 & 77 & 68430 & 539786 \\
\hline 2017 & 753 & 2730170 & 79 & 68127 & 557465 \\
\hline 2018 & 771 & 2762511 & 78 & 68016 & 572441 \\
\hline
\end{tabular}

Sources: data for 1990-2012 [14] updated for 2008-2012, data for 1990-2017 [15] updated for 2017, data for 2018 [16-18], Rosstat (EMISS database), authors' calculations according to the methodology [14, 15]. 
sion of the average annual value of fixed assets of the pure transport and communications sectors into 1990 constant prices was carried out on the basis of statistical data from Rosstat by the author's methodology described in [14, 15]. It should be noted that, in contrast to the results of [14], the authors use a slightly changed average annual value of fixed assets of the pure transport and communications sectors in 1990 comparable prices for 2008-2012 which is associated with the revision of the fixed assets revaluation index in 2008-2009. In addition, due to the revision of the average annual price index for investment products in Russia for 2017, equal to 1.026 , in contrast to [15], the authors use the updated average annual value of fixed assets of the national economy in 1990 constant prices for 2017. Due to the 2016 change of the methodology for calculating the average annual number of people employed in the national economy by Rosstat in order to proceed to an accurate comparison with the data for previous years, we calculate the values for 2017-2018 by average annual growth rates for 2017 and 2018 [15, 16].

\section{Results of the econometric study}

As a result of an econometric study of function (1) for the extended time intervals 19902018, it turns out (Table 2) that this function appropriately describes the process of expanded reproduction of the Russian economy both from the point of view of economic theory and the classical econometric criteria.

Relying on the table the following may be highlighted.

1. Signs at the coefficients of the production function are consistent with the provisions of economic theory.

\section{Results of an econometric study of the Russian economy's production function in regard to infrastructure (1) for 1990-2018}

\begin{tabular}{c|c|c|c|c|c}
\multirow{2}{*}{ Time period } & \multicolumn{2}{|c|}{ Coefficients and (in brackets) } & $t$-statistics & \multirow{2}{*}{$R^{2}$} & \multirow{2}{*}{$D W$} \\
\cline { 2 - 4 } & $\alpha$ & $\beta$ & $\gamma$ & 0.91 & 2.10 \\
\hline $1990-2003$ & $-7.84(-2.27)$ & $0.83(10)$ & $0.03(0.10)$ & 0.91 & 1.99 \\
\hline $1990-2004$ & $-11.15(-4)$ & $0.87(11)$ & $0.28(1.25)$ & 0.92 & 1.93 \\
\hline $1990-2005$ & $-12.94(-6)$ & $0.89(11)$ & $0.42(2.27)$ & 0.93 & 1.88 \\
\hline $1990-2006$ & $-14.18(-7)$ & $0.90(12)$ & $0.52(3)$ & 0.94 & 1.83 \\
\hline $1990-2007$ & $-15.09(-9)$ & $0.91(12)$ & $0.59(4)$ & 0.95 & 1.71 \\
\hline $1990-2008$ & $-16.13(-11)$ & $0.91(12)$ & $0.67(6)$ & 0.95 & 1.53 \\
\hline $1990-2009$ & $-17.01(-14)$ & $0.89(12)$ & $0.74(7)$ & 0.96 & 1.69 \\
\hline $1990-2010$ & $-16.36(-16)$ & $0.89(12)$ & $0.69(8)$ & 0.95 & 1.33 \\
\hline $1990-2011$ & $-15.29(-14)$ & $0.89(10)$ & $0.61(7)$ & 0.94 & 1.01 \\
\hline $1990-2012$ & $-14.28(-13)$ & $0.86(9)$ & $0.53(5)$ & 0.94 & 0.82 \\
\hline $1990-2013$ & $-13.40(-13)$ & $0.85(8)$ & $0.47(5)$ & 0.93 & 0.70 \\
\hline $1990-2014$ & $-12.67(-12)$ & $0.85(8)$ & $0.41(4)$ & 0.93 & 0.64 \\
\hline $1990-2015$ & $-11.97(-12)$ & $0.87(8)$ & $0.35(4)$ & 0.92 & 0.57 \\
\hline $1990-2016$ & $-11.31(-12)$ & $0.88(8)$ & $0.30(3)$ & 0.91 & 0.50 \\
\hline $1990-2017$ & $-10.80(-11)$ & $0.88(7)$ & $0.25(3)$ & 0.91 & 0.47 \\
\hline $1990-2018$ & $-10.46(-11)$ & $0.88(7)$ & $0.23(2.3)$ & & \\
\hline
\end{tabular}


2. All arguments of the function, i.e. factors of production, are statistically significant.

3 . High values of the coefficients of determination $R^{2}(0.91-0.94)$ indicate the presence of a very close goodness-of-fit between Russia's GDP and production factors (fixed assets, the number of employees, and fixed assets of infrastructure).

4. The fact that the Durbin-Watson $D W$ statistic falls into the zone of positive autocorrelation reduces, to some extent, the model's verification, but at the same time indicates the influence on Russia's GDP of other unaccounted factors, such as the world oil price, which was investigated by the authors in [15].

Moreover, the production function (1) has a fairly good predictive power for 2005-2018. Thus, the direction of the trend lines of the $e x$ post forecast of Russia's GDP coincides almost everywhere with the direction of the trend lines of the actual GDP (Figure 1), and the errors of the ex-post forecast, calculated by the formula: $A P E_{t}=\left|Y_{t(\text { forecast })} / Y_{t(\text { (actual })}-1\right|$ do not exceed $11 \%$ except for two years (Figure 2).

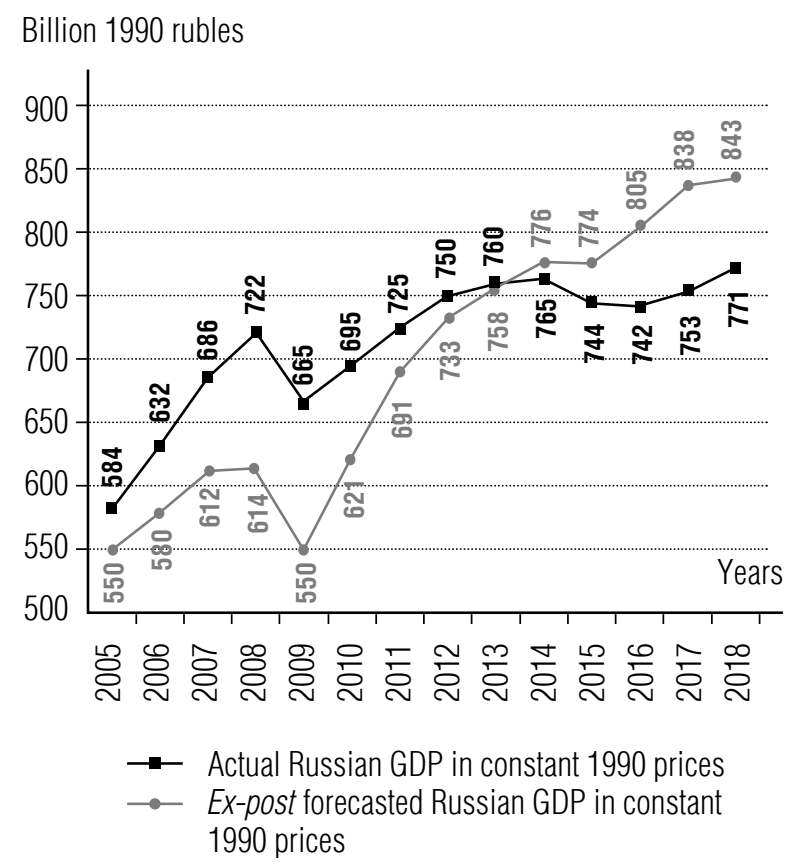

Fig. 1. Actual and ex-post forecasts for 2005-2018 Russian GDP in 1990 constant prices made by function (1) estimated in 1990-2004

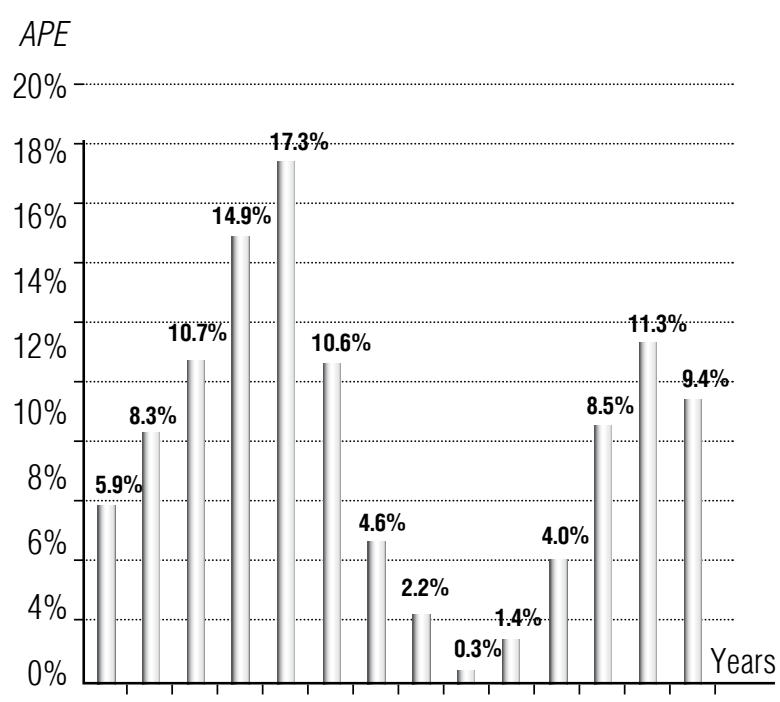

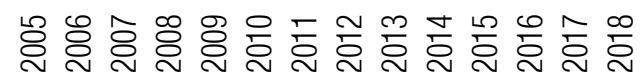

Fig. 2. Ex-post forecast errors APE of Russia's GDP in 1990 comparable prices for 2005-2018 made by function (1) estimated in 1990-2004

\section{Conclusions from the results of the econometric study}

Based on the results of econometric research (Table 2), we come to the following conclusions.

1. Russian GDP elasticity to production infrastructure $\gamma$, which characterizes the contribution of infrastructure to GDP reproduction, increased in 2003-2009 from 0.03 to 0.74 and decreased in 2009-2018 from 0.74 to 0.23 (Figure 3).

2. A decrease of 3.5 times (from 8 to 2.3 ) in the value of $t$-statistics of the coefficient for the infrastructure $\gamma$ during 2010-2018 indicates a weakening of the statistical significance of infrastructure and, consequently, its impact on the expanded reproduction of Russia's GDP.

One of the important factors indicating a decrease in the role of transport and communication infrastructure in the Russian economy since 2009 is a decrease in the weight (tonnage) of goods transported by all modes of transport in Russia in 2009-2018 (Figure 4). Thus, in 20032008 tonnage increased from 8.8 to 9.5 billion tons, while in 2009 it fell to 7.5 billion tons, and even though in subsequent years 2010-2018 the 
weight of the transported goods began to grow, it could not even reach the 2003 level.

What are the reasons for the decline in the role and importance of infrastructure in the expanded reproduction of the Russian national economy in 2009-2018?

In our opinion, the main reason for this decline is the reduction in capital investments in the Russian transport and communication infrastructure.

Indeed, in 2003-2009 the average annual rise of physical volume of investments in fixed assets of the pure transport and communications sectors was $117.2 \%$, and in 2010-2018 it was only $99.4 \%$ (calculated by the authors based on the data in Figure 5).

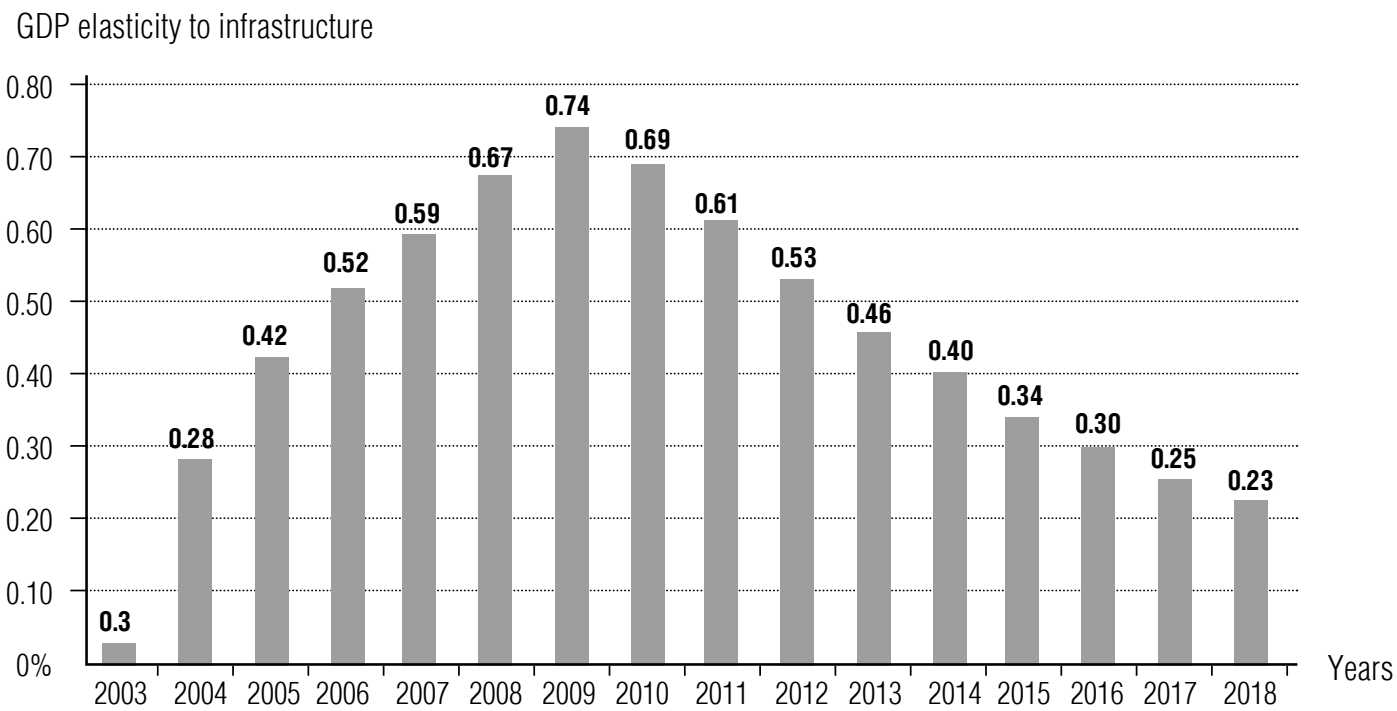

Fig 3. Russian GDP elasticity to production infrastructure $\gamma$ for 2003-2018 (Table 1)

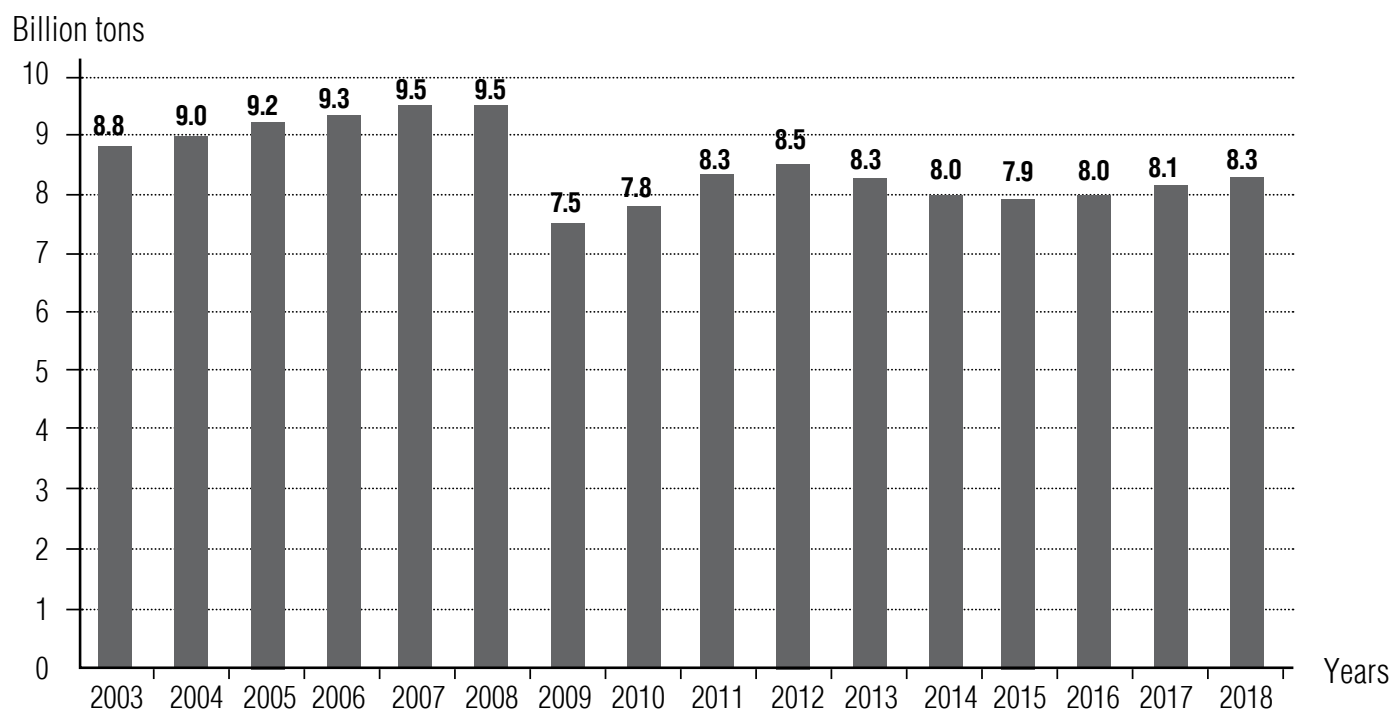

Fig. 4. Transportation of goods by all modes of transport in the Russian Federation in 2003-2018 Source: Rosstat (EMISS database) 


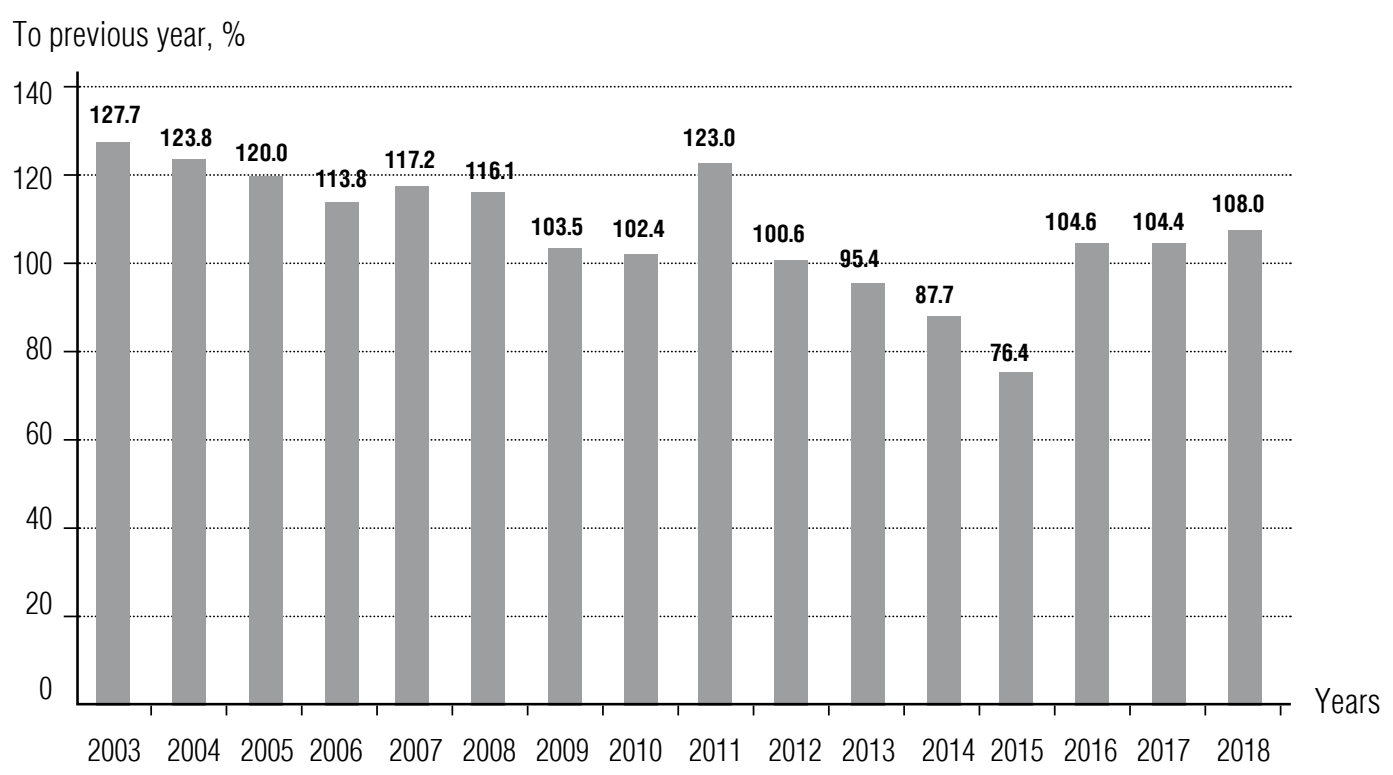

Fig. 5. Index of physical volume of investments in fixed assets for the full range of organizations for Russia's pure transport and communications sectors in 2003-2018. Source: Rosstat (EMISS database) and authors' calculations for 2017-2018

Thus, we see that today the transport and communication infrastructure of the Russian economy needs significant capital investments aimed at its effective modernization and sustainable development. It will, in turn, contribute to the acceleration of growth and sustainable development of the entire Russian national economy.

Meanwhile, since the beginning of 2020, the movement towards sustainable development and the acceleration of economic growth in both the Russian and world economies have been undermined by the wide spread of coronavirus disease 2019 (COVID-19), caused by the Wuhan coronavirus transmitted from person to person. The Wuhan coronavirus [22, 23] is the severe acute respiratory syndrome coronavirus 2 (SARS-CoV-2), which first appeared on the seafood market in the Chinese city of Wuhan in December 2019. Below we will use the term Wuhan coronavirus, which, along with the terms SARS-CoV-2, COVID-19, 2019$n C o V$, Wuhan seafood market pneumonia virus, is commonly used in scientific literature [22]. It is the original name of this novel coronavirus (proposed by Chinese researchers [22], including the Chinese Academy of Sciences [23]) and it is understandable to a wider range of readers with no medical background.

In the absence of specific anti-coronavirus medications, an anti-coronavirus vaccine and (at the initial stage) a sufficient amount of personal protective equipment, the Wuhan coronavirus, which started (according to official data) to actively spread in Russia from the end of February 2020, led to losses among the population. It forced the Russian State authorities to introduce, starting from March 2020, restrictions of varying severity on the movement of people, communication and the economic activities of enterprises and organizations. These restrictions, on the one hand, helped to slow the spread of the Wuhan coronavirus but, on the other hand, caused some damage to the Russian economy. In this respect, it seems relevant to modify the macroeconomic production function of Russia, in regard to the Wuhan coronavirus spread and the subsequent epidemic restrictions. 


\section{Modification of the model in regard to the Wuhan coronavirus spread for 2020}

One of the co-authors of this article offered and investigated by the least squares method an econometric model for the spring phase of the daily spread of Wuhan coronavirus cases in Russia (dated 10 May 2020 [20, 21]) and Moscow (dated 26 April 2020 [19]):

$$
y_{T}=\mathrm{e}^{a T^{2}+b T+c},
$$

where $y_{T}$ is the number of people infected with the Wuhan coronavirus per day;

$T$ is time (day);

e is the base of natural logarithm.

The results of the study are shown in Table 3. The functions investigated in [19-21] predict the daily number of people infected from 2 May 2020 to the end of July 2020 (Russia, Figures 6 and 7) and from 26 April 2020 to early July 2020 (Moscow, Figures 8 and 9).
As we can see in Figure 6, function 2 (Table 3) indicated the forecast date of the peak number of Russian citizens infected with the Wuhan coronavirus (13 May 2020, 11,618 people) two days after the actual peak (11 May 2020, 11,656 people).

Function 1 (Table 3, Figure 8) predicted a peak in the number of infected Muscovites on 6 May 2020 (5821 people), i.e. the day before the peak of the actual incidence on 7 May (6703 people), with an error in the number of infected citizens of Moscow equal to $13 \%$ (Figure 9). Functions (2) studied in [19-21] predicted the daily number of Russian citizens infected with the Wuhan coronavirus 30 days ahead, on 2-31 May 2020, with an arithmetic mean $A P E$ error of $10.4 \%$ (Figures 6 and 7, Table 3) and Moscow citizens for five weeks ahead, on 26 April - 1 May (function 15, Table 3) and 2-29 May 2020 (function 1, Table 3), with an arithmetic mean APE error of $10 \%$ (Figures 8 and 9), where

\section{Results of an econometric study for the quadratic exponential}

(Gaussian) function (2) of the daily number of people infected

with the Wuhan coronavirus in Moscow and across Russia, spring 2020

Table 3.

\begin{tabular}{|c|c|c|c|c|c|c|c|c|c|c|}
\hline \multirow[b]{2}{*}{ № } & \multirow{2}{*}{$\begin{array}{c}\text { Time } \\
\text { period }\end{array}$} & \multicolumn{3}{|c|}{$\begin{array}{l}\text { Coefficients } \\
t \text {-statistics }\end{array}$} & \multirow[b]{2}{*}{$R^{2}$} & \multirow[b]{2}{*}{$D W$} & \multicolumn{2}{|c|}{$\begin{array}{l}\text { Daily infection } \\
\text { peak forecast } \\
\text { for } 2020\end{array}$} & \multicolumn{2}{|c|}{$\begin{array}{l}\text { Onset of zero (single) daily } \\
\text { infection forecast for } 2020\end{array}$} \\
\hline & & $a$ & $b$ & $c$ & & & date & $\begin{array}{l}\text { number } \\
\text { of } \\
\text { infected, } \\
\text { persons }\end{array}$ & date & $\begin{array}{l}\text { total number } \\
\text { of people infected since the } \\
\text { beginning of the epidemic, } \\
\text { thousand people }\end{array}$ \\
\hline \multicolumn{11}{|c|}{ Moscow } \\
\hline 1 & $12.03-11.04$ & $\begin{array}{r}-0.0025 \\
(-1.43) \\
\end{array}$ & $\begin{array}{l}0.2788 \\
(5)\end{array}$ & $\begin{array}{l}0.8896 \\
(2.23)\end{array}$ & 0.88 & 2.70 & 6.05 & 5821 & 7.07 & 206.5 \\
\hline 15 & $12.03-25.04$ & $\begin{array}{c}-0.0030 \\
(-5)\end{array}$ & $\begin{array}{c}0.2935 \\
(11)\end{array}$ & $\begin{array}{c}0.8158 \\
(3)\end{array}$ & 0.93 & 2.68 & 29.04 & 3080 & 23.06 & 100.6 \\
\hline \multicolumn{11}{|c|}{ Russia } \\
\hline 2 & $2.03-1.05$ & $\begin{array}{c}-0.0018 \\
(-14)\end{array}$ & $\begin{array}{c}0.2648 \\
(31)\end{array}$ & $\begin{array}{l}0.3659 \\
(2.79)\end{array}$ & 0.99 & 1.07 & 13.05 & 11618 & 28.07 & 484.9 \\
\hline
\end{tabular}

Sources: [19-21] (numbering of functions is kept as in the original sources) 


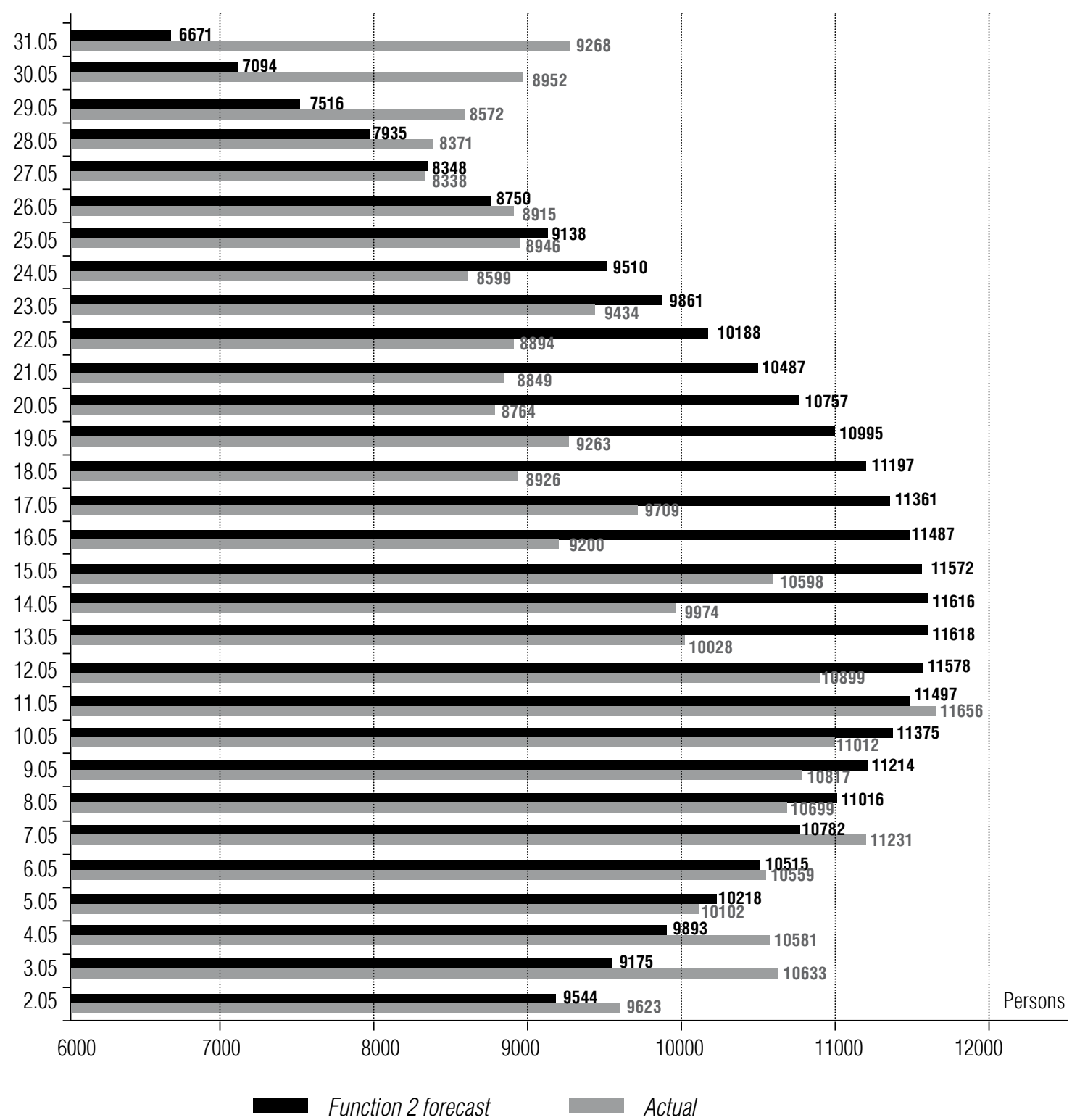

Fig. 6. Actual and forecasted values of the daily number of people infected with the Wuhan coronavirus in Russia for 2-31 May 2020 according to function (2) (Table 3) Source: [19] and "стопкоронавирус.рф"

$$
\begin{gathered}
A P E=\sum_{T=1}^{m} A P E_{T}, \\
A P E_{T}=\left|y_{T(\text { forecast })} / y_{T(\text { actual })}-1\right|
\end{gathered}
$$

$m$ is number of days of the forecast period.

A feature of the methodology of econometric forecasting by function (2) is that the degree of accuracy and scientific validity of the forecast, as well as confidence in it, depends not only on the correctly selected type of func- tional dependence, but also on how many of the estimated functions are confirmed by the forecast. Thus, the degree of confidence in the forecast is higher if the same or close values are predicted by a function estimated not over one time interval, but over several intervals. Indeed, all functions (2) for Russia (except one), estimated in the time intervals from 2 March 2 to 30 April - 10 May 2020, predict the same dates for the peak daily number of Russian citizens 


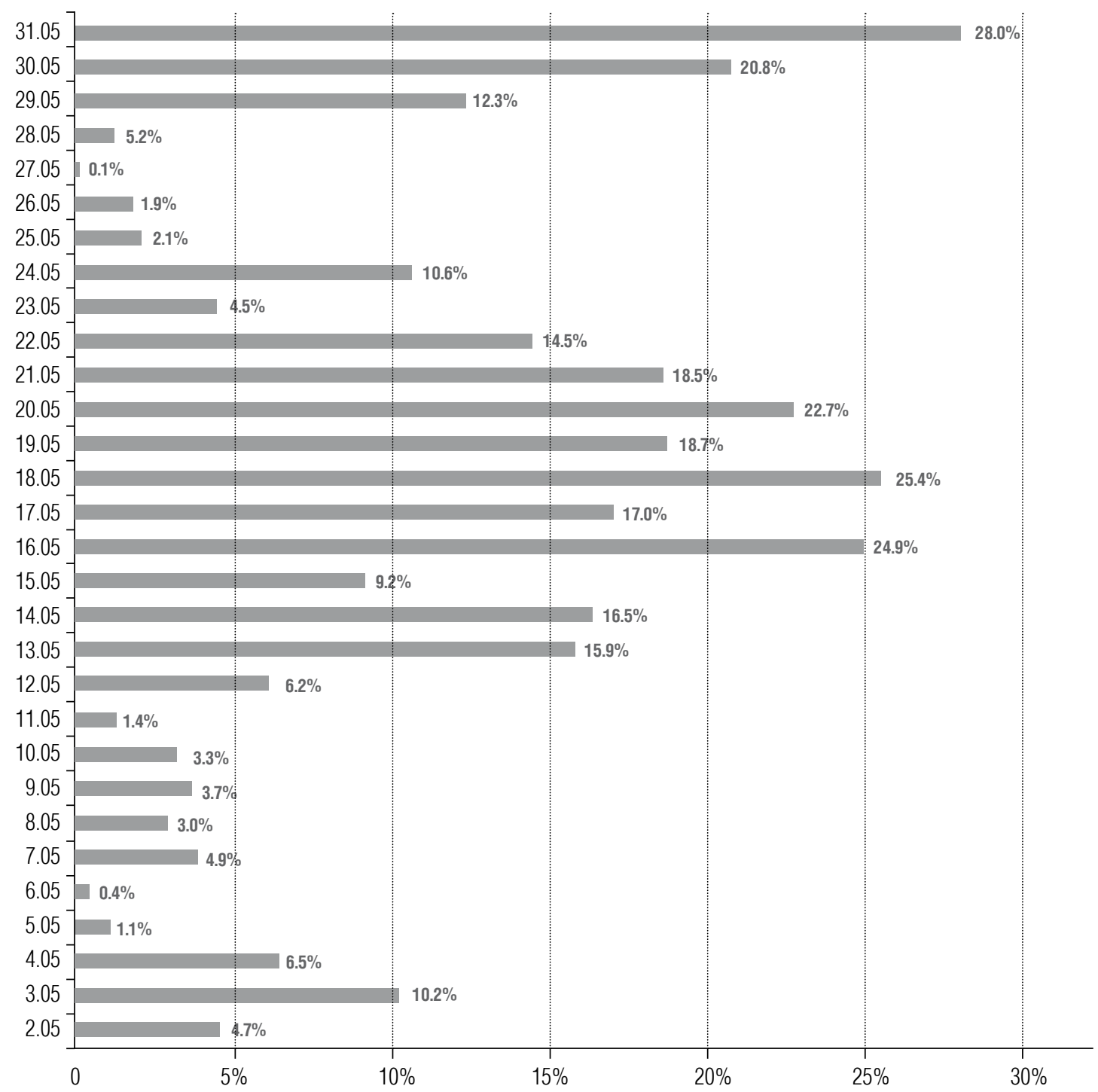

Fig. 7. APE forecast errors of the daily number of people infected with the Wuhan coronavirus in Russia for 2-31 May 2020 according to function (2) (Table 3 and Figure 6)

infected with the Wuhan coronavirus - 14 May 2020. Only one of the functions (2), studied from 2 March to 1 May 2020, predicts reaching the peak the day before - 13 May 2020, which is very close to the actual peak date -11 May 2020 (Figure 10). In addition, all 11 functions predict very close (within 5\% error) values of the peak daily cases in the range of 11.6-12.2 thousand people, which are very close to the actual peak daily cases on 11 May - 11.7 thousand people (Figure 11).
In addition, all these functions indicated very close dates of attenuation (onset of zero values) of the Wuhan coronavirus spread: 28 July (5 functions) and 29 July 2020 (the remaining 6 functions) (Figure 12). Despite the fact that the coronavirus in Russia was not defeated on these dates, there was a significant attenuation of its spread to 5.3-5.4 thousand people per day. It should be noted that significant discrepancies between the predicted and actual values of the daily number of Russia and Moscow citizens 


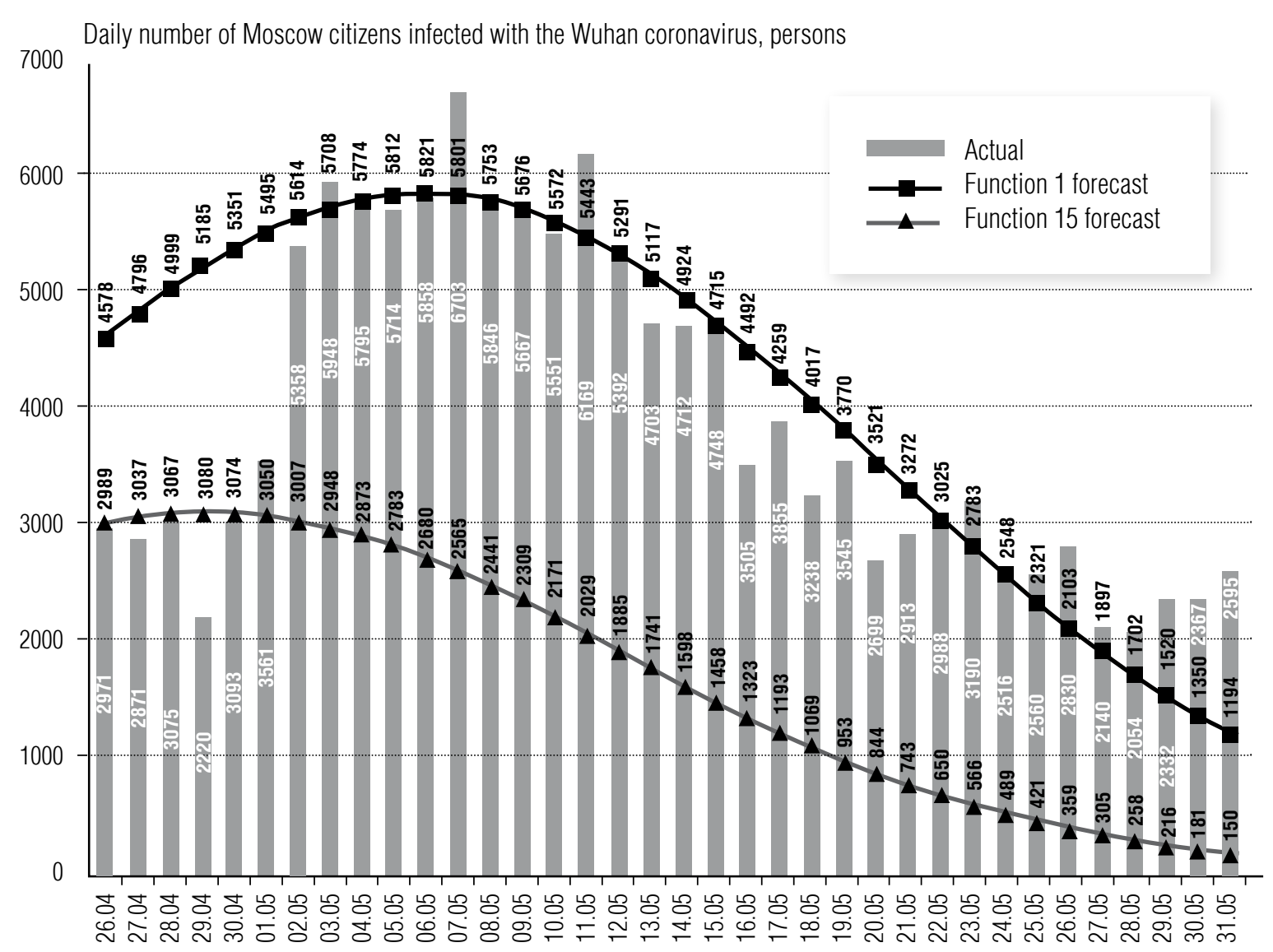

Fig. 8. Actual and forecasted values of the daily number of Moscow citizens infected with the Wuhan coronavirus for 26 April - 31 May 2020 according to functions 1 and 15 (Table 3). Source: [19-21] and "стопкоронавирус.рф"

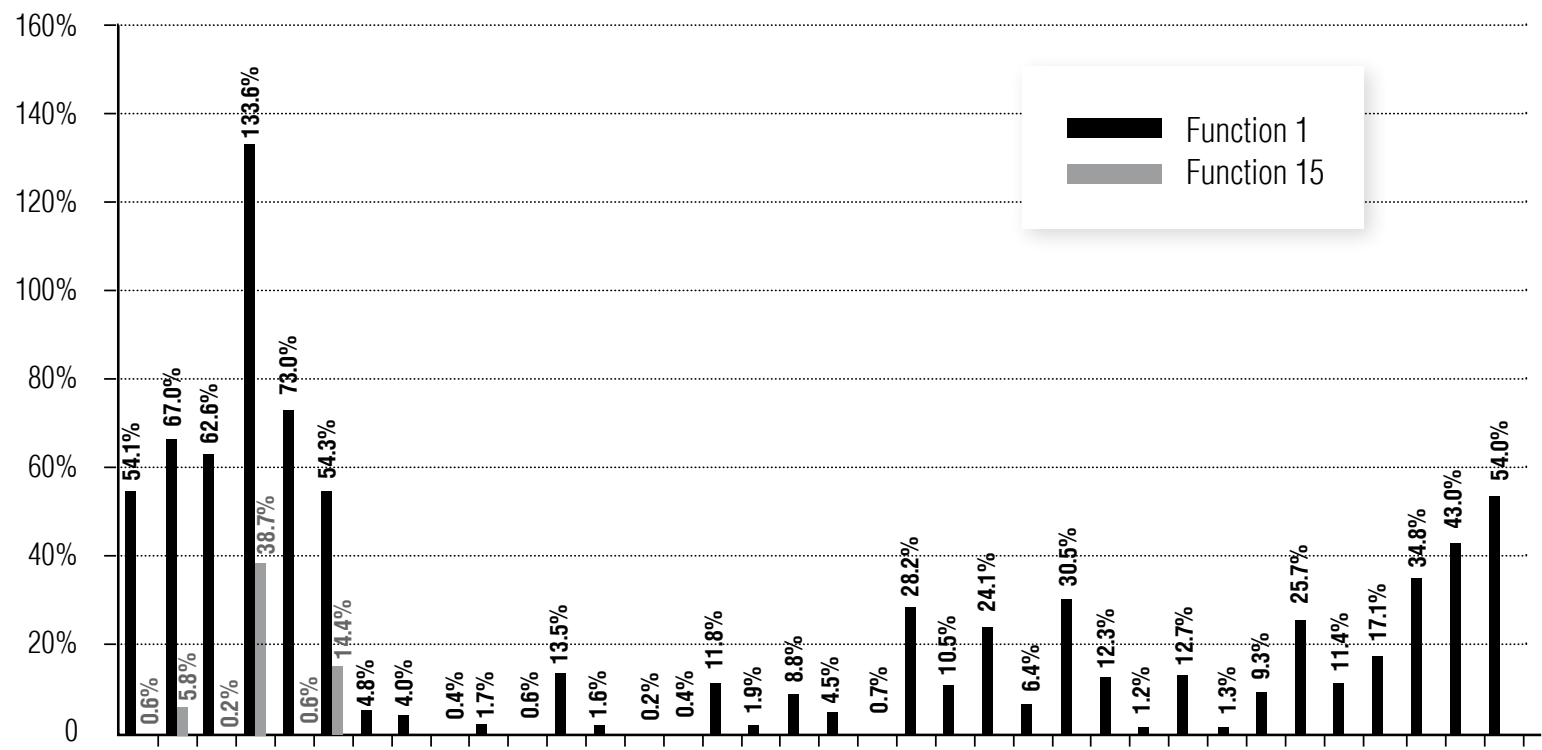

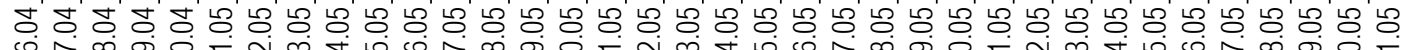

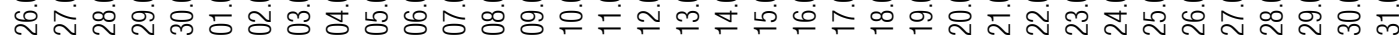

Fig. 9. APE forecast errors of the daily number of Moscow citizens infected with the Wuhan coronavirus 26 April - 31 May 2020 according to functions 1 and 15 (Table 3, Figure 8, [19]) 


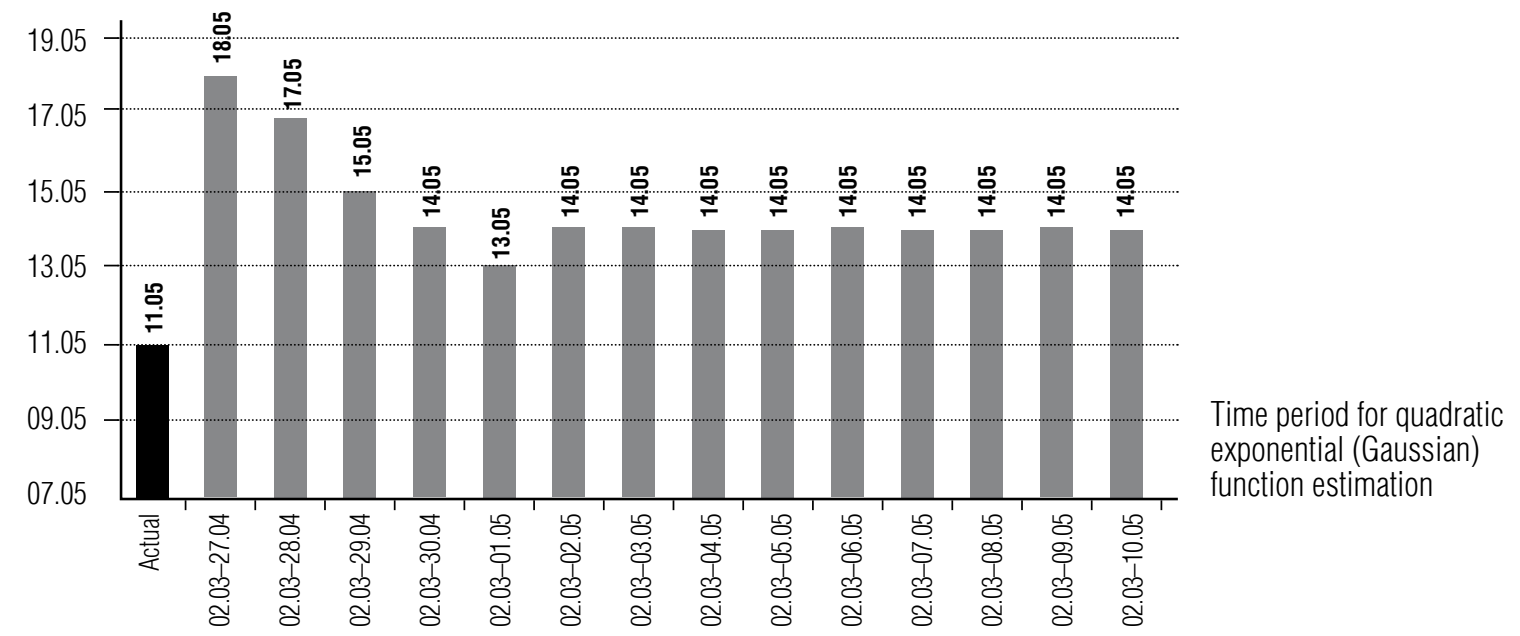

Fig. 10. Actual and predicted dates of the peak number of Wuhan coronavirus-infected Russian citizens according to function (2) estimated from 2 March to 27 April - 10 May 2020. Source: [19]

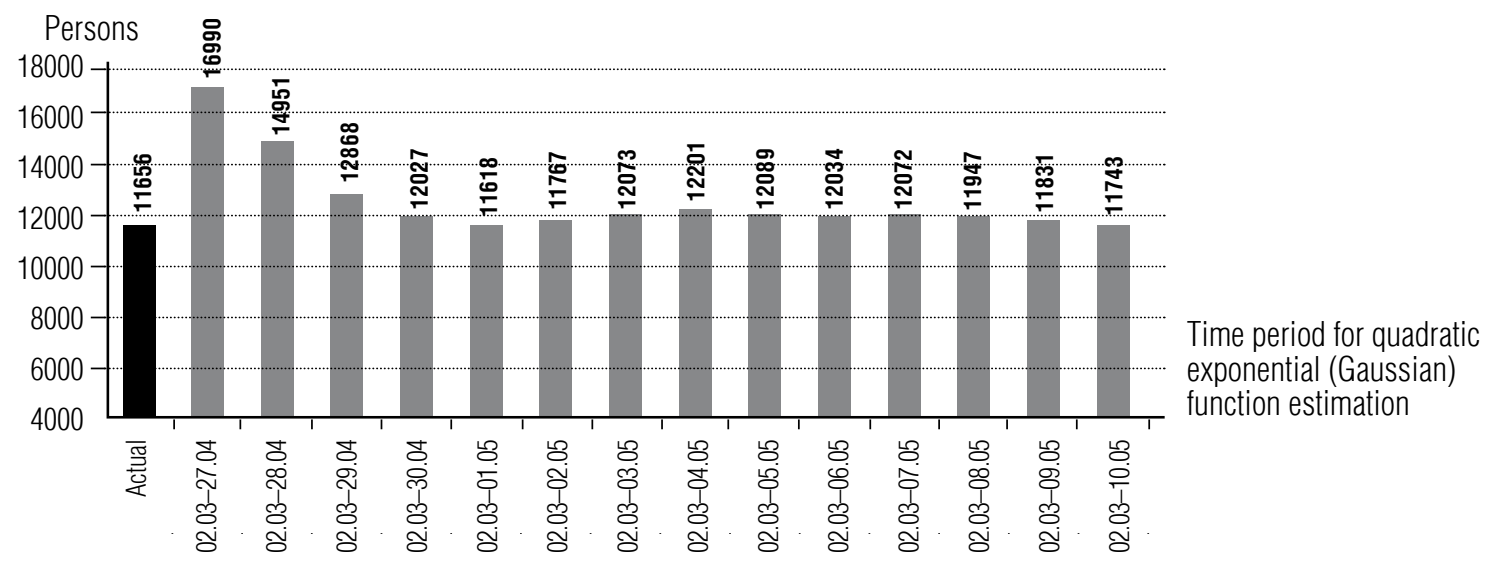

Fig. 11. Actual and predicted peak number of Russian citizens infected with the Wuhan coronavirus according to function (2) estimated from 2 March to 27 April - 10 May 2020, persons Source: [19]

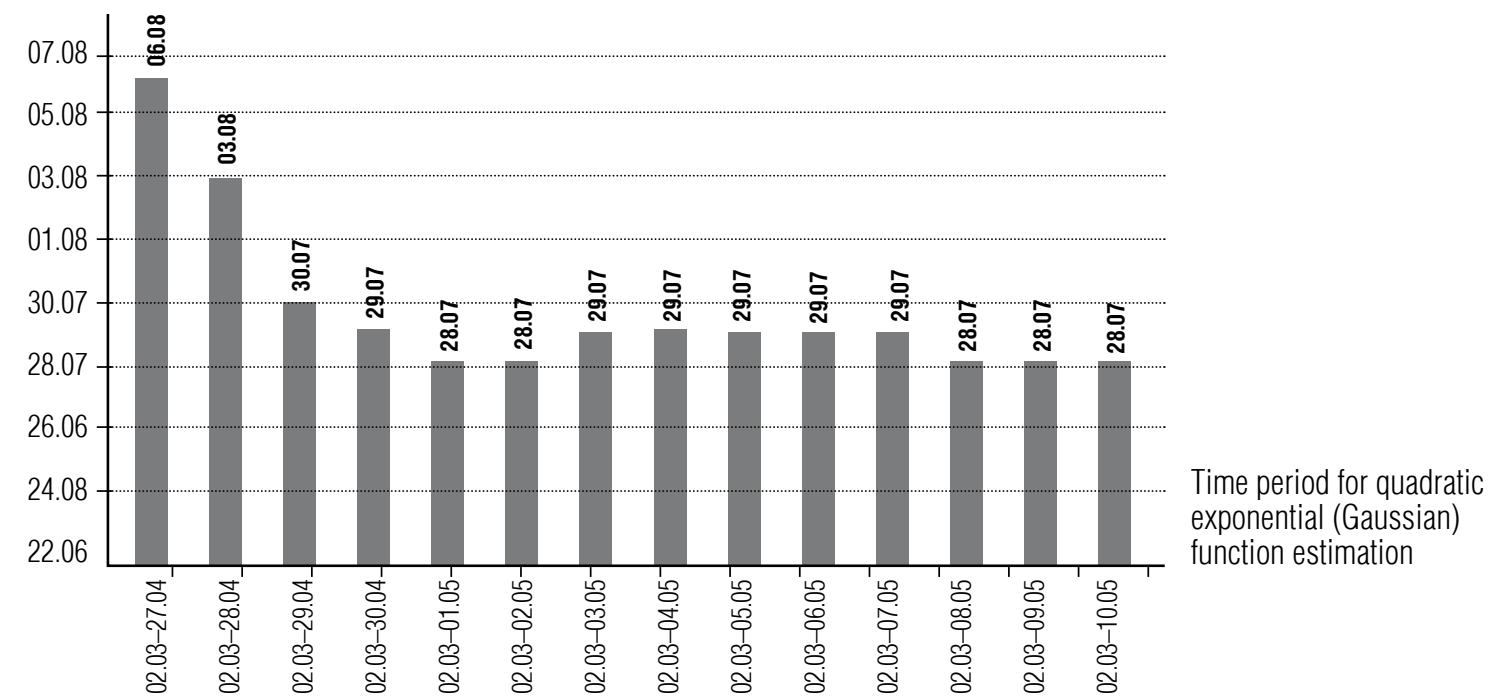

Fig. 12. The predicted dates for the onset of zero (unit) values of the number of Russian citizens infected with the Wuhan coronavirus according to function (2) estimated from 2 March to 27 April - 10 May 2020. Source: [19] 


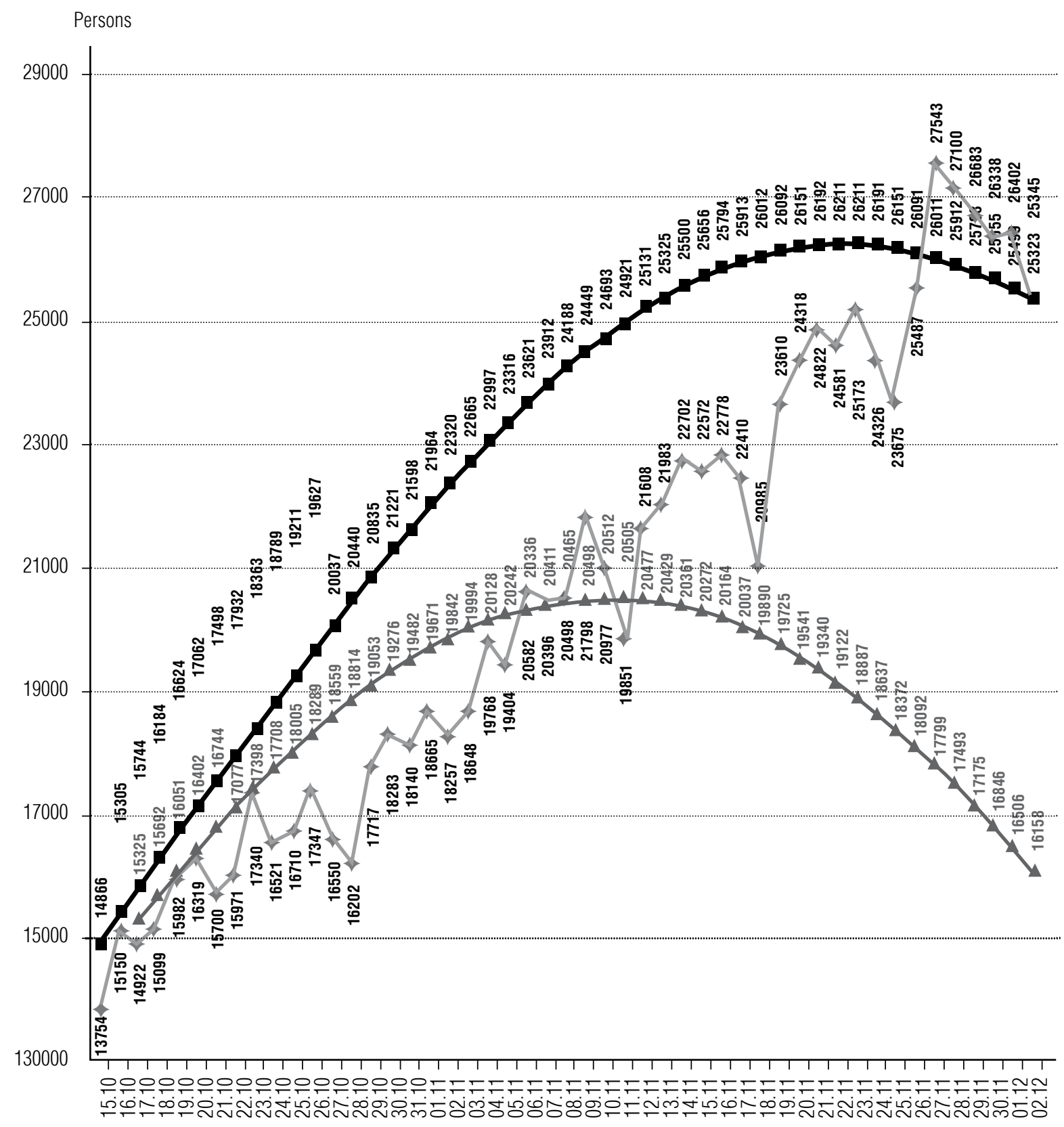

$\longrightarrow$ Actual $\longrightarrow$ Function 3a (Table 4) $\longrightarrow$ Function 4a (Table 4)

Fig. 13. Actual and forecasted values of the officially published daily number of people infected with the Wuhan coronavirus in Russia

for 15 October - 2 December 2020 according to functions 3a and 4a (Table 4)

infected with the Wuhan coronavirus, which appeared in the first days of June 2020, were caused by certain factors in mid-May - early June 2020: the weakening and subsequent cancellation of the strict isolation regime (length of which occupied the main part of the length of the time intervals for the function (2) econometric estimation), the availability of free testing for the Wuhan coronavirus and for the antibodies (which brought an element of greater 
randomness to the indicator of the daily number of Wuhan coronavirus infection).

Despite these considerations, it seems to us possible to use the above methodology for forecasting the fall-winter phase of the spread of the officially published (registered) cases of the Wuhan coronavirus in Russia. Indeed after some stabilization in August further statistics indicate an increase in cases of infection. First, we proceed with finding the pivot point (date) of growth which, as illustrated by the statistics, is 22 September 2020 .

It should be noted that functions (2) in the time intervals from 22 September to 13-31 October 2020 describe quite adequately from the point of view of classical econometric criteria the fall dynamics of the officially published daily number of people infected with the Wuhan coronavirus in Russia. One of them is function 4a, estimated from 22 September to 16 October: it is most accurately predicted from 17 October to 20 November 2020 (for 35 days ahead) with an average $A P E$ error of $6.5 \%$ (Table 4, Figures 13 and 14). However, starting from 19 November the forecast errors of the 4a function begin to grow, and the actual values from 19 November to 2 December 2020 are between the predicted values of the $3 \mathrm{a}$ and $4 \mathrm{a}$ functions, approaching the predicted values of the $3 \mathrm{a}$ function, the peak of which is expected on 22-23 November 2020 with 26211 persons (Figures 13 and 14). The average $A P E$ forecast error for 19 November 2 December 2020 (14 days ahead) for function $3 \mathrm{a}$ is $5.3 \%$. Thus, functions $3 \mathrm{a}$ and $4 \mathrm{a}$ indicate a forecast corridor with the $A P E$ arithmetic mean error for 7 weeks, which does not exceed $7 \%$.

Thus, function (2) can be used for further forecasting. According to this function forecasts (Table 4), the autumn-spring phase of the Wuhan coronavirus spread in Russia may reach its peak on 31 October - 10 November 2020 (17.1-20.5 thousand people per day) and subside by 4 March - 15 April 2021, when the total number of infected people reaches 2.2-2.6 million (functions 4a-6a from Table 4, Figure 15).
Under the worst-case scenarios, the officially published peak could be reached 26-30 thousand people per day on 23-30 November 2020 and the epidemic will subside by $5-30$ May 2021 when a total number of infected will be equal to 3.4-3.9 million people (functions 2a-3a from Table 4, Figure 15).

In the worst case scenario, the projected officially published peak population can reach 38 thousand people per day on 11 December 2020 , and the spread of the second phase of the virus will stop on 29 June 2021 with the total number of infected 5 million people (function 1o from Table 4, Figure 15).

It appears to us that the predicted values of the daily number of Russian citizens infected with the Wuhan coronavirus can serve as an input parameter for a modified production function.

The spread of the Wuhan coronavirus in Russia reduced, first of all, the level of use of almost all production factors: fixed assets - due to the temporary closure of many enterprises and organizations from 25 March to 11 May 2020; labor - due to the forced isolation of some citizens due to the coronavirus disease or close contacts with virus carriers; the transport part of the infrastructure - due to a decrease in the number of passenger flights, rail and sea transport. The only factor of production, the use of which has sharply increased during the period of restrictive measures on coronavirus and the transition of most people to remote communication and work, is the communication part of the infrastructure.

Thus, the modified Russian macroeconomic production function in regard to Wuhan coronavirus restrictions for 2020 looks as follows:

$$
Y_{t}=\mathrm{e}^{\alpha}\left(z_{t} K_{t}\right)^{\beta}\left(v_{t} L_{t}\right)^{1-\beta}\left(w_{T t} I_{T t}+w_{C t} I_{C t}\right)^{\gamma},
$$

where $v_{t}$ is the average annual rate of labor capacity use for year $t$;

$I_{T t}$ is the transport component of infrastructure for year $t$; 


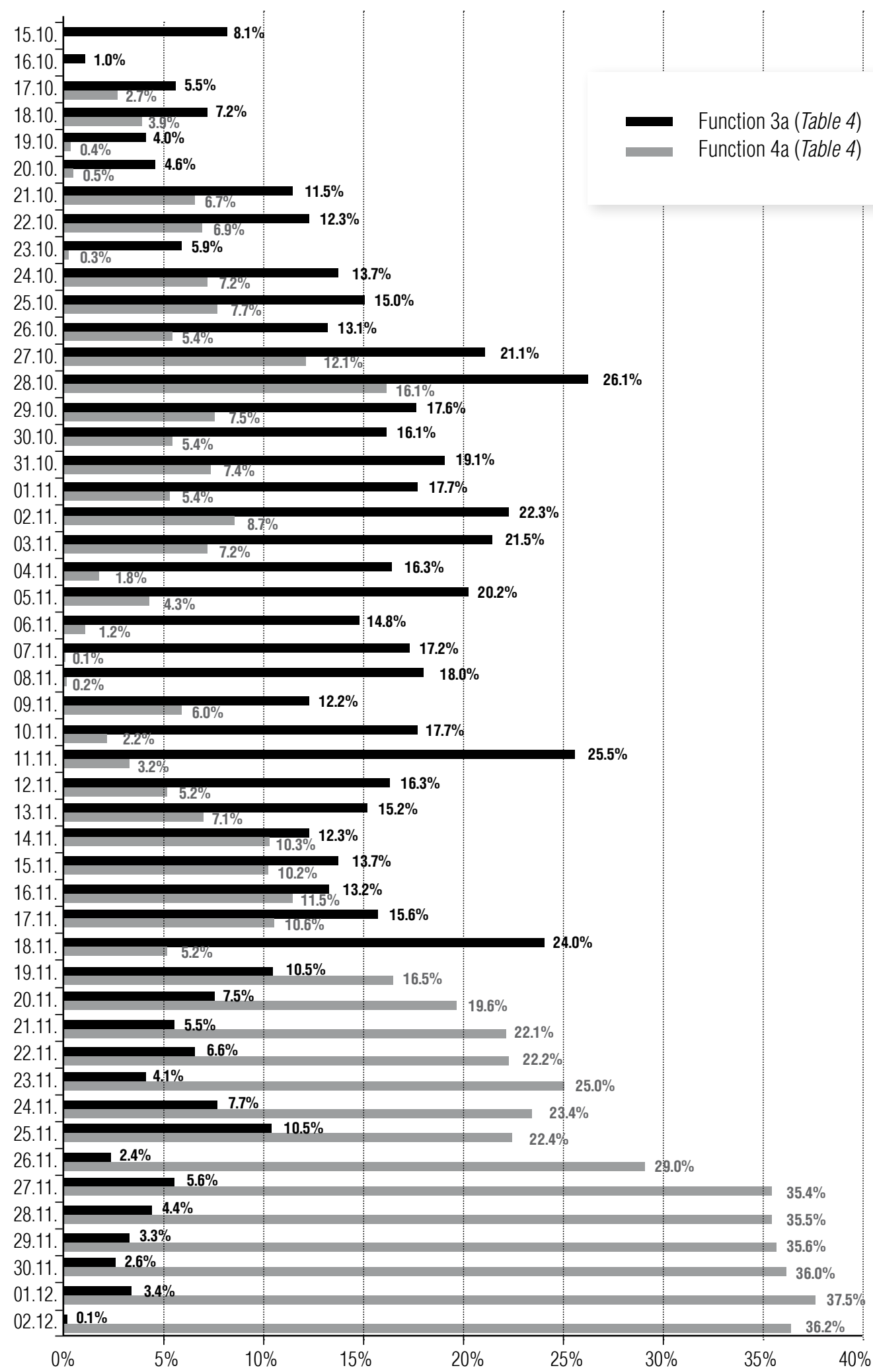

Fig. 14. APE forecast errors of the officially published daily number of people infected with the Wuhan coronavirus in Russia for 15 October - 2 December 2020 according to functions 3a and 4a (Figure 13), persons 


\section{Results of econometric study for the quadratic exponential (Gaussian) function (2) of the officially published daily number of Wuhan coronavirus-infected Russian citizens, fall 2020}

\begin{tabular}{|c|c|c|c|c|c|c|c|c|c|c|}
\hline \multirow[b]{2}{*}{ № } & \multirow[b]{2}{*}{$\begin{array}{l}\text { Time } \\
\text { period }\end{array}$} & \multicolumn{3}{|c|}{$\begin{array}{l}\text { Coefficients } \\
t \text {-statistics }\end{array}$} & \multirow[b]{2}{*}{$R^{2}$} & \multirow[b]{2}{*}{$D W$} & \multicolumn{2}{|c|}{$\begin{array}{l}\text { Daily infection } \\
\text { peak forecast } \\
\text { for } 2020\end{array}$} & \multicolumn{2}{|c|}{$\begin{array}{l}\text { Onset of zero (unit) daily infection } \\
\text { forecast for } 2021\end{array}$} \\
\hline & & $a$ & $b$ & $c$ & & & date & $\begin{array}{l}\text { number } \\
\text { of } \\
\text { infected, } \\
\text { persons }\end{array}$ & date & $\begin{array}{l}\text { total number of people } \\
\text { infected since the } \\
\text { beginning of the epidemic, } \\
\text { million persons }\end{array}$ \\
\hline $1 a$ & $22.09-12.10$ & $\begin{array}{c}-0.0003 \\
(-1.75)\end{array}$ & $\begin{array}{l}0.1613 \\
(2.32)\end{array}$ & $\begin{array}{l}12.46 \\
(1.66)\end{array}$ & 0.99 & 1.39 & 11.12 & 38362 & 29.06 & 5.0 \\
\hline $2 a$ & $22.09-13.10$ & $\begin{array}{c}-0.0003 \\
(-2.37)\end{array}$ & $\begin{array}{l}0.1848 \\
(3)\end{array}$ & $\begin{array}{l}14.96 \\
(2.26)\end{array}$ & 0.99 & 1.36 & 30.11 & 30191 & 30.05 & 3.9 \\
\hline $3 a$ & $22.09-14.10$ & $\begin{array}{c}-0.0004 \\
(-3)\end{array}$ & $\begin{array}{l}0.2040 \\
(4)\end{array}$ & $\begin{array}{l}17.01 \\
(2.90)\end{array}$ & 0.99 & 1.33 & $\begin{array}{l}22.11 \\
23.11\end{array}$ & 26211 & 5.05 & 3.4 \\
\hline $4 a$ & $22.09-16.10$ & $\begin{array}{c}-0.0005 \\
(-4)\end{array}$ & $\begin{array}{l}0.2540 \\
(5)\end{array}$ & $\begin{array}{c}22.35 \\
(4)\end{array}$ & 0.99 & 1.51 & 10.11 & 20512 & 5.04 & 2.6 \\
\hline $5 a$ & $22.09-19.10$ & $\begin{array}{c}-0.0006 \\
(-7)\end{array}$ & $\begin{array}{c}0.2803 \\
(8)\end{array}$ & $\begin{array}{c}25.17 \\
(6)\end{array}$ & 0.99 & 1.57 & 6.11 & 18892 & 23.03 & 2.4 \\
\hline $6 a$ & 22.09-28.10 & $\begin{array}{c}-0.0007 \\
(-15)\end{array}$ & $\begin{array}{c}0.3350 \\
(16)\end{array}$ & $\begin{array}{l}31.12 \\
(14)\end{array}$ & 0.99 & 1.56 & 31.10 & 17150 & 4.03 & 2.2 \\
\hline
\end{tabular}

Source of statistical data for econometric research: Communication Center of the Russian Federation Government (стопкоронавирус.рф)

$I_{C t}$ is the communication component of infrastructure for year $t$;

$w_{T t}$ is average annual rate of infrastructure transport component capacity use for year $t$

$w_{C t}$ is average annual rate of infrastructure communication component capacity use for year $t$.

It is reasonable to assume that the average monthly rate of labor capacity use for the month $\tau$ will represent some function $F$ which is a function of strict isolation depending on the number of people with Wuhan coronavirus disease and persons in contact with them. All those persons are out of the labor force completely or partially due to temporal illness or quarantine. The function increases by the total

Table 4.

\section{)}




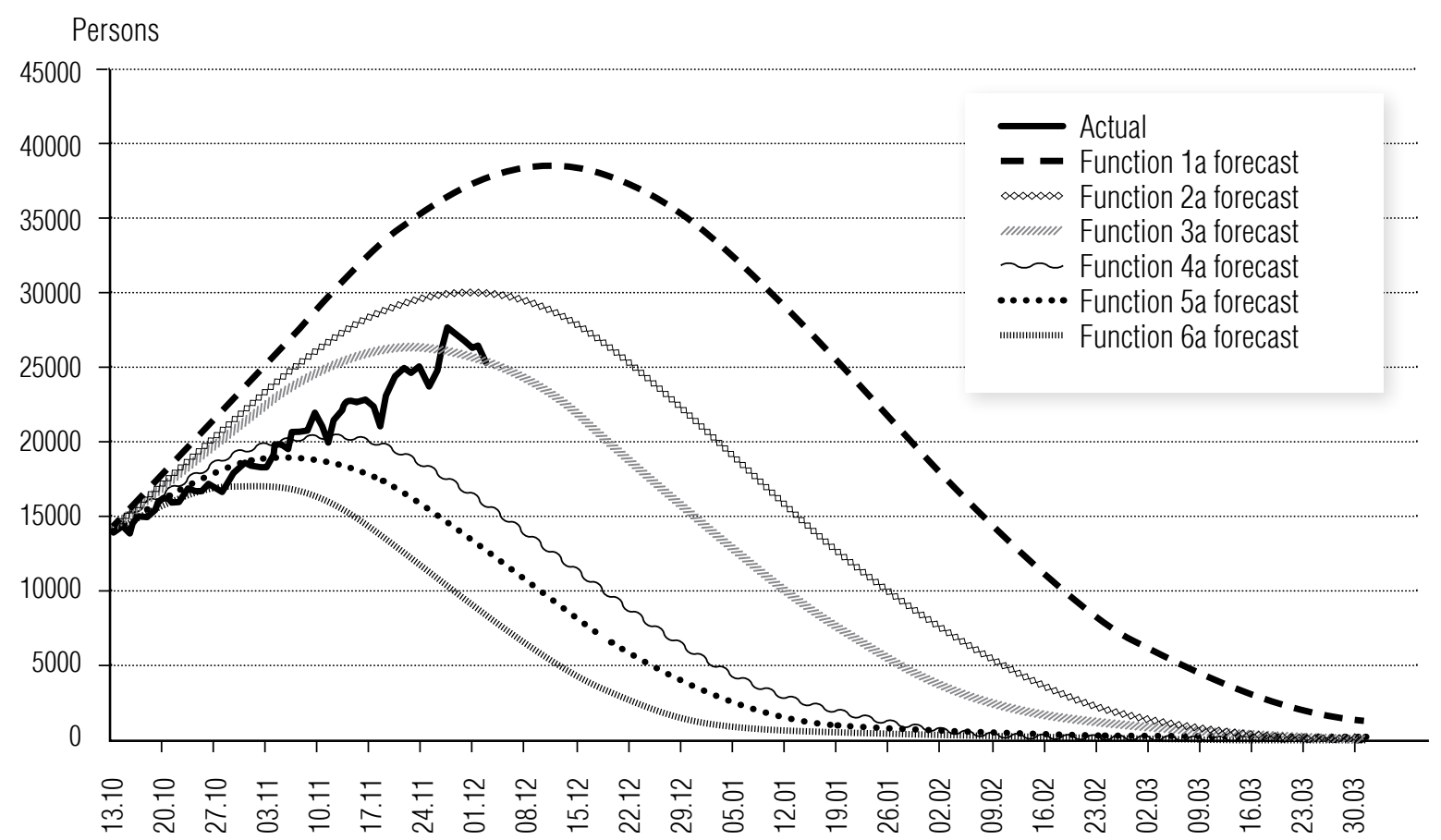

Fig. 15. Actual values (from 13 October to 2 December 2020) and forecasted values (for 13 October 2020 - 31 March 2021) of the officially published daily number of Russian citizens infected with the Wuhan coronavirus (Table 4)

depending on the fall of this indicator below thresholds:

$$
z_{\tau}=z\left(y_{\tau, T}\right)=\left\{\begin{array}{l}
z_{0}, y_{\tau, T}<\tilde{y}_{0} \\
z_{1}, \tilde{y}_{0} \leq y_{\tau, T} \leq \tilde{y}_{1} \\
z_{2}, \tilde{y}_{1} \leq y_{\tau, T} \leq \tilde{y}_{2} \\
z_{3}, y_{\tau, T}>\tilde{y}_{2}
\end{array}\right.
$$

where $\tilde{y}_{i}$ are the epidemic thresholds of the daily number of people infected with the Wuhan coronavirus in accordance with the three stages of coronavirus restrictions in Russia introduced by Rospotrebnadzor (Russian Federal Service for Surveillance on Consumer Rights), $i=1,2,3$. Moreover, $z_{0}$ corresponds to the pre-coronavirus level of production capacity use. It is obvious that $z_{0}>z_{1}>z_{2}>z_{3}$, i.e. the function decreases with respect to the number of people infected with the Wuhan coronavirus and the values of epidemic thresholds.

The function of the average monthly rate capacity use of the transport component of the infrastructure $w_{T t}$ will have the same piecewise linear form; it will also decrease with respect to the number of infected people.

On the contrary, the function of the average monthly rate capacity use of the communication component of the infrastructure $w_{C t}$ will increase according to the number of people infected with the Wuhan coronavirus and epidemic thresholds:

$$
w_{C \tau}=w_{C \tau}\left(y_{\tau, T}\right)=\left\{\begin{array}{l}
w_{C 3}, y_{\tau, T}>\tilde{y}_{2} \\
w_{C 2}, \tilde{y}_{1} \leq y_{\tau, T} \leq \tilde{y}_{2} \\
w_{C 1}, \tilde{y}_{0} \leq y_{\tau, T} \leq \tilde{y}_{1} \\
w_{C 0}, y_{\tau, T}<\tilde{y}_{0}
\end{array}\right.
$$

i.e. $w_{C 0}<w_{C 1}<w_{C 2}<w_{C 3}$, where $\tilde{y}_{i}$ are the epidemic thresholds of the daily number of people infected with the Wuhan coronavirus in accordance with the 3 stages of coronavirus restrictions in Russia introduced by Rospotrebnadzor, $i=1,2,3$.

Average annual values of factors capacity use rates are calculated as arithmetic mean of their monthly values: 


$$
\begin{gathered}
z_{t}=\frac{1}{12} \sum_{\tau=1}^{12} z_{\tau}, v_{t}=\frac{1}{12} \sum_{\tau=1}^{12} v_{\tau}, \\
w_{T t}=\frac{1}{12} \sum_{\tau=1}^{12} w_{T \tau}, w_{C t}=\frac{1}{12} \sum_{\tau=1}^{12} w_{C \tau} .
\end{gathered}
$$

We should note that the role of the infrastructure communication component $w_{C t} I_{C t}$ increases with the Wuhan coronavirus epidemic and the associated restrictive measures, which replaces, to a certain extent, the transport component $w_{T t} I_{T t}$.

\section{Conclusion}

We offer the econometric study of macroeconomic production function of the Russian Federation with transport and communication infrastructure (the fixed assets average annual value of the Russian transport and communications sectors) for 1990-2018. Our research demonstrates that in 2010-2018 the GDP elasticity to production infrastructure is decreasing. We explain it by the reduction in the volume of capital investments in infrastructure sectors' fixed assets.

In addition, we offer an analytical modification of the macroeconomic production function for 2020 in the context of the spread of the Wuhan coronavirus among the Russian population. In was done by introducing into this function the average annual rates of labor and infrastructure capacity use, which, along with the average annual rate of fixed assets capacity use are functions of the predicted values of the daily number of the infected Russian citizens. We make econometric forecasts of the officially published daily number of infected Russian population for fall 2020 - spring 2021. These forecasts have been made on the basis of timedependent quadratic exponential (Gaussian) function estimated by least squares method.

We would like to emphasize that the modification of the Russian macroeconomic production function in regard to the spread of the Wuhan coronavirus in 2020 was carried out in an analytical form. Its practical implementation, hindered at the moment by the lack of annual and, partly, of monthly statistical data for the current year, will be carried out at the next stage of our research.

\section{Acknowledgments}

This research is supported by the Russian Foundation for Basic Research (project No. 20-010-00629 A).

The authors express their sincere gratitude for the valuable advice and useful remarks to Prof. Yuri N. Blagoveshchensky and Prof. Eduard F. Baranov.

\section{References}

1. The President of Russia (2019) Message from the President of Russia to the Federal Assembly. Moscow, Kremlin, 20 February 2019. Available at: http://kremlin.ru/events/president/news/59863 (accessed 01 October 2020) (in Russian).

2. Afanasiev A.A., Ponomareva O.S. (2020) Some problems of the development and modernization of the Russian economy infrastructure. Proceedings of the 21st Russian Symposium on Strategic Planning and Enterprise Development. Section 5 "Forecasting Problems of the Enterprises' Activities". Moscow, 10-11 November 2020, pp. 652-654 (in Russian).

3. Dubelir G.D. (1910) City planning. Saint Petersburg: Slovo (in Russian).

4. Dubelir G.D. (1912) City streets and pavements. Kiev: A.M. Ponomarev (in Russian).

5. Dubelir G.D. (1912) Dirt roads, their construction and maintenance. Saint Petersburg: Slovo (in Russian).

6. Dubelir G.D., Zakharov G.F., Til B.I. (1934) Operation of carriage roads. Leningrad: OGIS-Gostransizdat (in Russian).

7. Dubelir G.D., Korneev B.G., Kudryavtsev M.N. (1939) Fundamentals of road design. Leningrad, Moscow: Publishing house of the People's Commissariat of the RSFSR (in Russian). 
8. Zavelsky M.G. (2009) Industrial infrastructure and economic development. Problems of Regional Economics, vol. 1, pp. 77-81 (in Russian).

9. Laverov N.P., Alekseevsky N.I., Berdnikov S.V., Gliko A.O., Granberg A.G., Danilov-Danilyan V.I., Dynkin A.A., Zemskoy Yu.A., Zolotarev P.S., Ivanter V.V., Kasimov N.S., Leonov Yu.G., Makosko A.A., Matishov G.G., Makhutov N.A., Osipov V.I., Pappe Ya.Sh., Filin B.N., Chalov R.S. (2008) Expertise on the project of construction of Eurasia international sea channel. Problems of national security: expert opinions, analytical materials, proposals. Moscow, Nauka (in Russian).

10. Livshits V.N., Mironova I.A., Shvetsov A.N. (2014) Transport infrastructure: effectiveness of strategic decisions. International Journal of Management Theory and Practice, no 7, pp. 78-89 (in Russian).

11. Posamantir E.I. (2014) Transport infrastructure development strategy: macroeconomic assessment of options. Audit and Financial Analysis, no 1, pp. 128-136 (in Russian).

12. Sadovnichii V.A., Osipov G.V., Akaev A.A., Malkov A.S., Shulgin S.G. (2018) Socio-economic effectiveness of the railway network development in Siberia and the Far East: Mathematical simulation and forecast. Economy of Region, vol. 14, no 3, pp. 758-777 (in Russian).

13. Makarov V.L. (2003) Economy of knowledge. Lessons for Russia. Herald of the Russian Academy of Sciences, vol. 73, no 5, pp. 450-456 (in Russian).

14. Afanasiev A.A., Ponomareva O.S. (2014) The aggregate production function of Russian economy in 1990-2012. Economics and Mathematical Methods, vol. 50, no 4, pp. 21-33 (in Russian).

15. Afanasiev A.A., Ponomareva O.S. (2020) The macroeconomic production function of Russia in 1990-2017. Economics and Mathematical Methods, vol. 56, no 1, pp. 67-78 (in Russian).

16. Rosstat (2019) Russia in figures 2019: Statistical handbook. Moscow: Rosstat (in Russian).

17. Rosstat (2019) Russian statistical yearbook 2019: Statistical handbook. Moscow: Rosstat (in Russian).

18. IMEMO RAS (2020) Russian Economic Barometer. Quarterly Bulletin, no 2 (in Russian).

19. Afanasiev A.A. Execution of the econometric forecast for the daily number of Moscow citizens infected with the Wuhan coronavirus (26 April - 9 May 2020). Available at:

https://istina.msu.ru/conferences/presentations/297636272/ (accessed 15 August 2020) (in Russian).

20. Afanasiev A.A. Econometric forecasting of the daily number of Moscow citizens infected with the Wuhan coronavirus from March to July 2020 (full version of 25 April 2020). Available at: https://istina.msu.ru/conferences/presentations/294603297/ (accessed 15 August 2020) (in Russian).

21. Afanasiev A.A. Econometric forecasting of the daily number of Moscow citizens infected with the Wuhan coronavirus from March to July 2020 (abridged version of 25 April 2020). Available at: https://indem.ru/coronavirus/Forecast_CV-19_In_Moscow.pdf (accessed 15 August 2020) (in Russian).

22. Shereen M.A., Khan S., Kazmi A., Bashir N., Siddique R. (2020) COVID-19 infection: Origin, transmission, and characteristics of human coronaviruses. Journal of Advanced Research, no 24, pp. 91-98. DOI: $10.1016 /$ j.jare.2020.03.005.

23. Chinese Academy of Sciences (2020) Wuhan coronavirus has strong ability to infect humans. Press release, 21 January 2020. Available at: https://view.inews.qq.com/w2/20200121A0M08X00?tbkt=F\&strategy=\& openid=o04IBALMrLyGDxbWNOPoDM1IfG-s\&uid=\&refer=wx_hot (accessed 15 August 2020).

\section{About the authors}

\section{Anton A. Afanasiev}

Dr. Sci. (Econ.);

Leading Researcher, Laboratory of Social Simulation, Central Economics and Mathematics Institute, Russian Academy of Sciences, 47, Nakhimovsky Prospect, Moscow 117418, Russia;

E-mail: aanton@cemi.rssi.ru

ORCID: 0000-0002-0300-5064

\section{Olga S. Ponomareva}

Senior Researcher, Laboratory of Institutional Dynamics, Central Economics and Mathematics Institute, Russian Academy of Sciences, 47, Nakhimovsky Prospect, Moscow 117418, Russia;

E-mail: fondf@cemi.rssi.ru 